\title{
Demonstration of a Small Modular BioPower System Using Poultry Litter
}

\section{DOE SBIR Phase-I Final Report}

Contract: DE-FG03-01ER83214

Community Power Corporation

Prepared by:

John P. Reardon, Art Lilley, Kingsbury Browne and Kelly Beard

Community Power Corporation

8420 S. Continental Divide Rd., Suite 100

Littleton, CO 80228

with

Jim Wimberly

Foundation for Organic Resources Management

101 W. Mountain St., Ste 200

Fayetteville, Arkansas 72701

and

Dr. Jack Avens

Department of Food Science and Human Nutrition

Colorado State University

234 Gifford Building

Fort Collins, CO 80523-1571

February 25, 2001 


\section{Demonstration of a Small Modular BioPower System Using Poultry Litter}

\section{Executive Summary}

The purpose of this project was to assess poultry grower residue, or litter (manure plus absorbent biomass), as a fuel source for Community Power Corporation's Small Modular Biopower System (SMB). A second objective was to assess the poultry industry to identify potential "onsite" applications of the SMB system using poultry litter residue as a fuel source, and to adapt CPC's existing SMB to generate electricity and heat from the poultry litter fuel biomass. Benchscale testing and pilot testing were used to gain design information for the SMB retrofit. A system design for a phase II application of the SMB system was a goal of the Phase I testing. Cost estimates for an onsite poultry litter SMB were prepared. Finally, a market estimate was prepared for implementation of the SMB.

The poultry industry contributes $\$ 23 \mathrm{~B}$ USD to the gross domestic product, producing 7 billion birds and 36 million tons manure annually; and $17 \%$ of domestic production is exported. The largest sector of the poultry industry is broiler production with $93 \%$ of the head production and $73 \%$ of the manure production. Turkey production is second to broilers for both head production $(4 \%)$ and manure production (22\%). Egg layers are not a target market for gasification technology.

The typical broiler production house produces 110,000 birds/year in multiple flocks and produces between 100 to 125 dry tons of litter. The value of litter is $\sim \$ 3 /$ ton on the house floor and $\sim 10$ to $\$ 12 /$ ton delivered to a fertilization or offsite litter processing facility. The wholesale value of post gasification mineral ash is on the order of $\$ 50-\$ 60 /$ ton which equates to $\$ 12-15 /$ ton dry litter. The average energy content of dry poultry litter was $6,000 \mathrm{Btu} / \mathrm{lb}$, so a ton of gasified litter would equal 93 gal LPG for a 75\% efficient gasifier. Poultry farmers typically pay $\$ 0.65 /$ gal for LPG in the mid southern poultry producing states. The equivalent energy value of litter produced per production house is 9,300 to 11,625 gal LPG, whereas the poultry farmer uses between 5,000 and 6,000 gal LPG/year and 22,000 to 24,000 kWh/year of electricity. An SMB system could meet all the heat and electricity requirements with a creative CHP implementation and would require $66 \%$ or more of the annual litter production. If implementation of a nutrient management program gave rise to excess litter above that required for heat an electricity on the farm-scale, then additional litter processing could be performed on-the farm without meeting the energy needs, or could be collected for third-party litter processing, but this off-farm system may still fall under the description of small-modular being on a scale of $250 \mathrm{~kW}$ to $1000 \mathrm{kWe}$.

The gasification of litter is challenging because of the high ash content in dry litter and because a large fraction of the ash contains potassium, which can lead to fusion of char in the fixed bed, or freezing of the bed media in a fluidized bed gasifier. Other problems can also occur with volatilized potassium. Temperature control is very important in the process and may require additives to prevent ash fusion. CPC successfully converted $99 \%$ of the energy content of a poultry litter sample without causing ash fusion in a bench scale experiment, resulting in a high 
quality ash product. The wholesale value of ash was estimated to be $\sim 50$ to $\$ 60 /$ ton based on the value of mineral constituents. Furthermore, $83 \%$ of the energy content was converted in a nonoptimized downdraft gasifier system during a 5-hour pilot test run. The SMB ran continuously generating $4 \mathrm{kWe}$ of electricity for the duration of the test as well as generating recoverable thermal energy.

The high organic nitrogen and sulfur content of poultry litter also poses a significant challenge to the gas clean up and emissions control equipment. CPC proposes a method of catalytically converting ammonia in the producer gas prior to combustion as a method of chemical NOx emission control. The sulfur and subsequent ammonia mitigation enables utilization of producer gas in direct combustion "brooder" furnaces common to the poultry production house. Sulfur absorber technology would be important to a Phase II system to enable catalytic methods of tar and ammonia mitigation.

Projected costs of an SMB system in production was estimated based on prototype costs and manufacturing technology assumptions. There are $\sim 60,000$ broiler production houses in the United States and as many as 26,000 turkey production houses. A $10 \%$ market penetration scenario of a production SMB system may cost around $\$ 1350 / \mathrm{kW}$, based on preliminary prototype cost estimates and manufacturing theory with a progress ratio of 0.8 .

\section{Keywords}

Poultry litter, gasification, litter management, small modular system, SMS, SMB, biopower, farm-scale, farm-scale, on-farm system.

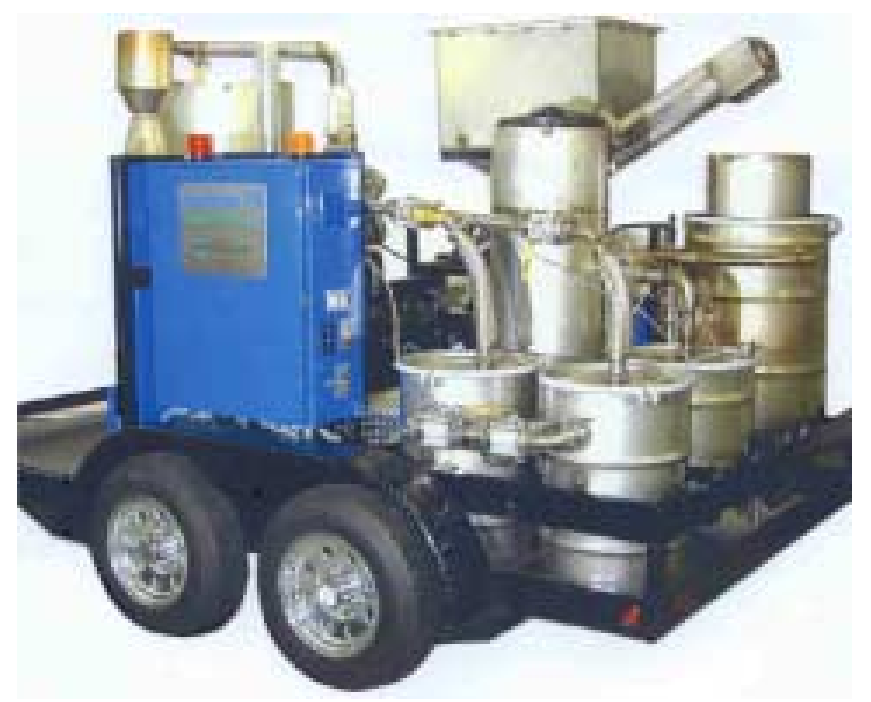

Biomax SMB System Used in Pilot Testing 


\section{Table of Contents}

EXECUTIVE SUMMARY.....................................................................................................................II

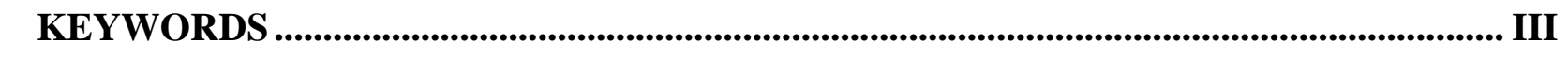

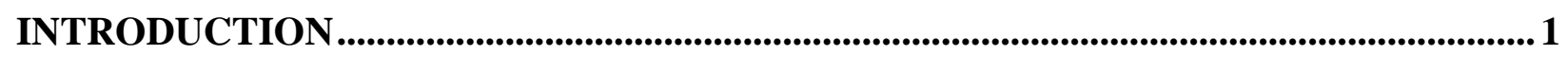

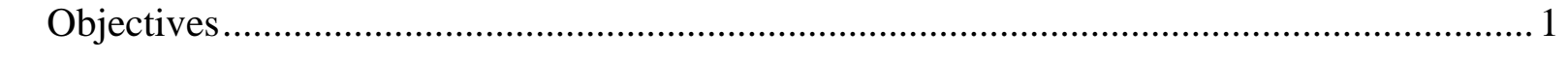

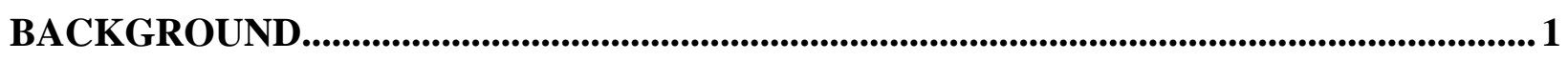

OVERVIEW OF THE US POULTRY INDUSTRY...........................................................

Economic Contribution..............................................................................................

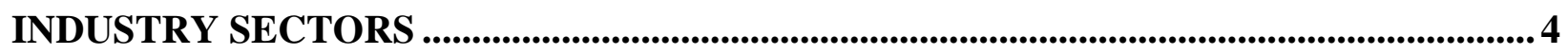

Inttustry Strttettre ................................................................................................

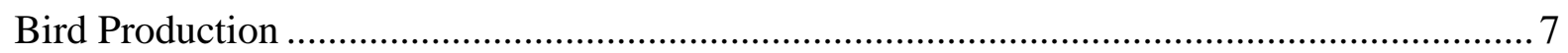

DESCRIPTION OF POULTRY PRODUCTION FACILITY ....................................................8

Proctuction Cycte..............................................................................................

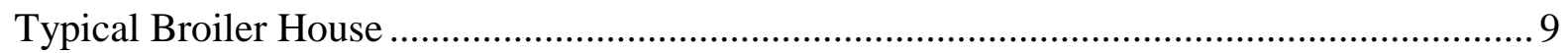

Energy Requirements ................................................................................................. 10

Current Energy Sources .......................................................................................... 13

Energy Costs ........................................................................................................... 14

PRODUCTION OF MANURE AND LITTER ..............................................................................15

Production of Mantre and titter.............................................................................15

Properties and Characteristics of Litter .............................................................................. 16

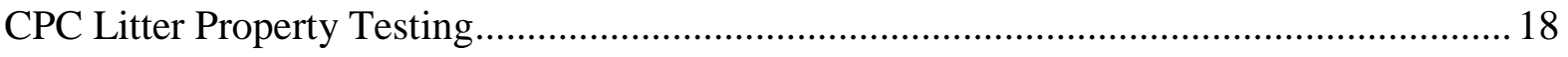

CONVERTING LITTER INTO ENERGY .............................................................................21

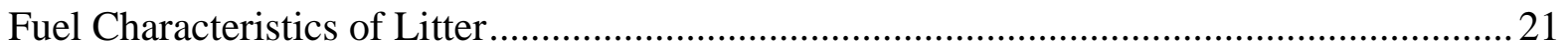

Fuel Energy Value Equivalents................................................................................... 24

Environmental Benefits......................................................................................... 25

ADAPTATION OF SMB TO GASIFY POULTRY LITTER .....................................................26

taboratory Gasification Test Results..................................................................26

SMB Pilot Scale Test Data (5 hours of Electricity Production) .......................................... 32

MATERIAL ENERGY BALANCE ...................................................................................................33

PHASE-ITSYSTEM DESTGNS .................................................................................34

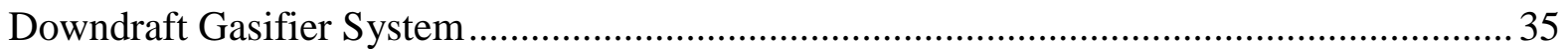

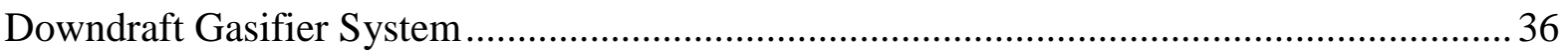




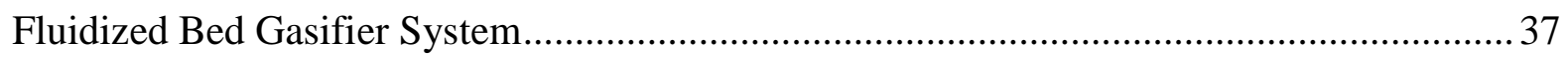

LIMCO Concept: Community-scale Hydrogen Enrichment and Ammonia Production ........38

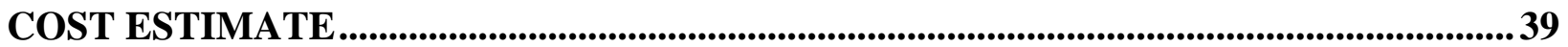

COST COMPARTSON

WALUEОF АSH PRОНUСТ .....................................................................................................43

MARKET ESTHMATE...................................................................................................................45

SUMAMARY 


\section{Introduction}

The purpose of this project is to assess the poultry industry for opportunities in small modular biopower (SMB) using gasification technology. This study emphasizes on-farm energy production applications, and it also ponders a community-scale poultry litter gasification system that is the technological foundation for a Litter Integrated Management Company, LIMCO. This study evaluates the economic benefits to the poultry production farmer when litter is used as an energy fuel, and it also considers the economic motivation for recovery of the gasification product ash as a feedstock material additive for commercial N-P-K fertilizer. Bench-scale testing was used to determine the feasibility of small-scale poultry litter gasification and ash recovery. Bench-scale testing was also used to determine the reactor design criteria for effective, reliable gasification. The feasibility to produce electric power in a small modular system (SMS) using poultry litter as a fuel was demonstrated with a modified gasifier in an existing SMB system - a five-hour power production test was successfully completed using poultry litter as a fuel.

Objectives

1. Perform an assessment of poultry waste as a fuel source for Community Power Corporation's (CPC) Small Modular Biopower System (SMB).

2. Assess the current poultry industry to identify potential on-site applications of the SMB system using poultry waste as the fuel source.

3. Adapt CPC's existing small modular biopower gasifier sub-system to generate electricity and heat from poultry waste

4. From testing, determine the material and energy balance

5. Measure producer gas and exhaust gas emissions

6. Develop a system design for a Phase II application of the SMB system at Whiting Farms

7. Prepare cost estimate for a Phase II application of the SMB system at Whiting Farms

8. Compare cost of on-site application at Whiting Farms with conventional methods

9. Develop market estimate for use of the SMB system in the poultry industry

\section{Background}

Both growers and integrators are concerned that increasingly stringent environmental policies governing litter management will add expense and decrease an already slim profit margin, or that these factors could make poultry production unprofitable for some producers. To address these concerns, the poultry industry has recently begun considering, and in a few instances pursuing, large-scale, centralized litter processing (e.g., pelletization, cogeneration) as alternative litter 
management strategies. However, such approaches involving large-scale, centralized facilities have several disadvantages including high capital and operating costs, increased use of nonrenewable energy for transportation and pelletization, small added value, concern for the spread of pathogens during raw litter transportation, litter availability and supply issues, and complex just-in-time management required to keep a large-scale process at economic capacity.

In contrast, this study postulates a farm-scale litter management scheme that may have positive economic benefits for the poultry farmer when utilized in small modular systems, including farm-scale gas production modules that fuel furnaces and brooders in a poultry house and that fuel combined heat and power systems. The farm-scale approach benefits from economies of mass production, low capital costs, simple on-farm litter management, no feedstock supply limitations, zero transportation costs, and pathogen sterilization before exporting the recovered ash to commercial fertilizer markets elsewhere. Although poultry litter has some economic value to the farmer as a soil amendment, displacing other fertilizer requirements, its value may be limited in some regions or may even have a negative cost to the farmer, because of concerns associated with traditional management practices, i.e., land application which has the potential for soil phosphorous accumulation that can lead to local water pollution.

This study also contemplates a community-scale litter management scheme to utilize excess litter left over from poultry house heating alone, or left over from combined heat and power applications at the poultry house scale. The community-scale gasification system would serve 10 to 20 farms, for example, and convert excess litter using a modular system that is somewhat larger than an on-farm system, but still smaller than a large regional processing facility. A community-scale approach would still minimizing transportation costs and give economic benefits to either a poultry integrator, a farmer cooperative, or a "third-party" litter management company, referred to as a Litter Integrated Management Company (LIMCO). This "third-party" litter management company should not be confused with a regional litter bank, broker or wholesaler, as in previous large-scale litter management studies, but rather it is the "fourth party" value added manufactufer from previous studies that operates without the "third-party" middleman, litter bank. $\square$ Studies showed that the current economic climate provides for limited economic opportunity for a "third-party litter bank"; in contrast, it is suggested here that a "thirdparty farm community-scale LIMCO may hold economic promise. The small modular system approach enables a separation from the large-scale paradigm and its necessity for regional-scale litter management with a litter bank. The LIMCO could be co-located with a small industry to meet its heat and power needs, or the LIMCO could generate high value fertilizer and chemical products by processing produced gas and ash to chemicals. The community-scale LIMCO would work in concert with participating farmers that have farm-scale litter furnaces and combined heat and power (CHP) systems, and would function as field service support and be responsible for collection and subsequent export of the mineral-rich ash derived from the gasification process to agricultural markets elsewhere, (and perhaps conversion of the ash to value added fertilizer products with an appropriate N-P-K balance for mid-western row crops, or local bovine forage grasses).

\footnotetext{
${ }^{1}$ Goodwin, H.L., Hipp, J., and Wimberly, J., “Off-farm Litter Management and Third-party Enterprises,” Jan 2000. Prepared by the Foundation for Organic Resources Management for Winrock International Corp, under USDA contract.
} 


\section{Overview of the US Poultry Industry}

\section{Economic Contribution}

The poultry industry's contribution to the US economy is worth nearly $\$ 23$ Billion in gross domestic product. The poultry industry's economic importance to the United States is significant, especially to the economies of the southern states, but recent years have seen a leveling and even a decline in the industry's GDP. From 1996 to 2000, poultry production gave rise to an average of $23.5 \%$ of the domestic livestock GDP.

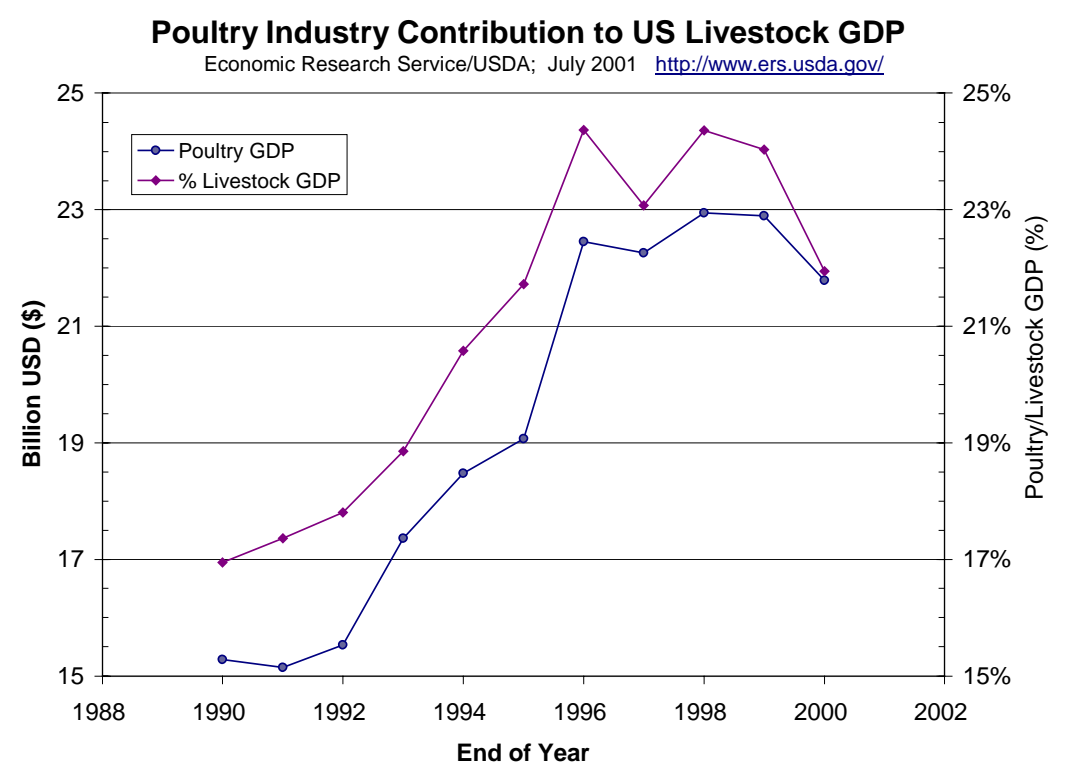

The US presently dominates the world poultry export trade with its share accounting for $43 \%$ of the total world poultry exports in 1998. Broiler meat exports account for $17 \%$ of total domestic broiler production. At this level volatility in world export prices can have a notable influence on the value of broiler production in the United States.

Environmental policies have been vigorously debated as to whether some "(environmental) policies actually impede competitiveness of US commodities in international markets, if other countries impose fewer regulations or maintain lower standards for their agricultural sectors." While some economic theorists argue that it does have an effect according to "comparative advantage theory", others contend that alternative uses for litter that add economic value can offset these economic costs and can contribute to US poultry industry competitiveness.

\footnotetext{
${ }^{2}$ Economic Research Service/USDA (2001)

${ }^{3}$ The United States Department of Agriculture (1990-2000), various publications.

${ }^{4}$ Ibid.
} 


\section{Industry Sectors}

\section{$\underline{\text { Industry Structure }}$}

The poultry industry is generally comprised of broiler chicken production, egg production, turkey production and other poultry, which includes breeder hen and pullet and even small sectors such as roosters raised for fly tie feathers. The 1997 USDA census shows that broiler chickens comprise $93 \%$ of the total poultry head production; egg layer hens encompass a small percentage of the total head (approximately $0.3 \%$ ); turkey production and chicken pullet and pullet chicks make up the balance.

\begin{tabular}{|c|c|c|c|c|c|}
\hline 1997 Agricultural Census Data & broilers & total turkeys & $\begin{array}{c}\text { pullet \& pullet } \\
\text { chicks }\end{array}$ & layers & total poultry \\
\hline Heads Produced & $6,492,661,487$ & $265,186,314$ & $224,884,926$ & $23,622,486$ & $7,006,355,213$ \\
\hline$\%$ & $92.7 \%$ & $3.8 \%$ & $3.2 \%$ & $0.3 \%$ & $100.0 \%$ \\
\hline Manure (tons/year), as excreted & $26,098,580$ & $7,654,633$ & 839,511 & 943,246 & $35,535,970$ \\
\hline$\%$ & $73.4 \%$ & $21.5 \%$ & $2.4 \%$ & $2.7 \%$ & $100.0 \%$ \\
\hline
\end{tabular}

Broiler and turkey manure comprise $95 \%$ of total poultry manure. Broiler chicken production is the largest sector in terms of both head and manure production, although turkey production is also significant. Broiler chickens produce an average of just over $8 \mathrm{lbs}$ manure/bird (3.65 $\mathrm{kg} / \mathrm{bird}$ ) at $75 \%$ moisture (as excreted) in a typical $61 / 2$-week growth cycle, and turkeys produce nearly $58 \mathrm{lbs}$ manure/bird (26.2 kg/bird) in a 16 week growth cycle.

\section{Poultry Gross Receipts in Billions USD (2000 Data)}

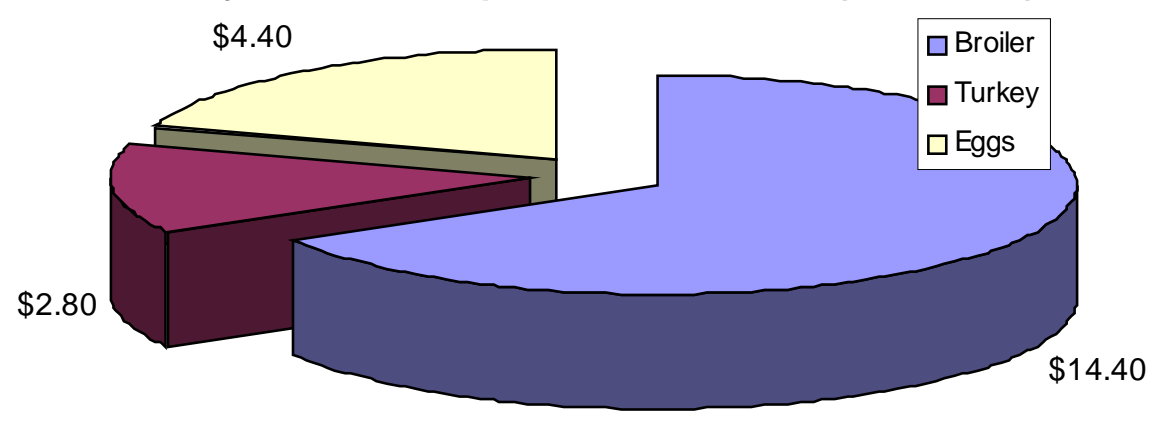

Commercial broiler chicken and turkey production in the leading production states would be the most important market for the litter-to-energy gasifiers because of the higher concentration of production facilities (target clients) and the greater likelihood that producers in those states may need to pursue alternative litter management practices. While egg production has a large economic value, contributing $20 \%$ of the total poultry gross receipts, the manure generated by layer hens has a much smaller contribution to the total manure supply, is typically produced without bedding, has a lower fuel value, and is often managed with wet removal methods that preclude its utility as a biomass energy combustion fuel. 


\section{Producers vs. Integrators}

Most commercial broiler chickens produced in the United States are grown on family owned farms under contract with a vertically integrated poultry company that owns the hatchery, birds, feed mills, and processing plants. The United States was estimated to have 60,000 broiler houses and 26,000 turkey houses in 1997 according to analysis of the USDA's 1997 Agricultural Census data.

The contractual arrangement between the grower and the integrator company is considered to be mutually beneficial. An independent broiler grower relies on the assured connection to a bird processing facility that has access to large volume established product markets, thereby insulating the producers from the vagaries and risks of the marketplace. The integrator gets access to low-cost labor for production supervision and avoids investments in production facilities. Production units are typically organized in a "complex" - a system consisting of a feed mill and a processing plant (with a typical processing capacity of about one million birds per week) and sufficient contract production facilities (within a 25-mile radius) to support the complex size. Because of economies of scale and other factors, it is not profitable to establish a small volume independent processing plant on a farm scale.

The ten largest broiler chicken companies in the United States in year 2000 produced 456 Million pounds of ready-to-cook (RTC) chicken, or 70.1 percent of the total production of all companies. The ten largest U. S. turkey companies processed 72.5 percent of all live pounds processed in 2000 .

\section{Production Ranked Top-Five} Broiler Integrator Companies:

1) Tyson Foods, Inc.

2) Gold Kist, Inc.

3) ConAgra Poultry Cos.

4) Perdue Farms, Inc.

5) Pilgrim's Pride.

\section{Production Ranked Top-Five Turkey Integrator Companies:}

1) Jennie-O Foods

2) Cargill

3) Butterball Turkey Company

4) Wampler Foods, Inc.

5) Carolina Turkeys.

These top producing broiler chicken and turkey companies control the bulk of poultry meat production and are in brand name competition to supply the increasing consumer demand for "further processed", "value-added", premium-priced food products rather than primary processed commodity meat. These poultry processing companies are vertically integrated, owning live bird production phases literally from conception (breeding), through production, marketing, and consumer purchase. With the exception of the production facilities (owned mostly by individual private contractors), the "integrator company" owns all aspects of the enterprise: live production

\footnotetext{
${ }^{5}$ Foundation for Organic Resources Management (FORM); Analysis of 1997 USDA Census Data.

${ }^{6}$ Smith, T. W. 1997. Broiler production in Mississippi. Mississippi State University Extension Service. http://www.msstate.edu/dept/poultry/broprod.htm.

7 Thornton, G. 2001. Watt Poultry USA's rankings, broilers. Poultry USA, 2 (1): 27-34.

${ }^{8}$ O'Keefe, T. 2001. Watt Poultry USA's rankings, turkeys. Poultry USA, 2 (1): 64-79.

${ }^{9}$ Cosgrove, T. and S. M. Shane. 2001. Poultry's top performers, bruised but confident. Poultry, 9 (3): $10-15$.
} 
stock, hatcheries, feed mills, live bird haul trucks, primary processing and further processing facilities, and refrigerated product delivery trucks; and, integrators advertise and market to the consumer with an identifiable brand name.

The integrator company and contract farmer share the costs of live bird production. ${ }^{0.11}$ The integrator company owns the birds and delivers the feed and hatched chicks and removes the grown broilers at about 6.5 weeks for delivery to the processing plant. The company provides service personnel who advise on general management and diagnosis and treatment of diseases.

The contract farmer usually owns (and has a mortgage for) the production houses. The farmer is responsible for feeding, watering, and management of the growing birds during the grow-out period. $^{11,12}$ The farmer's operating expenses include hired labor (if any), utilities, maintenance of equipment and facilities, and costs for litter cleanout and management and bedding replacement. The time interval between flocks of birds is 1 to 3 weeks. The litter is typically removed once each year, after which the house is thoroughly cleaned and disinfected and new litter placed in. Litter removal and subsequent management is normally the farmer's responsibility: "Unlike many of the equipment and inventory management issues, waste management is the sole responsibility of the grower." 12 In a few places around the country, integrators share a portion of the cost of fuel for winter space heating with the grower, but electricity costs are generally the grower's sole responsibility.

\section{Ownership and Responsibility of Litter Management}

Litter management is an important apsect of poultry production. Unlike many of the equipment and inventory mangement issues, growers are solely responsible for litter and mortality management. ${ }^{14}$ Some state regulations require growers to manage all wastes including litter and dead birds. For example, "The Oklahoma Feed Yard Act requires growers to manage their (litter and dead birds), to provide for heneficial use of the (litter and dead birds), and to prevent adverse effects to the environment. 15 Litter management may represent production costs that are not always included in standard production budgets. However, with appropriate planning, (poultry litter and bird carcasses) can be a valuable by-product of bird production. 16

According to the OSU Extension facts, a grower may be required to comply with a state regulated litter management program if there is improper management of litter that results in surface or ground water contamination. In Oklahoma, failure to comply with regulated litter management programs imposed on a recidivist grower may result in a fine. It is possible that farm-scale furnace incinerators may require state licensure or approval process in order to benefit

10 IBID. Smith, T. W. 1997.

${ }^{11}$ IBID. Moreng, and Avens 1991.

${ }^{12}$ Doye, D.G., Berry, J.G., Green, P.R., and Norris, P.E., "Broiler Production: Considerations for Potential Growers," Oklahoma State University Cooperative Extension Service publication F-202. OSU Extension Facts.

${ }^{13}$ Overhults, D. G. and R. S. Gates. 1994. "Energy use in tunnel ventilated broiler housing with different controls". Presented at the 1994 International Winter Meeting, American Society of Agricultural Engineers, Paper No. 944561. ASAE, 2950 Niles Rd., St. Joseph, MI 49085-9659.

${ }^{14}$ Walters, L.M., and Chembezi, D.M., "Impact of Environmental Policy on U.S. Broiler Industry: Implications for Domestic Use and Exports," Alabama A\&M University, March 2000.

${ }^{15}$ IBID. Doye, D.G., et. al, OSU Extension Facts F-202.

${ }^{16}$ IBID. 
from acceptance as part of regulated litter management program for productive litter or carcass incineration.

Poultry litter is typically used on the production farm as a soil amendment (fertilizer and humus) for forage or row-crop production, although limited and informal off-farm markets often exist (in a few instances around the country, quantities of litter are sold to centralized pelletized facilities). The economics of litter vary around the country, depending on the availability of off-farm markets, increased restrictions regarding on-farm land application, and other factors. In the Northwest Arkansas region, litter has historically had a value of about $\$ 3 /$ ton "as is" (i.e., on the floor of the production house); the off-farm market value in the region has been about $\$ 15 /$ ton (delivered and applied), which essentially reflects only the nitrogen content of the material. ${ }^{7}$ If all the agronomic value could be realized (e.g., in export markets where phosphorous is still needed)then litter has a calculated value of about $\$ 38$ to $44 /$ raw ton based on the N-P-K content. ${ }^{18}$ However, in such cases the net returns to the litter producer would still be near zero (if not negative) due to the high costs of transporting the material to such distant markets.

\section{$\underline{\text { Bird Production }}$}

The top 20 broiler production states produce over 98 percent of the U. S. total. In 2000, the top 5 production states in rank order were Georgia, Arkansas, Alabama, Mississippi, and North Carolina. The top 5 turkey production states were Minnesota, North Carolina, Arkansas, Virginia, and Missouri. Egg producing farms are not the target market for the modular biopower system since the manure is less well suited for gasification and may be more appropriately processed with wet anaerobic digestion, as has been done in the United States and in several republics of the former Soviet Union. 19

USDA-National Agricultural Statistics Service ${ }^{20}$

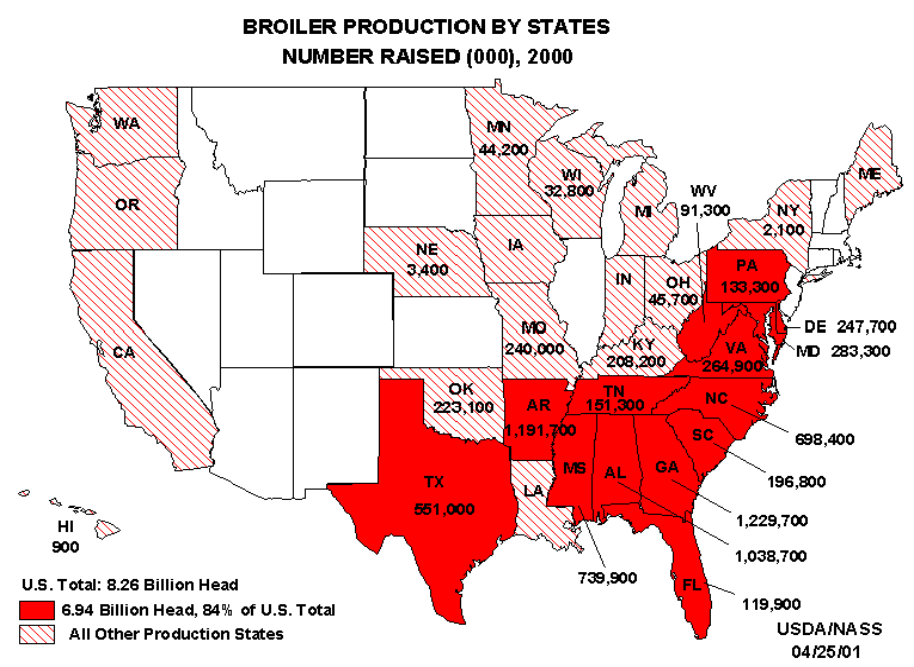

\footnotetext{
${ }^{17}$ Wimberly, J., and Goodwin, H.L., "Alternative Poultry Litter Management in the Eucha/Spavinaw Watershed," Part-I Raw Litter Export. Nov 2000.

${ }^{18}$ IBID.

${ }^{19}$ Jack Avens and Afroim Mazin, personal communications; Dec 2001.

${ }^{20} \mathrm{http}: / /$ www.usda.gov/nass/aggraphs/brlmap.htm
} 


\section{USDA-National Agricultural Statistics Service ${ }^{21}$}

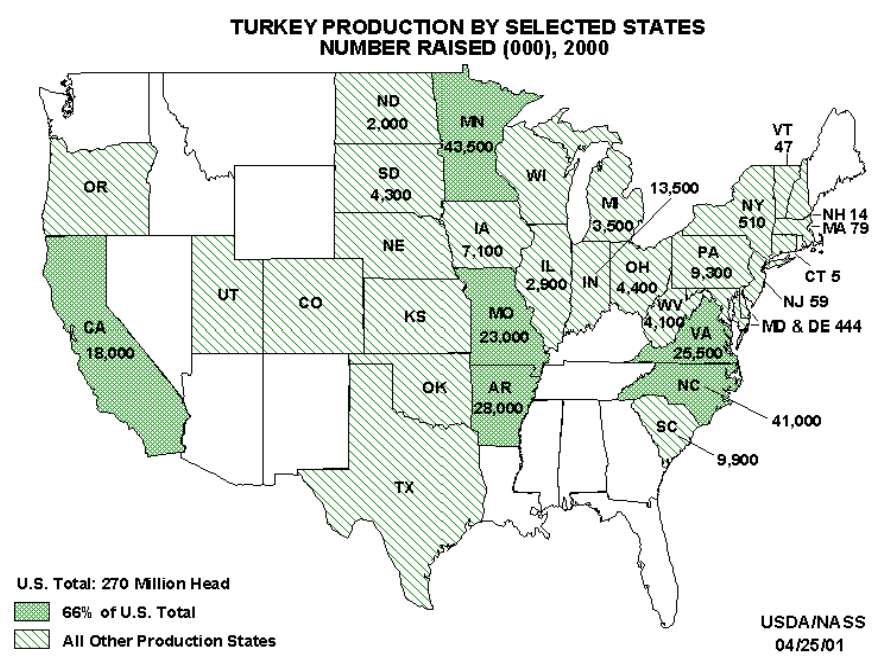

\section{Description of Poultry Production Facility}

\section{Production Cycle}

Contract broiler grower farms are provided with patched chicks from integrator company hatcheries, usually delivered on the day of hatch. Integrator-owned hatcheries obtain fertile eggs for incubation from parent breeder farms, typically under contract with private secondary breeding companies. Parent birds are supplied to contract breeder farms from different primary breeder companies, who maintain and develop grandparent flocks and pedigree lines. A broiler production cycle ranges from 6 to 7 weeks per flock, and an average of 5.5 to 6 flocks are grown per year. The down time between growth cycles is on the order of one to three weeks. Litter is typically cleaned out of a house after one year of production.

Turkeys are brooded in complete confinement and then transferred to another building or semiconfinement dry-lot shelter at about 7 to 10 weeks of age for finishing. ${ }^{23}$ A number of different feed formulations are used to grow a turkey from poult to market weight, usually including starter, grower, and finisher rations. Turkey growing farms may be either contractor owned or owned by the integrator company. Approximately $20 \%$ of litter material may consist of a coarse crust that is removed in the form of a cake. Litter management by the turkey grower is similar to broiler producers; except that turkey grows tend to clean out more frequently (after every flock). Some turkey farms may remove the crust of the litter bed between successive flocks and retain a deeper absorbent core for multiple years.

${ }^{21} \mathrm{http}: / /$ www.usda.gov/nass/aggraphs/tkymap.htm

${ }_{22}$ Wimberly, J., J. S. Hipp, and H. L. Goodwin. 2000. Off-Farm Litter Management and Third Party Enterprises. Foundation for Organic Resources Management

${ }^{23}$ Moreng, R. E. and J. S. Avens. 1991. Poultry Science and Production. Waveland Press, Inc. Prospect Height, IL. 


\section{Typical Broiler House}

A typical broiler production house is designed to support 20,000 birds flocks in a 16,000 sq. $\mathrm{ft}$ poultry house. Therefore a typical 20,000 bird house would grow 110,000 to 120,000 birds in a production year less mortality with 5.5 to 6 flocks/year. Some larger production houses are in existence that are designed to support flocks of 25,000 birds or more and could grow as many as 150,000 birds/house/year. According to the Foundation for Organic Resources Management (FORM), a typical broiler farm in northwest Arkansas has 4 production houses with an average size of $40 \mathrm{ft} \times 400 \mathrm{ft}\left(16,000 \mathrm{ft}^{2}\right)$ and a capacity of approximately 20,000 birds per house.

A conventional broiler production house has open sidewalls for ventilation that are covered with plastic in the winter months. Studies have shown a fuel energy savings for house designs that have additional insulation in the roof, tunnel ventilation with solid sidewalls, and evaporative cooling systems. Almost all new broiler \&

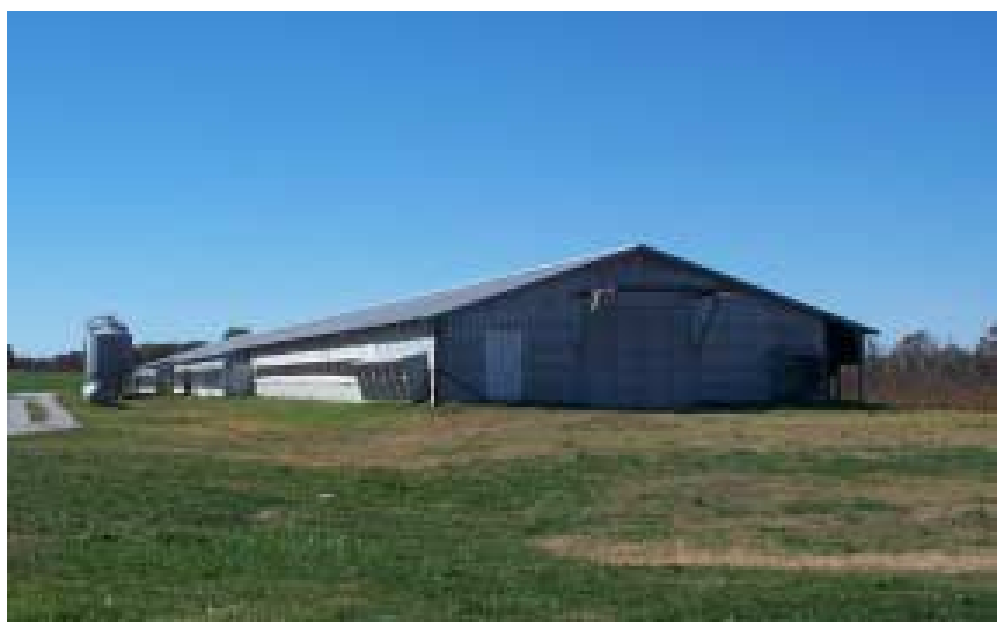
turkey houses are now utilizing the tunnel ventilation designs; thousands are already in use. And almost all new houses use improved insulation techniques. Only a small percent use stirring or circulating fans, as most still rely on ventilation fans for all air movement within the houses. Inhouse forced air circulation is generally limited to those houses that use gas-fired forced air heaters;
Arkansas broiler production house shows negative pressure ventilation fans on left side of building.

many houses use only gas-fired radiant heaters.

Table 1. Model Broiler Production Houses at The University of Arkansas

\begin{tabular}{|c|c|c|c|c|c|}
\hline $\begin{array}{c}\text { Type of Poultry } \\
\text { House }\end{array}$ & Walls/Ventilation & $\begin{array}{c}\text { Ceiling } \\
\text { Insulation }\end{array}$ & $\begin{array}{c}\text { Furnace } \\
\text { Heat }\end{array}$ & Brooder Heat & $\begin{array}{c}\text { Total Peak } \\
\text { Heating (Btu/hr) }\end{array}$ \\
\hline Conventional & $\begin{array}{c}\text { Open sidewalls, Plastic } \\
\text { covered in winter, exhaust } \\
\text { fans }\end{array}$ & R-10 & $\begin{array}{c}40 \% \\
2 \text { furnaces }\end{array}$ & $\begin{array}{c}20 \text { radiant } \\
\text { brooders } \\
(30,000 \mathrm{Btu} / \mathrm{hr} \\
\text { each })\end{array}$ & $\begin{array}{l}720,000 \mathrm{Btu} / \mathrm{hr} \\
\text { (6.9 gph LPG) }\end{array}$ \\
\hline Advanced & $\begin{array}{l}\text { Solid Sidewalls, Tunnel } \\
\text { Ventilation, static pressure } \\
\text { controlled exhaust }\end{array}$ & R-19 & $\begin{array}{c}60 \% \\
3 \text { furnaces }\end{array}$ & $\begin{array}{c}12 \text { radiant } \\
\text { brooders } \\
(30,000 \mathrm{Btu} / \mathrm{hr} \\
\text { each })\end{array}$ & $\begin{array}{l}870,000 \mathrm{Btu} / \mathrm{hr} \\
(8.3 \mathrm{gph} \mathrm{LPG})\end{array}$ \\
\hline
\end{tabular}

The Center for Excellence in Poultry Science at the University of Arkansas has several model broiler production houses including a conventional house and a modern efficient production house. The conventional house has open sidewalls that are covered with plastic in the winter months, and R-10 insulation in the ceiling. The modern house has solid sidewalls with R-19

\footnotetext{
${ }^{24}$ According to the Foundation for Organic Resources Management.
} 
insulation in the ceiling, an advanced tunnel ventilation system and evaporative cooling. The conventional design is more dependent on radiant flame brooders with less heat delivered by gas furnaces than compared to modern designs.

\section{Energy Requirements}

Both heat and electrical energy are vital to the broiler production house. Heat is vital for the brooding period of a newly hatched chick, and heating in the winter helps optimize feed consumption and growth. Electrical energy is important for automatic feed delivery and especially for ventilation and cooling purposes. Ventilation failures or sustained electrical outages can be disastrous leading to high or complete mortality rates for a summer flock, and failure of a heating system or lack of fuel supply can have similar disastrous effects.

\section{Heating Fuel Requirements}

The "brooding period" for the newly hatched baby chick or turkey poult is critical to the production cycle of the growing bird. ${ }^{25}$ Not only the birds' survival, but also their growth and future production performance depend on various factors affecting optimum growth to market weight. The farmer must provide adequate space, warmth, protection, moisture control, fresh air, and easily accessible feed and clean water. Since the newly hatched chicks or poults are not yet able to regulate their own body temperature, a space heater or "brooder" must provide enough supplemental heat to maintain optimum body temperature; natural or propane gas flame brooders are commonly used. It is estimated that $75 \%$ of poultry houses in the Arkansas use propane and $25 \%$ use natural gas. ${ }^{26}$ It is assumed that this distribution is consistent with the poultry producing southern states and representative of the poultry market.

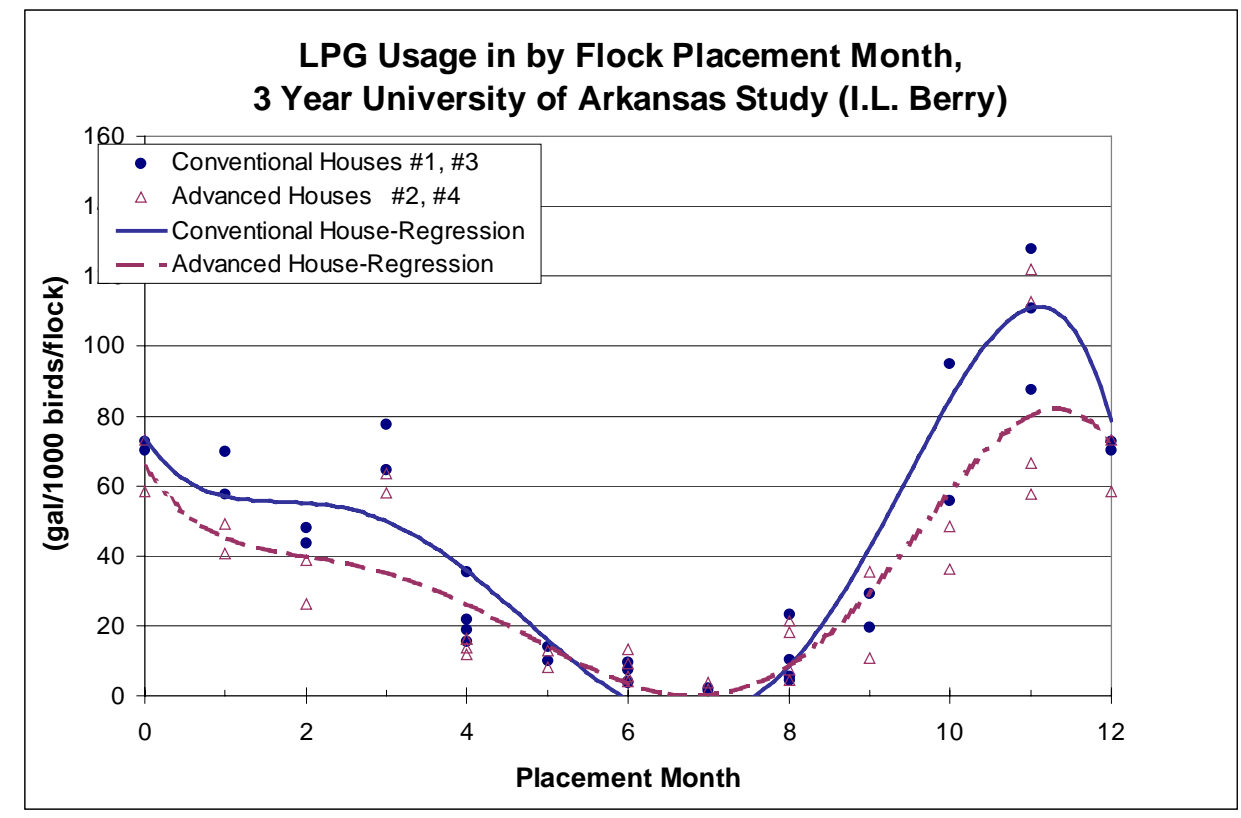

${ }^{25}$ IBID. Moreng and Avens (1991).

${ }^{26}$ According to the Foundation for Organic Resources Management 
Energy usage will vary from region to region, year to year, and even house to house for various production house designs and house ages. One set of data from a 3 year study reported normalized annual fuel consumption rates of 37 to 49 gal LPG/1000 birds for a conventional broiler production house, and 31-26 gal LPG/1000 birds for an advanced house. ${ }^{27}$ A 10-year study of the "Applied Brpiler Research Unit" evaluated houses with tunnel ventilation systems and increased insulation. ${ }^{28}$ In general the propane usage for various houses ranged from 32 to 52 gal/1000 birds for the period between 1990-1994, and ranged from 30 to 47 gal/1000 from 19952000. The overall average was approximately $40 \mathrm{gal} / 1000$. The industry rule of thumb for Arkansas poultry production and similar mid-southern regions is 50 gal LPG/1000 birds. For a 20,000 bird house with 6 flocks per year, 40 to 50 gal LPG/1000 birds equates to 4,800 to 6,000 gallons of propane per year per house. Generally, fuel consumption is related fo climate and weather conditions and typically varies from 4,000 6,000 gallons per year. ${ }^{2}$ In this study we will use 5,000 gallons LPG/year for a typical 20,000-bird broiler production house, assuming 5.5 to 6 flocks/year. The figure below shows how the propane usage varies as a function of placement month and illustrates the seasonal affect on propane consumption.

Statistical analyses of heating rates vs. cumulative propane consumption available in literature ${ }^{0}$ show that a gasifier sized to provide $90 \%$ of the peak heat rate would be in the range 409,000 $\mathrm{Btu} / \mathrm{hr}\left(120 \mathrm{~kW}_{\mathrm{th}}\right)$ for advanced ventilation systems to $471,000 \mathrm{Btu} / \mathrm{hr}(138 \mathrm{~kW}$ th $)$ for conventional broiler houses, or an equivalent of 3.9 to $4.5 \mathrm{LPG}$ gal/hour.

\section{Table 2. Statistical Sizing Criteria for Gas Production Module} (Equivalent Propane Consumption Rate gal/hr)

\begin{tabular}{|r||c|c|c|c|c|c|}
\hline Cumulative Energy \% & $\mathbf{7 0 \%}$ & $\mathbf{8 0 \%}$ & $\mathbf{9 0 \%}$ & $\mathbf{9 5 \%}$ & $\mathbf{9 8 \%}$ & $\mathbf{1 0 0 \%}$ \\
\hline \hline Conventional \#1 & 3.19 & 3.64 & 4.47 & 5.18 & 6.20 & 9.8 \\
\hline Conventional \#3 & 2.81 & 3.28 & 4.02 & 4.55 & 5.55 & 8.0 \\
\hline Advanced \#2 & 2.66 & 3.15 & 3.92 & 4.59 & 5.49 & 8.0 \\
\hline Advanced \#4 & 2.70 & 3.21 & 4.11 & 4.74 & 5.69 & 7.9 \\
\hline
\end{tabular}

A gasifier that provides combustible gas to an existing furnace and brooder heating system would be an important installation to augment and displace propane or natural gas usage; however, the gas clean-up system of the biomass gasification system would have to remove chemical NOx (fuel derived) and volatilized amines from the gas prior to delivery to a direct heat furnace or radiant burner array. ${ }^{2} 2$ Fuel ammonia and chemical NOx content for fuel burned inside the poultry house would cause unsuitable air emissions from the direct heat furnace unless ammonia were mitigated from the gas stream prior to combustion in radiant combustion burners.

\footnotetext{
${ }^{27}$ Berry, Ivan, L., "Use of Liquified Petroleum Gas in Four Broiler Houses." A report to the Foundation for Organic Resources Management (FORM); June 30, 1999.

${ }^{28}$ Tabler, G.T., and Berry, I.L., “Applied Broiler Research Unit Report: Ten-Year Summary of Broiler Production Results." Report by the Center of Excellence for Poultry Science and the Biologival and Agricultural Engineering Department, University of Arkansas. (2001)

${ }^{29}$ Personal communications between Jim Wimberly, FORM, and poultry producers, integrator staff, and staff at the University of Arkansas Poultry Science Department.

${ }^{30}$ IBID. Berry (1999)

${ }^{31}$ Statistical sizing criteria derived from results of 3-year broiler production study, IBID. Berry (1999).

${ }^{32}$ Direct heat furnace that mixes combustion products with air in contrast to an indirect furnace that uses heat exchangers.
} 


\section{Electrical Energy Requirements}

A typical broiler production house may have 12 ventilation fans rated at 1-hp each, 6 feeders at 1/4-hp, and more than 40 lights at $60-\mathrm{W}$ each. The resulting total peak power would be $12.5-\mathrm{kW}$, not including starting current, and the estimated power factor at full load is 0.84 . Estimates of electrical energy consumption from several broiler house designs are presented for various placement months. Energy consumption was as high as $440 \mathrm{kWh} / 1000$ birds for house \#3, during a July flock placement cycle. The 5-year average electrical energy usage over all placement months ranged from 167 to $176 \mathrm{kWh} / 1000$ birds for various houses, while the average over all houses was $171 \mathrm{kWh} / 1000$ birds for this period. The 10-year average (1990-2000) for four houses ranged from 188 to $196 \mathrm{kWh} / 1000$ birds. The average energy consumption over all houses for all placement months for a 10 -year period was $192 \mathrm{kWh} / 1000$ birds. Future calculations assume 22,000 kWh/yr for 5.5 flocks and $24,000 \mathrm{kWh} / \mathrm{yr}$ for 6 flocks. Energy consumption for growing broiler chickens and turkeys ranges from $0.1 \%$ to $0.6 \%$ of the total utility energy production in the top producing states; or a total of $1.17 \times 10^{6} \mathrm{MWh}_{\mathrm{e}}$ for the states listed below.

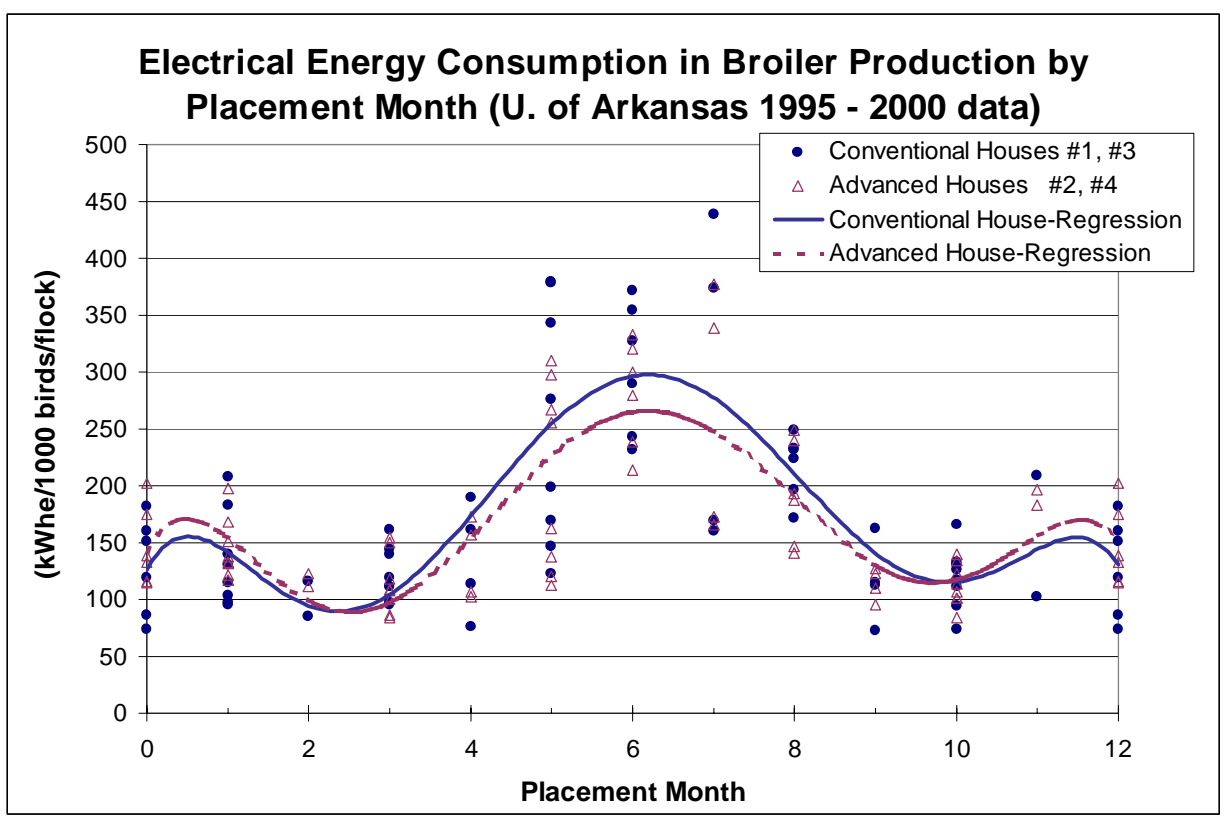


Table 3. Leading Poultry States: Production, Utility Energy Demands

\begin{tabular}{|c|c|c|c|c|c|}
\hline Leading Poultry States & $\begin{array}{c}1999 \text { Utility } \\
\text { Generation } \mathrm{MWh}_{\mathrm{e}}\end{array}$ & $\begin{array}{l}2000 \text { Broiler } \\
\text { Production }\end{array}$ & $\begin{array}{c}2000 \text { Turkey } \\
\text { Production } \\
\end{array}$ & $\begin{array}{c}\text { Estimated Poultry } \\
\text { Grower Energy } \\
\text { Consumption }{ }^{\text {B3 }}{ }_{\text {MWh }} \\
\end{array}$ & $\begin{array}{c}\text { Growers' } \\
\% \text { State Utility } \\
\text { Energy } \\
\end{array}$ \\
\hline Arkansas & $44,130,705$ & $1,191,700,000$ & $28,000,000$ & 253,180 & $0.6 \%$ \\
\hline Mississippi & $32,212,133$ & $739,900,000$ & 0 & 147,980 & $0.5 \%$ \\
\hline Georgia & $110,536,794$ & $1,229,700,000$ & 0 & 245,940 & $0.2 \%$ \\
\hline Alabama & $113,908,587$ & $1,038,700,000$ & 0 & 207,740 & $0.2 \%$ \\
\hline North Carolina & $109,882,388$ & $698,400,000$ & $41,000,000$ & 161,410 & $0.1 \%$ \\
\hline Virginia & $65,071,068$ & $264,900,000$ & $25,500,000$ & 66,495 & $0.1 \%$ \\
\hline Missouri & $73,504,882$ & $240,000,000$ & $23,000,000$ & 60,190 & $0.1 \%$ \\
\hline \multirow[t]{2}{*}{ Minnesota } & $44,153,826$ & $44,200,000$ & $43,500,000$ & 31,895 & $0.1 \%$ \\
\hline & $593,400,383$ & $5,447,500,000$ & $161,000,000$ & $1,174,830$ & $0.20 \%$ \\
\hline
\end{tabular}

\section{Current Energy Sources}

The typical broiler production house uses non-renewable fossil fuels such as propane and natural gas to fuel brooders and poultry house furnaces. The estimated fuel usage split for broiler production houses in NW Arkansas is 75\% propane and 25\% natural gas. (Fuel usage splits for other leading broiler or turkey production states are unknown to the authors.) However, based on a gross estimate of $50 \mathrm{gal}$ LPG/1000 birds produced, the heating equivalent fuel energy requirements of the top 8 poultry production states would approach $300 \mathrm{M}$ gal LPG/year. The merits of supplying a portion of the heat load in a broiler production house by using industrial wood pellets and sawdust residues from the forest industry in Arkansas has been discussed elsewhere.

Table 4. Electric Power Generation Mix: Top Broiler and Turkey Production States

\begin{tabular}{|c|c|c|c|c|c|c|}
\hline Poultry States & $\begin{array}{l}\text { Coal } \\
(\%)\end{array}$ & $\begin{array}{c}\text { Natural Gas } \\
(\%)\end{array}$ & $\begin{array}{c}\text { Nuclear } \\
(\%)\end{array}$ & $\begin{array}{c}\text { Hydro } \\
(\%)\end{array}$ & $\begin{array}{c}\text { Petroleum } \\
(\%)\end{array}$ & $\begin{array}{c}\text { Other } \\
(\%)\end{array}$ \\
\hline Arkansas & 38.1 & 25.6 & 1.2 & 17.5 & 14.7 & 2.7 \\
\hline Mississippi & 37.4 & 25.2 & 9.0 & 24.1 & - & 4.2 \\
\hline Georgia & 64.2 & 2.7 & 1.5 & 26.7 & 2.3 & 2.6 \\
\hline Alabama & 61.0 & 2.9 & 0.2 & 25.6 & 6.4 & 3.8 \\
\hline North Carolina & 61.6 & 1.0 & 0.8 & 31.9 & 3.3 & 1.4 \\
\hline Virginia & 48.0 & 6.3 & 4.6 & 38.2 & -- & 3.8 \\
\hline Missouri & 83.5 & 1.6 & 0.4 & 11.4 & 3 & 0.1 \\
\hline Minnisota & 62.2 & 2.1 & 2.2 & 27.4 & 2.4 & 3.6 \\
\hline
\end{tabular}

The source of electricity generation for the leading broiler and turkey production states is heavily dominated by coal power with significant contributions by natural gas and nuclear power. Other energy sources, that may include renewable power generation, typically account for $4 \%$ or less of the power generation mix in each of the top poultry states. Supplying the electrical energy demands of broiler chicken and turkey production using distributed renewable energy in Arkansas and Georgia alone would amount to an offset of 500,000 $\mathrm{MWh}_{e}$, and the combined

\footnotetext{
${ }^{33}$ Broiler \& Turkey Production only. Broiler production: $20 \mathrm{kWh} / 100$ birds. Turkey production: $53 \mathrm{kWh} / 100$ birds.

${ }^{34}$ Energy Information Agency, Department of Energy; http://www.eia.doe.gov
} 
contribution from the top five states (Georgia, Arkansas, Alabama, Mississippi, and North Carolina) would amount to more than $1 \mathrm{TWh}_{\mathrm{e}}$. The contribution to energy consumption ranges from $0.1 \%$ to $0.6 \%$ of the given states' total electrical utility energy generation. Utility electricity production in the leading poultry production states is dominated by coal, and these states have very little non-hydro renewable energy. Using poultry litter as a fuel to offset grid electricity at the farm-scale would have a significant impact on the growth of non-hydro renewable electricity generation in these poultry states.

\section{$\underline{\text { Energy Costs }}$}

Poultry growers purchase electricity at commercial rates, which have averaged $6.8 \mathrm{c} / \mathrm{kWh}$ for the last ten years in the top five poultry producing states. The peak power charges and total electrical energy bills have not been studied in detail to determine an average electrical energy cost for poultry farmers. However, $\$ 0.068 / \mathrm{kWh}$ is an average price for electricity costs for commercial electricity in mid-southern poultry producing states. Using $23,000 \mathrm{kWh} / \mathrm{yr}$ for a typical broiler production house raising 110,000 to 130,000 birds/year gives an electrical energy cost of $\sim \$ 1500 / \mathrm{yr} /$ house.

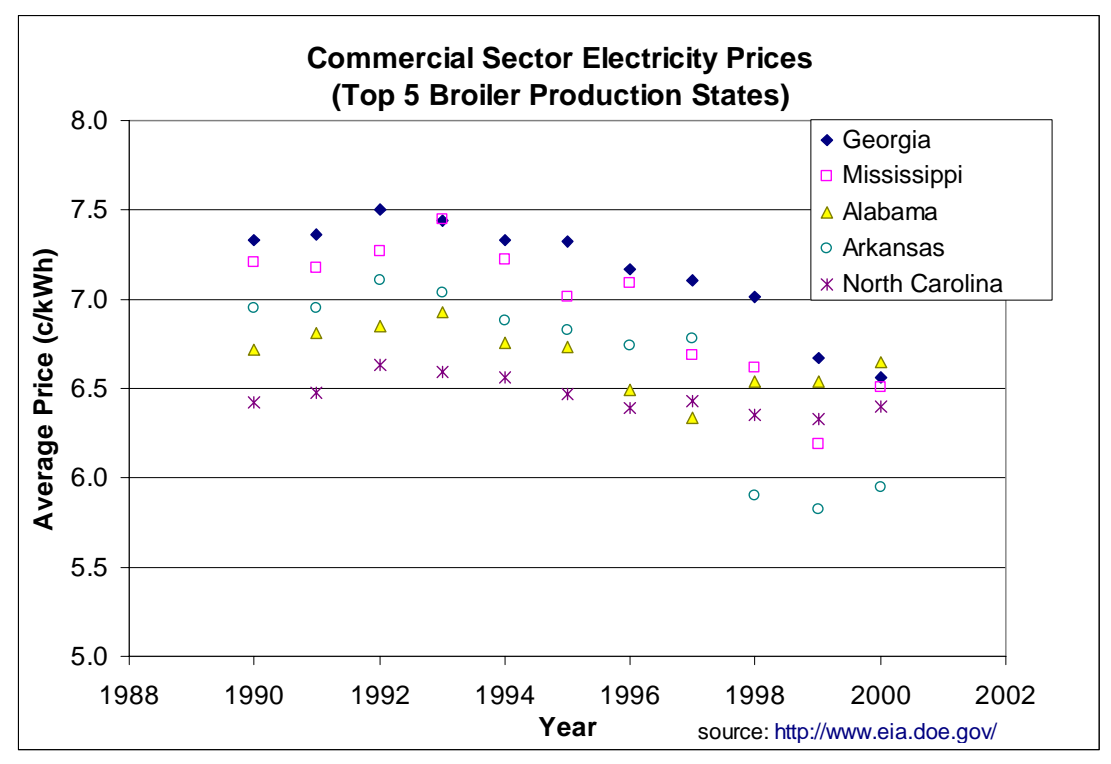

Extensive utility cost surveys have not been performed for this report, but a sampling of growers indicates that in recent years propane is purchased at $\sim \$ 0.65 / \mathrm{gal}(\sim 6.2 / \mathrm{MMBtu})$, which is $\sim 37 \%$ lower than the typical average of $\$ 1.03 /$ gal paid throughou the top five poultry states for commercial propane service, according to the DOE EIA. 35 By comparing with the industrial propane price we find that the poultry grower's propane price equates to a mark-up of approximately $30 \%$ above the industrial propane price, whereas commercial propane service has a mark-up of about $100 \%$ relative to the industrial propane price. Therefore, using this principal we can estimate propane costs for growers using industrial propane prices recorded by DOE EIA database. Propane prices track crude oil prices, and over the past ten years the commercial propane price has varied approximately $\pm 10 \%$ from the 10 -year average of $\$ 1.03 /$ gal in the

${ }^{35}$ Source: The Energy Information Agency, Price and Expenditure Report (1999). http://www.eia.doe.gov 
poultry production states. Propane is most expensive in Georgia and least expensive in Alabama. Natural gas is less expensive per Btu than propane, but it is unknown if poultry growers receive a similar discount or other incentive for natural gas purchase relative to the average commercial sector gas price. The 1999 commercial sector natural gas price was $\$ 5.28 / \mathrm{MMBtu}$, which is about $15 \%$ lower than the poultry industry propane purchase price on an energy cost basis. Heating energy costs are estimated to be $\$ 3250 /$ year/house if propane is used $(5,000$ $\mathrm{gal} / \mathrm{year} / \mathrm{house}$ ), and $\$ 2770 / \mathrm{yr} /$ house if natural gas is used as a fuel.

\section{Production of Manure and Litter}

\section{Production of Manure and Litter}

The Foundation for Organic Resources Management reports that cumulative manure production for broiler chickens is just over $8 \mathrm{lbs} / \mathrm{bird}$, as excreted at $75 \%$ moisture. For a 20,000-bird house with 5.5 to 6 annual growth cycles, 440 to 480 wet tons of manure is produced in a year. At $25 \%$ dry matter, there is 110 to 120 dry fons manure/year for each production house. By comparison,

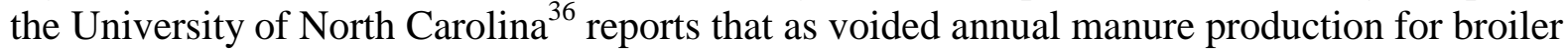
chickens is 0.024 tons/house on a flock capacity basis, which for a 20,000 bird flock capacity house is 480 tons/yr as voided and 120 tons dry matter. In comparison, the Oklahoma State University Extension Facts bulletin F-202 reports 125 tons litter/manure produced each year in a 25,000-bird production house, equivalent to 100 tons/house for 20,000-bird capacity; at unspecified moisture.

\section{Dense Poultry Manure Production in the United States}

(Foundation for Organic Resource Management, 1997 US Agricultural Census Data

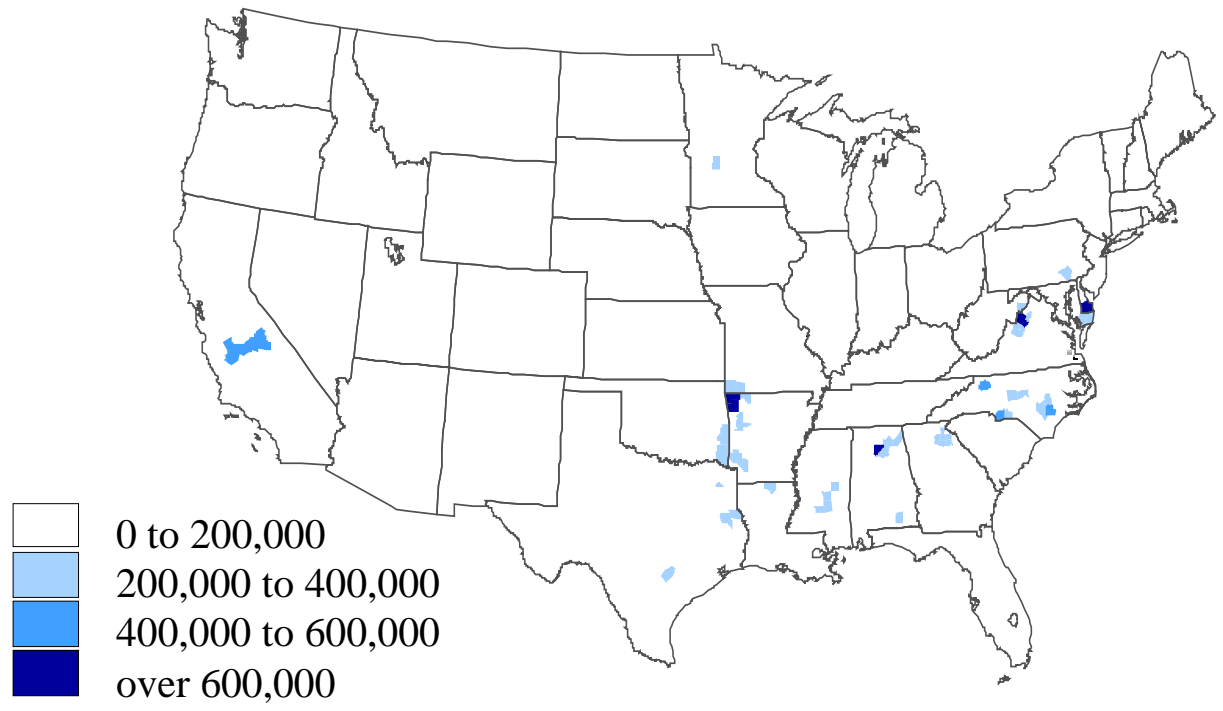

Tons (as excreted) / county / year

\footnotetext{
${ }^{36}$ Barker, J.C., Hodges, S.C., and Walls, F.R., "Livestock Manure Production Rates and Nutrient Content.” 2002 North Carolina Agricultural Chemicals Manual, Chapter X, Fertilizer use. http://ipmwww.ncsu.edu/agchem/chptr10/1011.PDF
} 
The term "litter" refers to the mixture of bedding material plus the manure generated by the birds. The bedding material—primarily high carbon content biomass-contributes to the energy content of litter. A variety of absorbent biomass including pine shavings, saw dust and rice hulls are typically added to the broiler house floor to control moisture. The amount of absorbent distributed in a house is not specifically known and is variable, but accumulated litter production rates for North Carolina are consistent with litter production reported elsewhere. UNC also reports average litter accumulation for broiler chickens at a rate of 0.0063 tons/year/flock capacity with $78.6 \%$ dry matter content; which is 126 tons/year at $21.4 \%$ moisture for 20,000 bird flocks, or 99 dry tons litter/year/house, curiously below the reported manure production rate in the same source. Nevertheless, 126 to 127 tons litter/broiler house is consistent with litter production rates for the lower Delmarva Peninsula (assuming 110,000 birds/house/year) reported by the Antares group in their report to the Northeast Regional Biomass Program. ${ }^{6}$ The UNC reports 0.01 tons litter/year/house capacity at $76.2 \%$ average dry matter content for Roaster Chickens, or 152 tons litter/house/year for 20,000-bird house capacity. Turkeys are grown in longer production cycles and in some cases housing 10,000 birds. However, in California larger turkey flocks are grown in houses with a capacity of $\sim 50,000$ birds/flock. Litter accumulation for turkey grower hens in a 10,000 bird house is 200 tons/yr at an average $73.2 \%$ dry matter content, or 4.18 dry tons/1000. Grower tom turkeys in 10,000-bird houses accumulate litter at a rate of 410 tons/year with an average of $73.2 \%$ dry solids content, or 8.6 dry tons/1000. Farm scale litter management for turkey production in California would require about 5 times the processing capacity of the typical system for broiler production in the southeastern United States.

\section{Table 5. Poultry House Litter Characteristics, Summary of UNC Data.}

\begin{tabular}{|l|c|c|c|c|c|c|}
\hline Manure Source & $\begin{array}{c}\text { Assumed } \\
\text { House } \\
\text { Capacity }\end{array}$ & $\begin{array}{c}\text { Manure+Litter } \\
\text { Accumulation } \\
\text { (tons/house/yr) }\end{array}$ & $\begin{array}{c}\text { Dry } \\
\text { Solids } \\
\text { content } \\
(\% \text { w.b. })\end{array}$ & $\begin{array}{c}\text { Dry Litter } \\
\text { Accumulation } \\
\text { (tons/house/yr) }\end{array}$ & $\begin{array}{c}\text { Birds/House } \\
\text { Annual }\end{array}$ & $\begin{array}{c}\text { Dry Litter } \\
\text { Accumulated } \\
\text { Per Bird } \\
\text { (tons/1000) }\end{array}$ \\
\hline Broiler Chicken & 20,000 & 126 & 78.6 & 99.0 & 110,000 & 0.9 \\
\hline Broiler Roaster & 20,000 & 200 & 76.2 & 152.4 & 110,000 & 1.38 \\
\hline Turkey Grower Hen & 10,000 & 200 & 73.2 & 146.4 & 175,000 & 4.18 \\
\hline Grower Tom & 10,000 & 410 & 73.2 & 300.1 & 175,000 & 8.57 \\
\hline
\end{tabular}

\section{Properties and Characteristics of Litter}

Poultry house litter contains an N-P-K ratio (lbs/ton) that averages about 72-68-47 for Broiler chickens at a $21 \%$ average moisture with a 12 to $16 \mathrm{lb} /$ ton ammonium nitrate content according to UNC data; whereas, grower turkey litter is 56-63-40 (lbs N-P-K per ton). Applying poultry litter residues to crop soil will increase organic matter and as a result the soil's water-holding capacity and improve soil tilth. With proper application of poultry litter, phosphorus, micronutrients, and most of the potassium not used by the crop will be bound by the soil and be available the next year or two. Crops that respond well to poultry litter soil application are corn, sorghum, millet, small cereal grains, cotton, green pastures, and hay. Legumes such as peanuts, soybeans, alfalfa, and clovers will not respond as well. A soil analysis is important to determine the appropriate balance of N-P-K and $\mathrm{Ca}$ for the desired crop, and although poultry litter contains

\footnotetext{
${ }^{37}$ Antares Group Inc., T.R. Miles Consulting, and Foster Wheeler Development Corp., "Economic and Technical Feasibility of Energy Production and Nutrient Filter Biomass on the Lower Delmarva Penninsula." Final Report August 1999. Prepared for the Northeast Regional Biomass Program.
} 
many of the valuable macronutrients found in expensive commercial fertilizers, the NPK ratios may not be ideally suited to the soil nutrient needs. Some litter pelletization plants are modifying litter NPK ratios for certain soil requirements, and producing as a result a higher value product.

Table 6. Typical Nitrogen, Phosphorous and Potassium Values for AR Broiler Litter

\begin{tabular}{|l|c|c|c|c|c|}
\hline & $\begin{array}{c}\% \mathrm{H}_{2} \mathrm{O} \\
\text { (wet basis) }\end{array}$ & $\begin{array}{c}\text { Total } \mathrm{N} \\
(\mathrm{lb} / \text { ton) }\end{array}$ & $\begin{array}{c}\mathrm{P}_{2} \mathrm{O}_{5} \\
(\mathrm{lb} / \text { ton })\end{array}$ & $\begin{array}{c}\mathrm{K}_{2} \mathrm{O} \\
\text { (lb/ton) }\end{array}$ & $\begin{array}{c}\mathrm{Ca} \\
(\mathrm{lb} / \text { ton })\end{array}$ \\
\hline Minimum & 2 & 22 & 18 & 23 & 18 \\
\hline Maximum & 47 & 98 & 96 & 80 & 108 \\
\hline Mean & 23 & 60 & 58 & 52 & 45 \\
\hline
\end{tabular}

On the average $\mathrm{N} / \mathrm{P}_{2} \mathrm{O}_{5}$ ratios are 1.03 for poultry litter in Arkansas, and $\mathrm{N} / \mathrm{K}_{2} \mathrm{O}$ ratios are 1.15. Since the nutrient needs for many forage grasses require $\mathrm{N} / \mathrm{P}_{2} \mathrm{O}_{5}$ ratios that are 2.4 to 3.9 , (for example rye grass, fescue, Sudan grass, wheat, Bermuda grass, and Bahia grass) the application of poultry litter on a nitrogen basis would lead to an excess phosphorous burden in the soil. Excess application or misapplication of litter residues to soil can result in excess phosphorous in the soil that can be an anthropogenic eutrophication concern for surface and groundwater through leaching and water runoff from rain. Although much less nitrogen is retained in the soil, litter applications in subsequent years can and should be reduced with a application of nitrogen rich fertilizers as needed to improve crop production. Long-term application of litter could result in overloading soil with micronutrients as well such as zinc and copper that could cause crop toxicity. Details of the fertilizer components of litter and its application as a fertilizer replacement can be found elsewhere.

\section{Phosphorus Loading Rates: Poultry}

(Foundation for Organic Resource Management, 1997 US Agricultural Census Data

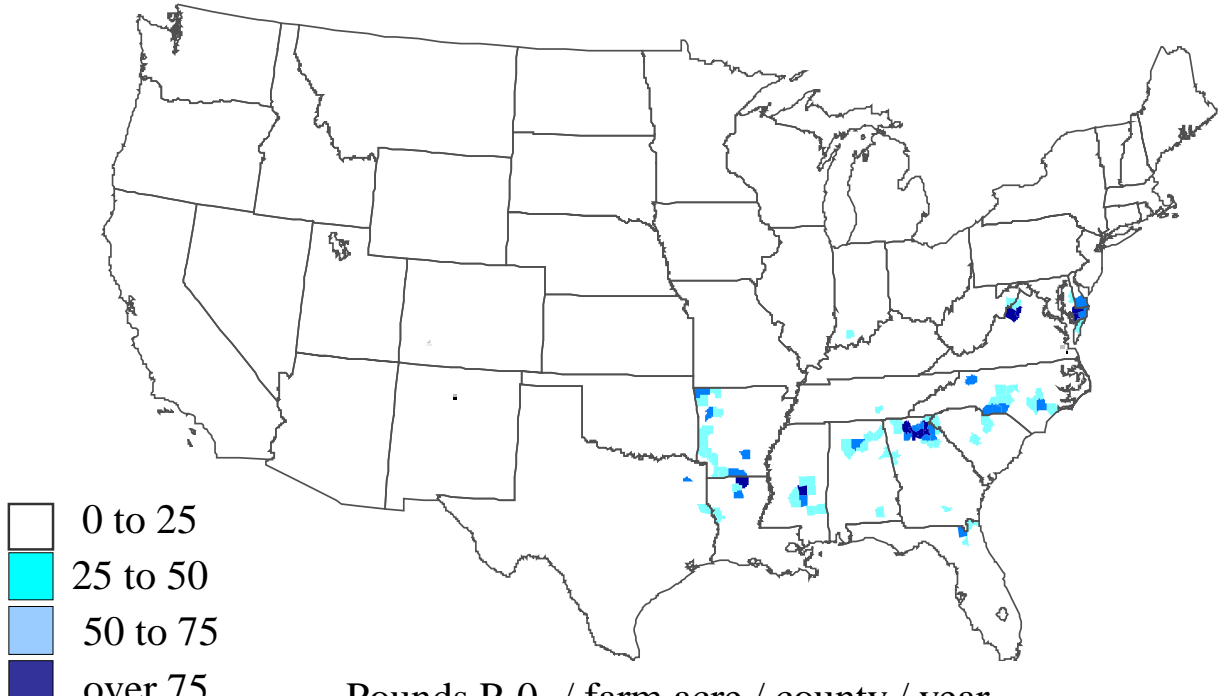

over $75 \quad$ Pounds $\mathrm{P}_{2} 0_{5} /$ farm acre / county / year

\footnotetext{
${ }^{38}$ IBID.

${ }^{39}$ Soil Facts: Poultry Manure as a Fertilizer Source. http://www.soil.ncsu.edu/publications/Soilfacts/AG-439-05

${ }^{40}$ VanDevender, K., Langston, J., daniels, M., "Utilizing Dry Poultry Litter-An Overview,"
} 


\section{Phosphorus Loading Rates: Poultry + Swine + Dairy + Beef}

(Foundation for Organic Resource Management, 1997 US Agricultural Census Data

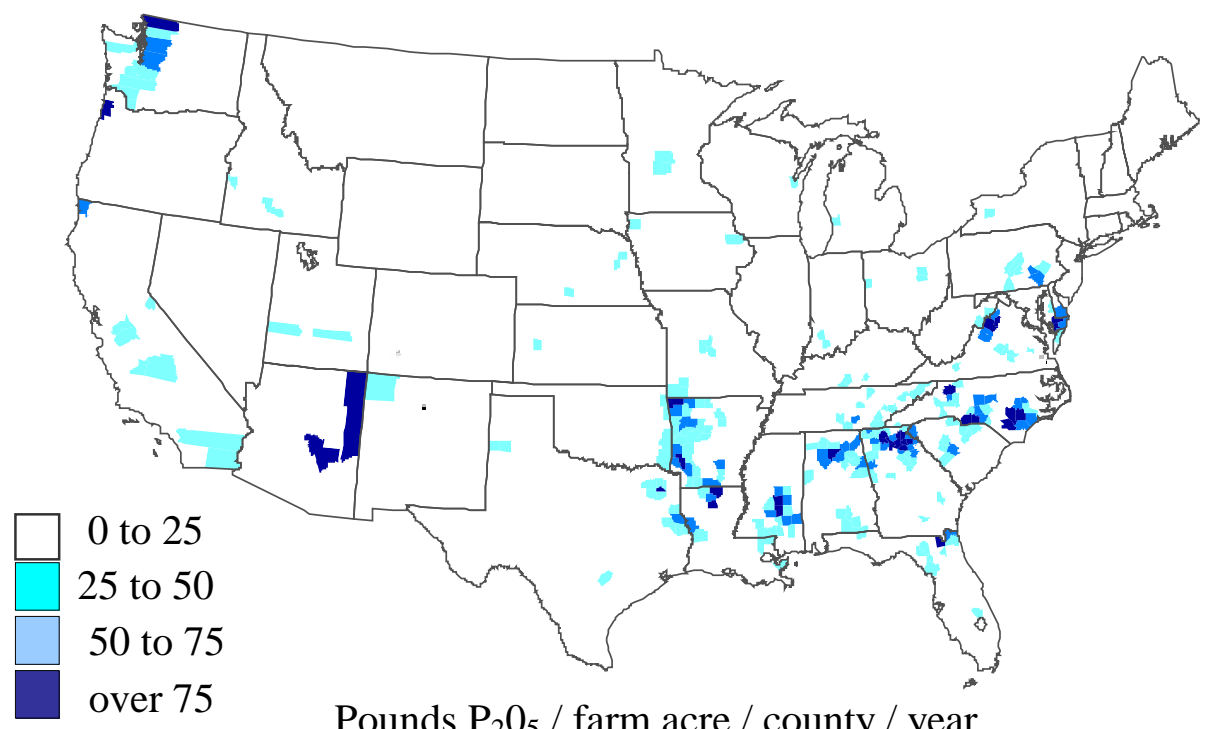

Pounds $\mathrm{P}_{2} \mathrm{O}_{5} /$ farm acre / county / year

Areas of concentrated poultry production have increased phosphorous loading rates as indicated by the figures above, but the combined contributions from multiple animal production sectors have compounded the problem.

\section{$\underline{\text { CPC Litter Property Testing }}$}

CPC was interested in the feasibility of demonstrating a biopower system at Whiting Farms in western Colorado, but also wanted to address feasibility of the larger market in the southeastern United States. Representative samples were collected using a sampling protocol supplied by FORM (Appendix-A), which involved collecting 18 core samples from area distributed locations and pooling in a 5-gallon bucket with homogenization, then removing a sample for analysis. The procedure was replicated three times to obtain three replicate samples.

\section{Table 7. Litter Sample Designations}

\begin{tabular}{|l|l|l|l|}
\hline $\begin{array}{l}\text { Sample } \\
\text { Code }\end{array}$ & $\begin{array}{l}\text { Replicate } \\
\text { Sample } \\
\text { Designation }\end{array}$ & Description & $\begin{array}{l}\text { Coarse/Fine } \\
\text { Particle } \\
\text { Character }\end{array}$ \\
\hline I & -A, B, C & Colorado Turkey Litter-Full Core & Fine \\
\hline I & -D, E, F & Colorado Turkey Litter-Crust Only & Coarse \\
\hline II & -A, B, C & Arkansas Broiler Litter (Pine Shavings) & Fine \\
\hline III & -A, B, C & Arkansas Broiler Litter (Pine Shavings + Rice hulls) & Fine \\
\hline IV & -A, B, C & Colorado Specialty Bird Floor Brooder Litter (Woodchips) & Coarse \\
\hline IV & -D, E, F & Colorado Specialty Rooster Manure & Coarse \\
\hline V & & Honeycrest Farms Broiler Litter-Pelletized & Coarse \\
\hline
\end{tabular}

\footnotetext{
${ }^{41}$ Figures are courtesy of the Foundation for Organic Resources Management. 1997 US Agriculture Census Data.
} 
Initially, CPC considered Whiting Farms in Delta, Colorado as a potential site for a phase II demonstration. Whiting farms raises Hoffman Roosters, Herbert Miner ${ }^{\mathrm{TM}}$, Junglecock, and Coq de Leon feather birds and other exotic pheasants for their hackle feathers and marketed as premium fly tying feathers. Although batch testing showed that it probably is feasible to utilize their Rooster manure in a downdraft gasifier, comparison of their biomass resource showed that it is probably not representative of the larger poultry market for broiler and market turkey litter management. The Whiting Farms rooster manure and brooder litter have very favorable characteristics for a downdraft gasifier in that the biomass has a course particle size and favorable energy content. Whiting Farms raises Roosters without litter, and the manure produced is yielded in quantities much greater than their brooder litter that is essentially woodchips. The Rooster manure has a uniform agglomerate size with $75 \%$ greater than 0.187 ', and $8 \%$ fines smaller than .062 ".
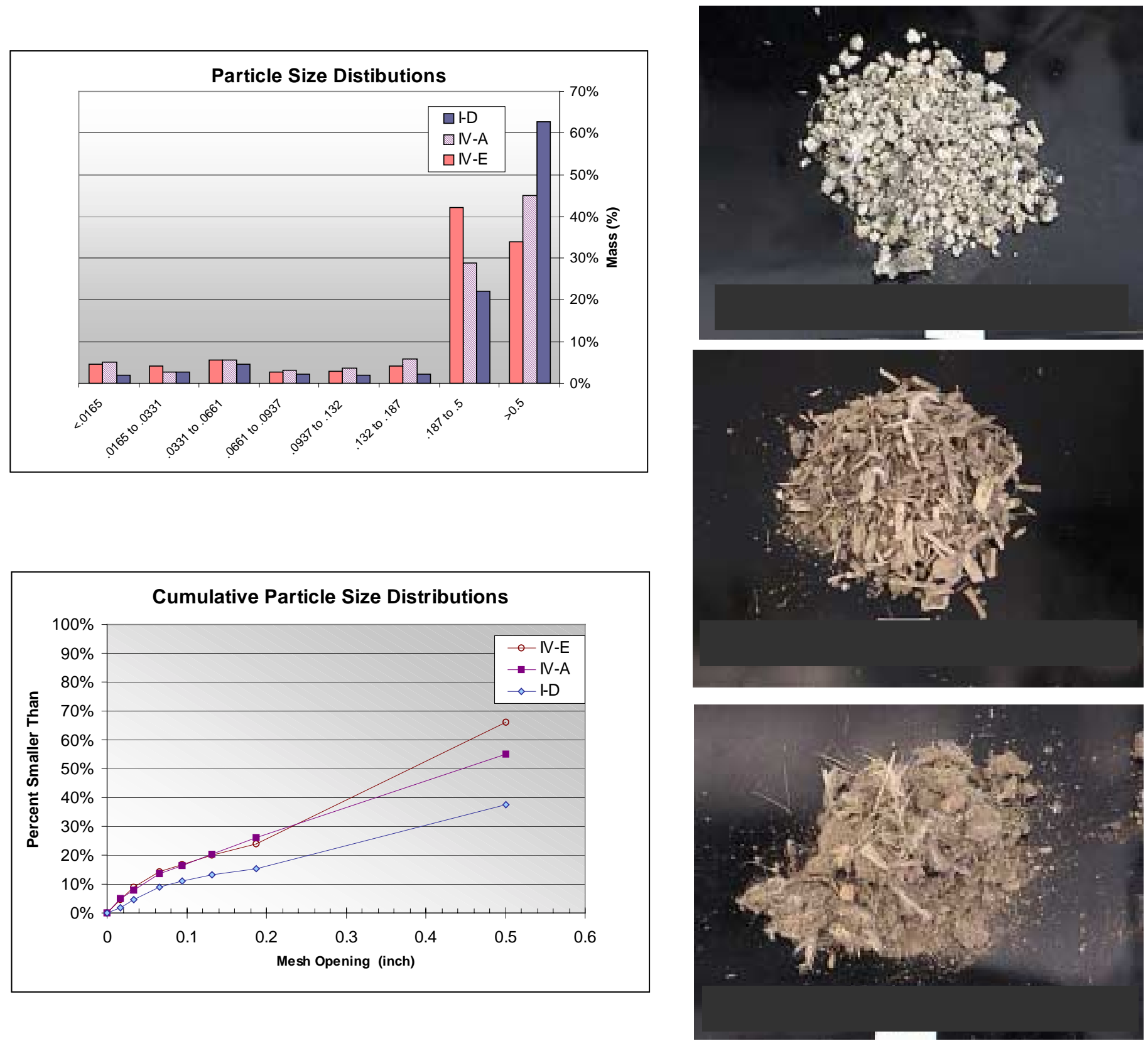
The Colorado turkey farm only removes the crust of the litter on an annual basis, and removes the finer particle sub-layer, or core, on an as needed basis or on a cycle of several years. The limited crust removal and long core litter removal cycle may be a strategy to minimize bedding and litter management challenges. So the coarse litter of Whiting Farms has excellent particle size qualities for a downdraft gasifier, but the finer particle sizes of the Arkansas broiler litter and the Turkey Litter Cores have much smaller particle sizes. The turkey litter core had $37 \%$ if its mass retained in the 0.187 inch mesh, while less than $20 \%$ of the Arkansas Broiler litter was retained in the 0.187 " screen. The turkey litter core fines content was $38 \%$ for $<1 / 16$ ", while the Arkansas Broiler litter IIA (pine shavings) had a $34 \%$ fines, and the Arkansas Broiler litter IIIA (pine

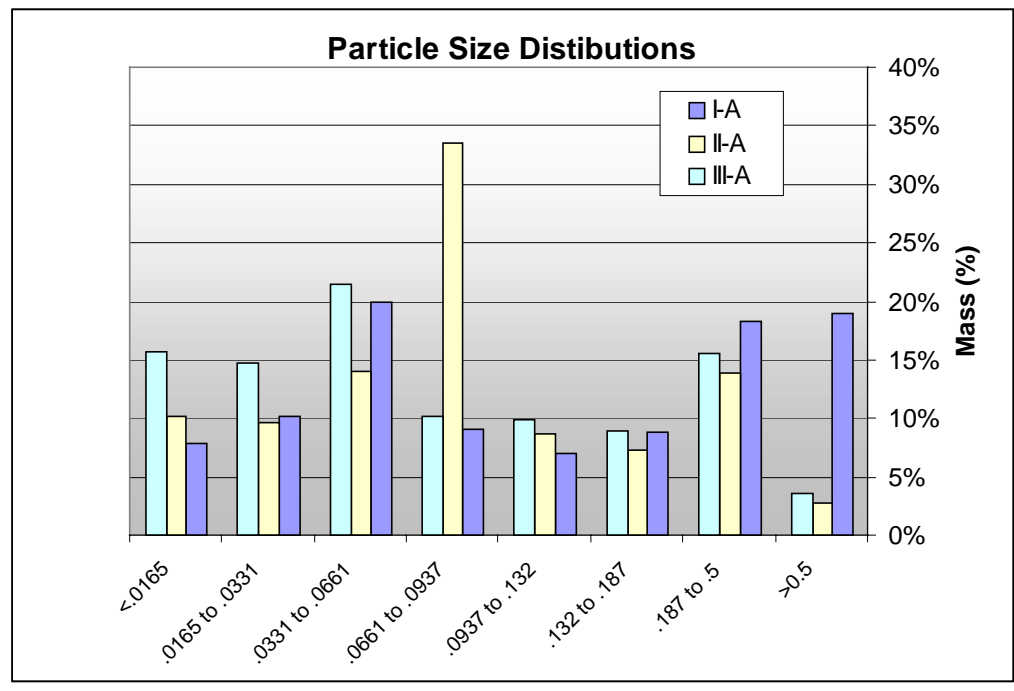

shavings + rice hulls) had the highest fines content of $52 \%$.
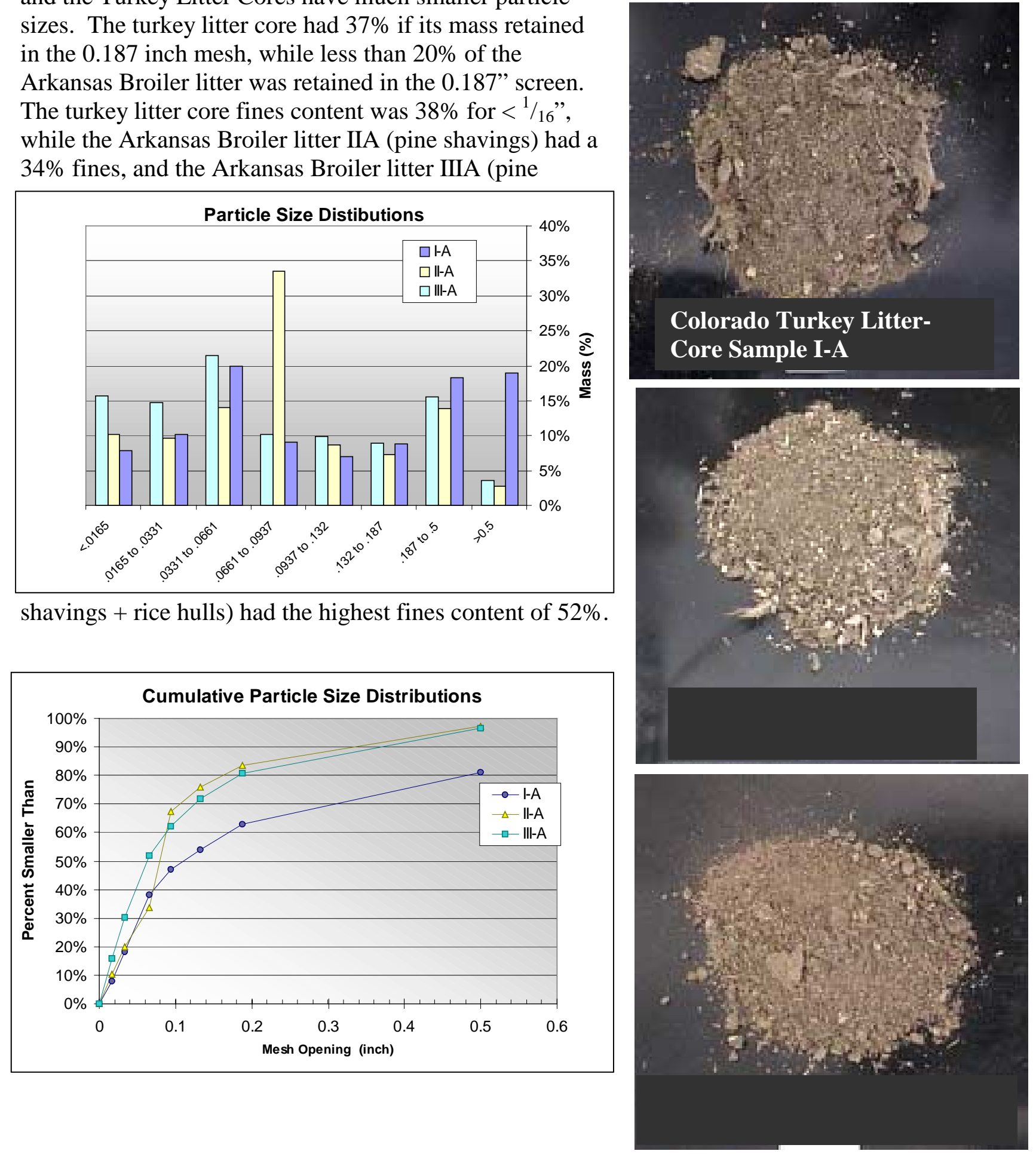
These finer litter materials are the most common in the poultry industry, and would require pelletization or cubing if used in the downdraft gasifier or would need to be managed in a fluidized bed gasification system. Farm-scale pelletization equipment has been identified that uses piston pelletizers that are lower cost than large-scale rotary extruders. ${ }^{42}$ \CPC has also considered the air-blown fluidized bed gasification technology as a potential approach to litter gasification in the small modular biopower system, as it would manage finer litter and other small particle size biomass residues without the pelletization expense.

\section{Converting Litter into Energy}

\section{Fuel Characteristics of Litter}

As received heating values for poultry litter samples collected by $\mathrm{CPC}$, excluding Colorado woodchip brooder litter, averaged approximately $4484 \mathrm{Btu} / \mathrm{lb}$ with average moisture content of $25.5 \%$, and a dry basis energy content that averaged to $6048 \mathrm{Btu} / \mathrm{lb}$. The heating values of all litter residues studies are presented in the figure below. It is clear that litter with the highest volatile matter content will have the highest heating value, and would also generate the richest producer gas when the biomass is pyrolized and gasified.

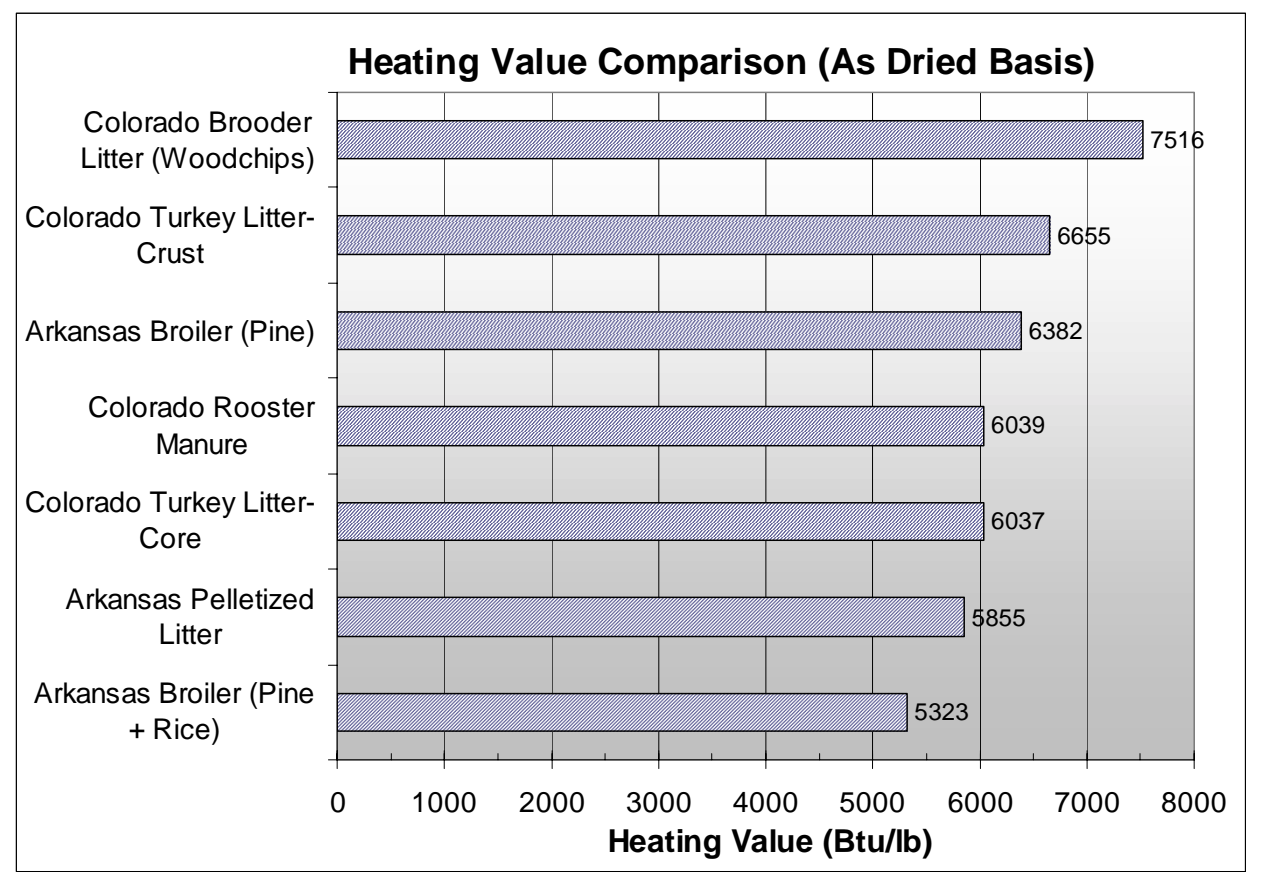

\footnotetext{
${ }^{42}$ Farm scale piston pelletizers are available such as the Enviro2000 pelletizer $\$ 105,000$ US (\$160k CAN) that has been demonstrated on poultry litter by the manufacturer. This farm-scale piston pelletizer may produce $8-12$ tons/hour and could be assembled with an integral dryer. One option is to acquire this equipment and rent to enduseres by the week with an operator to pelletize 150 tons/wk. A bit larger scale and lower density cuber is also available and is another potential strategy for downdraft gasifier fuel preparation.
} 
The brooder litter used by Whiting Farms has the highest energy content, 7516 Btu/lb dry basis; the highest volatile matter content, $71.9 \%$ dry basis; the lowest moisture, $15.1 \%$ w.b.; and lowest ash content $10.9 \%$ d.b. In fact the Whiting Farms Brooder litter is essentially a woodchip biomass with increased ash content and is nearly ideal for gasification in the Community Power Small Modular Biopower System. However, the Whiting Farms brooder litter is not the most important residue produced at Whiting Farms, rather, rooster manure is the primary poultry residue at this Colorado farm. In as much as Whiting Farms brooder litter is uncommon in the Poultry Industry and is so favorable for gasification, the authors chose to separate this litter from the typical poultry residue litters studied in this report by highlighting it in all tabular presentations and by excluding its property values from all cross-litter property averages.

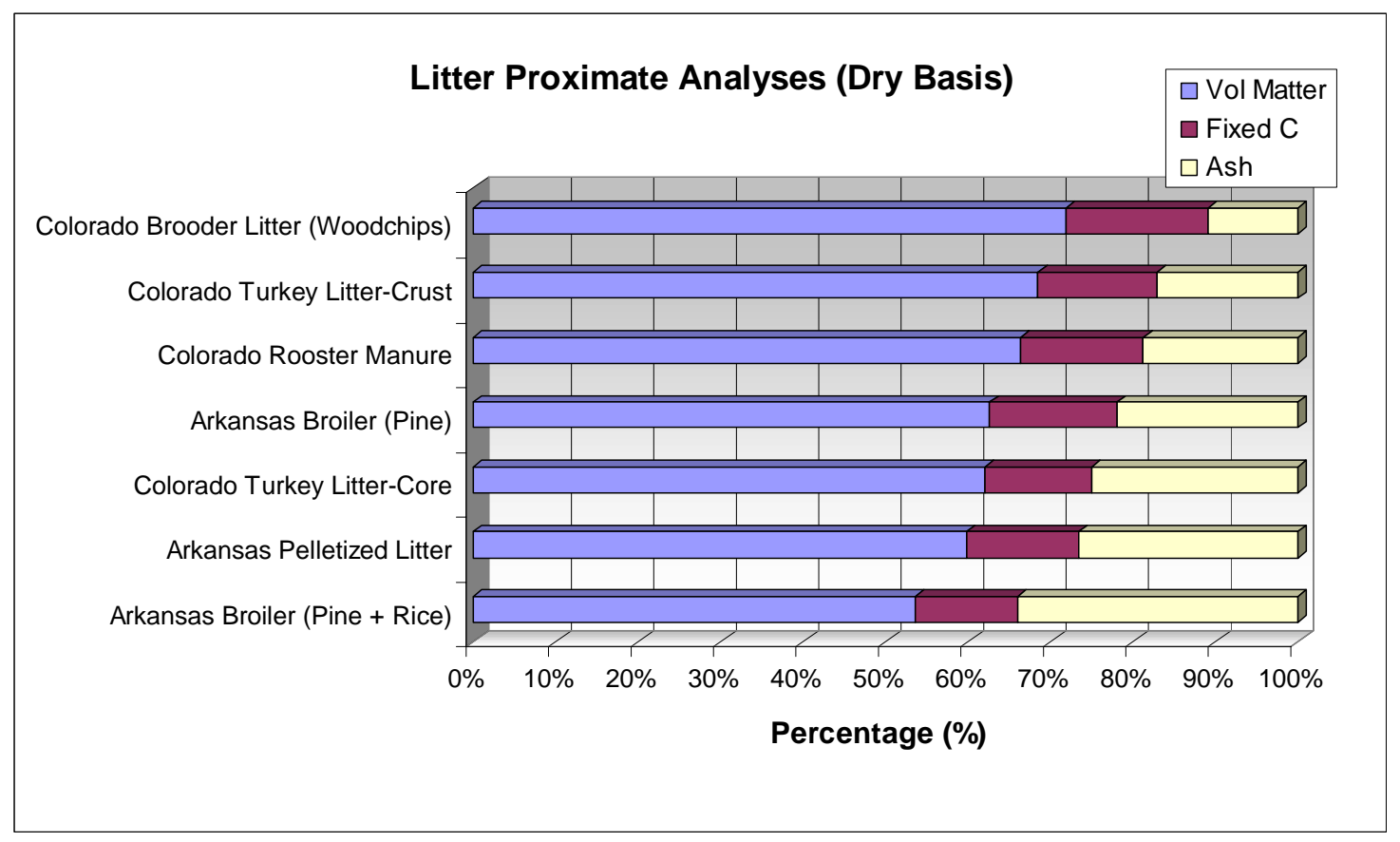

Table 8. Litter Proximate Analysis (Dry Basis) and Moisture Content (Wet Basis)

\begin{tabular}{|l|r|r|r||r|}
\hline Averages (excluding brooder litter) & $62.2 \%$ & $23.9 \%$ & $14.0 \%$ & $25.5 \%$ \\
\hline $\begin{array}{l}\text { Presented data are average results } \\
\text { from 3 replicate samples }\end{array}$ & & & & \multicolumn{1}{|c|}{} \\
\hline \hline Arkansas Broiler (Pine + Rice) & 53.6 & 33.9 & 12.4 & 22.9 \\
\hline Arkansas Pelletized Litter & 59.8 & 26.5 & 13.7 & 12.5 \\
\hline Colorado Turkey Litter-Core & 62.0 & 25.0 & 12.9 & 37.8 \\
\hline Arkansas Broiler (Pine) & 62.7 & 21.9 & 15.4 & 24.4 \\
\hline Colorado Rooster Manure & 66.3 & 18.7 & 15.0 & 14.0 \\
\hline Colorado Turkey Litter-Crust & 68.5 & 17.1 & 14.4 & 41.3 \\
\hline Colorado Brooder Litter (Woodchips) & 71.9 & 10.9 & 17.2 & 15.7 \\
\hline
\end{tabular}


The canonical stoichiometric representation of direct wood gasification (oxygen or air blown) is presented below. Direct wood gasification can be represented by the stoichiometric expression:

$$
\mathrm{CH}_{1.4} \mathrm{O}_{0.6}+0.4 \mathrm{O}_{2} \longrightarrow 0.8 \mathrm{CO}+0.2 \mathrm{CO}_{2}+0.2 \mathrm{H}_{2} \mathrm{O}+0.5 \mathrm{H}_{2}
$$

A molar comparison of the average ultimate analysis data suggests a very similar molar representation for poultry litter biomass, including a $\mathrm{C} / \mathrm{N}$ ratio of 0.13 and a $\mathrm{C} / \mathrm{S}$ ratio of 0.01 . The gasification of Poultry litter biomass would have a similar reaction expression, but gasification of poultry litter biomass has the following stoichiometric representation:

$$
\begin{aligned}
\mathrm{CH}_{1.53} \mathrm{O}_{0.62} \mathrm{~N}_{0.13} \mathrm{~S}_{0.01}+ & 0.37 \mathrm{O}_{2} \longrightarrow \\
& 0.8 \mathrm{CO}+0.2 \mathrm{CO}_{2}+0.16 \mathrm{H}_{2} \mathrm{O}+0.4 \mathrm{H}_{2}+0.13 \mathrm{NH}_{3}+0.01 \mathrm{H}_{2} \mathrm{~S}
\end{aligned}
$$

Gasification of poultry litter will produce increased levels of inorganic nitrogen and sulfur product gases compared to wood gasification. The result is that poultry litter fuel produces certain levels of NOx, ammonia, acid gas, and hydrogen sulfide, which will require gas treatment before combustion so that the life of an engine or furnace may be preserved and to minimize the

\begin{tabular}{|c|c|c|c|c|c|c|c|}
\hline Averages (excluding brooder litter) & $35.6 \%$ & $4.6 \%$ & $29.8 \%$ & $5.3 \%$ & $0.9 \%$ & $23.9 \%$ & 6,048 \\
\hline $\begin{array}{l}\text { Presented data are average results } \\
\text { from } 3 \text { replicate samples }\end{array}$ & Carbon & Hydrogen & Oxygen & Nitrogen & Sulfur & Ash & $\begin{array}{c}\text { BTU/lb } \\
\text { dry }\end{array}$ \\
\hline Arkansas Broiler (Pine + Rice) & 30.8 & 4.0 & 27.2 & 3.3 & 0.69 & 33.9 & 5,323 \\
\hline Arkansas Pelletized Litter & 33.7 & 4.5 & 29.3 & 5.0 & 0.95 & 26.5 & 5,855 \\
\hline Colorado Turkey Litter-Core & 35.6 & 4.6 & 29.2 & 4.5 & 1.08 & 25.0 & 6,037 \\
\hline Colorado Rooster Manure & 38.1 & 4.4 & 29.0 & 8.9 & 0.96 & 18.7 & 6,039 \\
\hline Arkansas Broiler (Pine) & 36.6 & 4.9 & 32.0 & 3.9 & 0.78 & 21.9 & 6,382 \\
\hline Colorado Turkey Litter-Crust & 38.6 & 5.1 & 32.3 & 6.0 & 1.05 & 17.1 & 6,655 \\
\hline Colorado Brooder Litter (Woodchips) & 43.4 & 5.4 & 38.8 & 1.4 & 0.20 & 10.9 & 7,516 \\
\hline
\end{tabular}
need for downstream air pollution control equipment.

Table 9. Poultry Litter Ultimate Analyses (mass\%) and Heating Values (dry basis)

Table 10. Litter Moisture Content and As-Received Lower Heating Value

\begin{tabular}{|l|c|c|}
\hline Averages (excluding brooder litter) & $20.6 \%$ & 4484 \\
\hline $\begin{array}{l}\text { Presented data are average results } \\
\text { from 3 replicate samples }\end{array}$ & Moisture & $\begin{array}{c}\text { Btu/lb } \\
\text { as received }\end{array}$ \\
\hline \hline Arkansas Broiler (Pine + Rice) & 22.9 & 4,105 \\
\hline Arkansas Pelletized Litter & 12.5 & 5,124 \\
\hline Colorado Turkey Litter-Core & 37.8 & 3,754 \\
\hline Colorado Rooster Manure & 14.0 & 5,196 \\
\hline Arkansas Broiler (Pine) & 24.4 & 4,822 \\
\hline Colorado Turkey Litter-Crust & 41.3 & 3,905 \\
\hline Colorado Brooder Litter (Woodchips) & 15.7 & 6,339 \\
\hline
\end{tabular}

\footnotetext{
${ }^{43}$ Samples were air dried at $85^{\circ} \mathrm{C}$ to a constant weight before analysis.
} 


\section{Fuel Energy Value Equivalents}

It is quite interesting to calculate the fuel cost equivalent of poultry litter using the energy content results from this present study. For example,

$$
\left(\frac{6000 \mathrm{Btu}}{\mathrm{lb}}\right)\left(\frac{2000 \mathrm{lb}}{\mathrm{ton}}\right)\left(\frac{1 \mathrm{gal} \mathrm{LPG}}{96,800 \mathrm{Btu}}\right) \times 75 \% \text { gasification }=\frac{93 \text { gal } L P G}{\text { dry ton litter }} .
$$

Assuming $6000 \mathrm{Btu} / \mathrm{lb}$ dry, and 75\% gasification efficiency. This calculation indicates that a dry ton of dry litter would produce a fuel gas that is equal to 93 gallons of LPG in energy equivalence. If LPG is purchased at $\$ 1 /$ gal then the value of litter would be $\$ 93 /$ dry ton, but if LPG is $\$ 0.65 / \mathrm{gal}$ then the value would be only $\$ 60.43 /$ dry ton, or $\$ 45.32 /$ ton as received at $25 \% \mathrm{M}$.

Table 11. Fuel Value and Consumption of Litter for On-Farm Applications, Single House

\begin{tabular}{|c|c|c|c|c|c|c|c|}
\hline \multirow{3}{*}{ On Farm Applications } & \begin{tabular}{|c} 
Displaced \\
Propane- \\
Aux. Gas \\
Direct Heat \\
\end{tabular} & $\begin{array}{c}\text { Displaced } \\
\text { Propane CHP } \\
\end{array}$ & \begin{tabular}{|l|} 
Displaced \\
Electricity \\
\end{tabular} & $\begin{array}{c}\begin{array}{c}\text { Gasified } \\
\text { Litter }\end{array} \\
\end{array}$ & $\begin{array}{c}\begin{array}{c}\text { Total Value } \\
\text { of Energy }\end{array} \\
\end{array}$ & $\begin{array}{c}\text { Fuel Value } \\
\text { of Litter } \\
\text { (Dry) }\end{array}$ & \begin{tabular}{|c} 
Excess \\
Litter \\
\end{tabular} \\
\hline & (gal) & (gal) & $(\mathrm{kWh})$ & (dry tons) & $(\$)$ & $\$ /$ ton dry & dry tons \\
\hline & \multicolumn{7}{|c|}{$\$ 0.65 /$ gal LPG; $\quad \$ 0.068 / \mathrm{kWh}$} \\
\hline Heat Only & 5,000 & 0 & 0 & 53.78 & 3,250 & 60.43 & 71.22 \\
\hline CHP (Power + Waste Heat) & 0 & 1,847 & 23,000 & 48.44 & 2,764 & 57.06 & 76.56 \\
\hline \multirow[t]{2}{*}{ CHP+Aux. Gas Production } & 3,153 & 1,847 & 23,000 & 82.36 & 4,814 & 58.45 & 42.64 \\
\hline & \multicolumn{7}{|c|}{$\$ 0.85 /$ gal LPG; $\quad \$ 0.068 / \mathrm{kWh}$} \\
\hline Heat Only & 5,000 & 0 & 0 & 53.78 & 4,250 & 79.03 & 71.22 \\
\hline CHP (Power + Waste Heat) & 0 & 1,847 & 23,000 & 48.44 & 3,134 & 64.69 & 76.56 \\
\hline \multirow[t]{2}{*}{ CHP+Aux. Gas Production } & 3,153 & 1,847 & 23,000 & 82.36 & 5,814 & 70.59 & 42.64 \\
\hline & \multicolumn{7}{|c|}{ \$1 /gal LPG; $\quad \$ 0.068 / \mathrm{kWh}$} \\
\hline Heat Only & 5,000 & 0 & 0 & 53.78 & 5,000 & 92.98 & 71.22 \\
\hline CHP (Power + Waste Heat) & 0 & 1,847 & 23,000 & 48.44 & 3,411 & 70.41 & 76.56 \\
\hline CHP+Aux. Gas Production & 3,153 & 1,847 & 23,000 & 82.36 & 6,564 & 79.70 & 42.64 \\
\hline
\end{tabular}

In this study the engine-generator combined efficiency is $18 \%$, and the gasifier efficiency is $75 \%$, so the litter consumption rate for CHP is $4.21 \mathrm{lb} / \mathrm{kWh}$ (2.106 tons/MWh). For combined heat and power $50 \%$ of the waste heat is assumed to be recoverable and usable. The electricity rate is $\$ 0.068 / \mathrm{kWh}$. The gas production rate for a $12.5 \mathrm{kWe}$ generator system would be 237,000 $\mathrm{Btu} / \mathrm{hr}$, so additional gasifier capacity could be afforded to supply additional gas for direct heating demands above the CHP supplied level, this concept is referred to as CHP + Direct Heat. The gasifier efficiency and fuel costs are important parameters, so a trade study was performed to show that litter would have the same value for CHP as it would for direct heating if electricity were $7.5 \mathrm{c} / \mathrm{kWh}$ when propane is $\$ 0.65 / \mathrm{gal}$, or $9.8 \mathrm{c} / \mathrm{kWh}$ if propane were to cost $\$ 0.85 / \mathrm{gal}$.

\footnotetext{
${ }^{44} 70 \%$ gasification efficiency was demonstrated in this Phase I study, but $75 \%$ efficiency is possible through heat recuperation for gasification air preheat. LHV of liquefied propane is $96,800 \mathrm{Btu} / \mathrm{gal}$ based on $\mathrm{HHV}=50,400 \mathrm{~kJ} / \mathrm{kg}$ and ${ }^{\circ} \mathrm{API}=112.5$; and $\mathrm{LHV}-\mathrm{HHV}=\sim 2400\left(\mathrm{M}+9 \mathrm{H}_{2}\right)$, where $\mathrm{M}$ and $\mathrm{H}_{2}$ are moisture and hydrogen mass fractions.
} 
It is also realized that with the assumed system efficiencies, not all of the generated litter is consumed to meet its thermal and electrical demands. In fact only 54 dry tons would be gasified to meet all the thermal demands, and only 83 dry tons would be required to meet all the electrical and all the heat load demands. Clearly, the SMB will not always be operating at peak efficiency, but at this stage it does appear that there would be some excess poultry litter available for other on-farm or off-farm purposes. Since a broiler house will accumulate litter at 100 to 125 dry tons/house/year, there could be a potential for excess litter generation on the order of 10 to 42 tons in max utilization mode (CHP + auxiliary gas production) depending on litter generation rate, energy demands and transient SMB efficiencies. Excess litter that is produced could be pooled from several participating near-by farms at a farm cooperative site and utilized to supply process heat or electricity for synergistic small industry, a pelletization plant, or the feedstock could be used to make other value added products such as fertilizer from the pooled sterilized ash product streams. The concept of ash and excess litter pooling from participating farms has been termed a Litter Integrated Management Company (LIMCO) by Community Power Corporation.

It is important to recognize that the recovered ash adds value to the gasified litter equal to $\sim \$ 10$ to $\$ 12 /$ ton litter [25\% Moisture (w.b.) assumed and 20\% ash (d.b)], based on a value of $\$ 50$ to \$60/ton ash FOB NW Arkansas. The Litter Integrated Management Company (LIMCO) could utilize ash directly by manufacturing a commercial fertilizer, adding NPK balancing components and micronutrients. The product could be packaged for resale through an established fertilizer distribution network to gain a maximum wholesale value. In addition to the consideration of ash sales and recovery value, the economic evaluation of small-scale poultry litter management should include discounting for capital equipment and operation expense and equipment maintenance costs. The economics of small modular biopower and value of litter also depends on the particular energy application and its value. For example, litter management through small modular biopower could displace on-farm heat, on-farm heat and power (CHP), or off-farm $\mathrm{CHP}$, or at a large enough scale could be utilized for ammonia production and fertilizer manufacture.

\section{$\underline{\text { Environmental Benefits }}$}

Poultry litter is a renewable energy resource. Gasification of poultry litter to displace fossil fuels used in heating poultry houses and utility electricity used for lights and ventilation has important environmental and societal benefits with the use of an on-farm litter-to-energy scheme. This approach farm-scale litter to energy scheme would give poultry growers an alternative litter management scheme with favorable economics. The current utility grid mix in Arkansas has less than $2.7 \%$ non-hydroelectric renewable energy, and more than $78 \%$ of the grid mix is supplied by fossil energy. The largest non-hydro renewable energy fraction for the big-eight poultry states is Mississippi with $4.2 \%$, and the lowest is Missouri with $0.1 \%$. Implementation of a farmscale litter-to-energy scheme in Missouri could result in more than $80 \%$ increase in the renewable energy fraction of this state. The total annual energy supplied to 9600 broiler houses and 2700 market turkey houses in Arkansas would is $253,000 \mathrm{MWh}_{\mathrm{e}},(0.6 \%$ of the utility grid energy), and $\sim 62$ Million gallons of LPG equivalent (assuming 5,000 gallons/house). Supplying all the poultry houses with litter-derived renewable energy would result in a $20 \%$ growth in (nonhydro) renewable energy for the state, and result in a conservation of 62 million gallons of fossil derived LPG fuel. If the big-eight poultry and turkey producing states displaced their electricity 
with litter-derived energy then the resulting annual renewable energy contribution would be 1.17 TeraWatt-hours, and could save 283 Million gallons of LPG equivalent fossil fuel energy.

\section{Adaptation of SMB to Gasify Poultry Litter}

Some alkali metal vapors are evolved inside a typical gasifier when utilizing poultry litter as a fuel. The presence of VAM's present a significant challenge to the design and optimization of a poultry litter gasifier because it can cause freezing of the post gasification ash and char inside the downdraft gasifier. It may also cause fusion of bed media inside a fluidized bed gasifier. Temperature control is very important in the regards, although onset of potassium evolution occurs as low as $600^{\circ} \mathrm{C}$. One approach taken in the air-blown fluidized bed gasifier is to control temperatures and minimize volatilization of potassium and to also feed up to $5 \%$ refractory dolomite, $\mathrm{CaMg}\left(\mathrm{CO}_{3}\right)_{2}$, or calcite (limestone), $\mathrm{CaCO}_{3}$ along with the poultry litter. CPC's approach in several downdraft gasifier experiments was to investigate reduced moisture and limiting the superficial velocity to improve flame front propagation and to control temperature at the pyrolysis front with reduced primary air superficial velocities. Batch testing indicated that a pyrolysis front propagation rate exists that will give high conversions and good gas quality without freezing the ash product in the downdraft gasifier.

Chloride content was not measured during this study, but chlorine and sulfur are both present in poultry litter and both are promoting elements in the volatilization of alkali metals, e.g., potassium. Certain concentrations of chlorine and sulfur relative to the alkali metal content of the ash contributes to the formation of low melting point eutectics in the char. The volatilization of alkali metals is particular significant with potassium and to a lesser extent phosphorous. The challenge with gasification of poultry litter is the presence of potassium in the product ash and its tendency to volatilize at gasification temperatures $>600^{\circ} \mathrm{C}$. Once the alkali metals atomically dispersed in the gas phase as chlorides, sulfides and hydroxides, the alkali metal vapors can deposit at elevated temperatures (as high as $1100^{\circ} \mathrm{C}$ ) in a process similar to Chemical Vapor Deposition (CVD) through reaction with silica and other mineral compounds present in the char or pyrolysis media, e.g., as in sand of a fluidized bed gasifier, or on pitted heat transfer tubes or other activated metal surfaces.

\section{$\underline{\text { Laboratory Gasification Test Results }}$}

A small batch gasifier test stand was assembled for this project to study the influence of various parameters on the quality of producer gas and char/ash product. Parameters investigated included superficial velocity, orientation (downdraft vs inverted downdraft), pellet density, and fuel moisture. CPC tested pelletized poultry litter from an Arkansas pellet mill, Honeycrest Farms. The mill uses a high-pressure $(120,000+$ psi) extruder to make a 1/4" litter pellet product. Since the pelletized litter was readily available, we chose to focus a significant amount of testing on this fuel. We also performed testing on the low density Rooster manure agglomerates, because they required no pelletization. A small die-piston pelletizer was used to make some laboratory pellet disks for testing some of the finer litter samples using low-density pelletization (20,000 psi). 


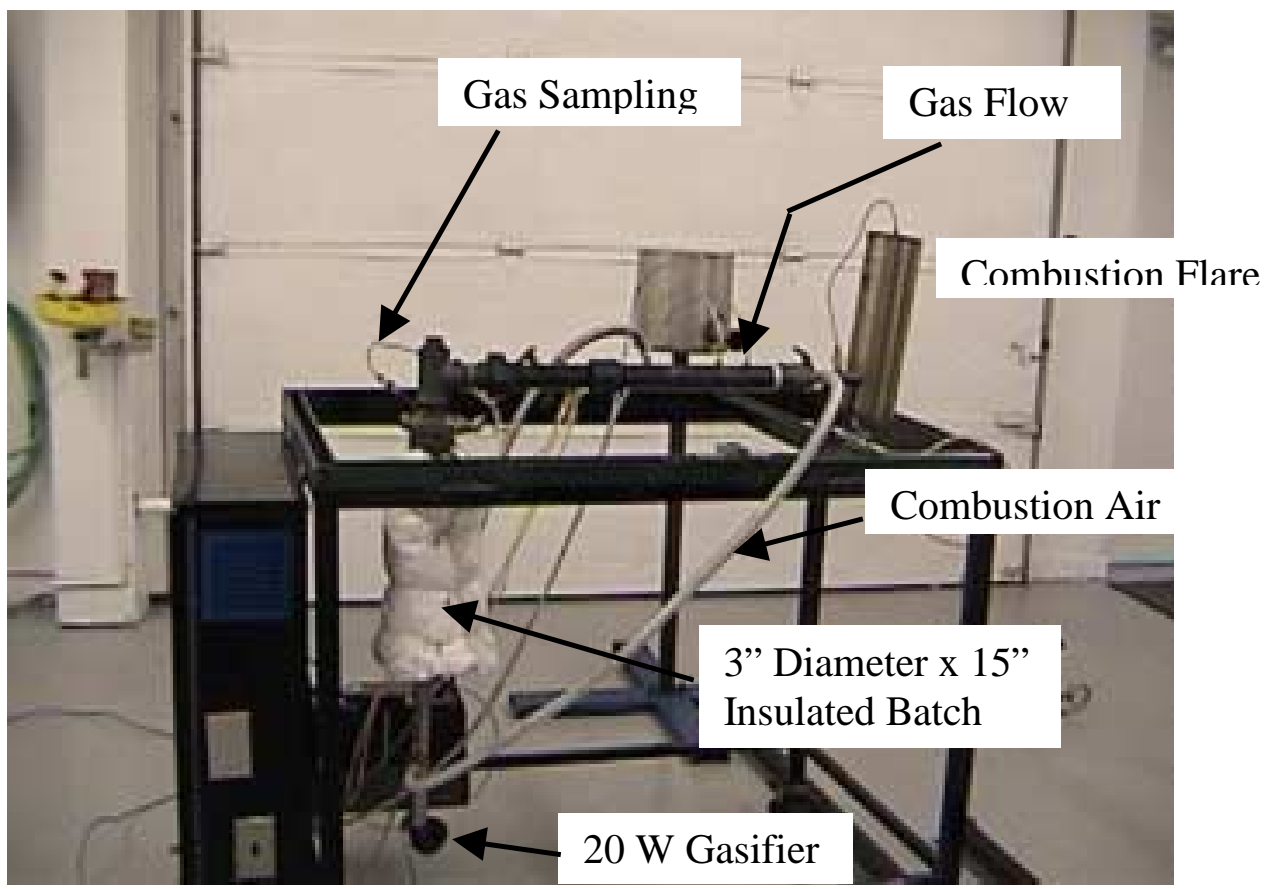

As received litter pellets had $12.6 \%$ moisture and were difficult to light. An inverted updraft configuration (air flow up, light fuel on the top, flame front propagates downward) was chosen for batch testing initially because it mimics a standard downdraft gasifier because fresh fuel is encountered in the direction of air flow before pyrolysis and char, and this configuration allows the flaming pyrolysis front to propagate downward to the bottom of the fuel cartridge passing through a fixed thermocouple position. In this manner the pyrolysis temperature can be measured. However, the propagation of the flame front was so slow that poor gas quality resulted from in this configuration.

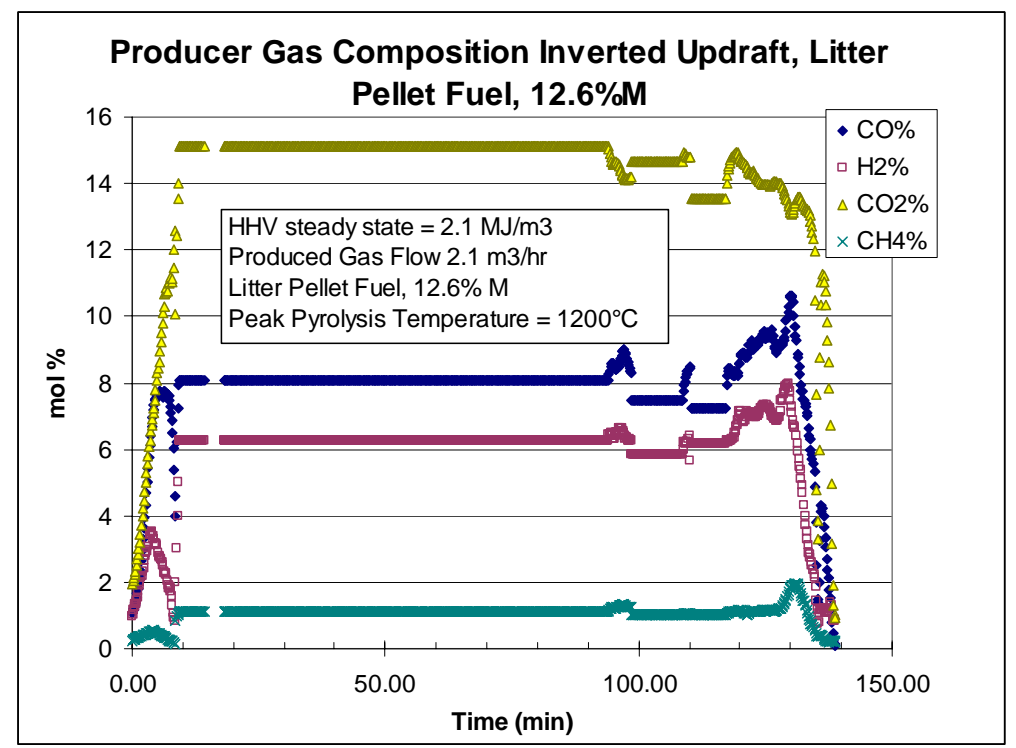


The slow flame front propagation rate leads to high pyrolysis temperatures and significant $\mathrm{CO}_{2}$ concentration in the produced gas indicating more combustion and poor gasification. At a fixed airflow rate the propagation of the flame front to fresh fuel is related can be equated to an effective an air/fuel ratio. A slow flame front propagation drives the effective air/fuel ratio toward combustion, giving a lower quality gas.

The updraft configuration has an unfavorable orientation for conduction heat transfer that is important for propagation of the flame front in the opposite direction as the airflow. Therefore, a test was performed with pellet fuel of the same moisture content, $12.6 \%$, where the airflow orientation was downward and the gasifier was lit on the bottom; this is the classic downdraft gasifier configuration. This classic downdraft configuration showed a $63 \%$ improvement in gas quality, or $3.47 \mathrm{MJ} / \mathrm{m}^{3}$. Still, the calculated higher heating value was $40 \%$ lower than the target for good gasification, $5.5 \mathrm{MJ} / \mathrm{m}^{3}$, and the flame front propagation rate was still too slow for good gas quality. The fact that orientation alone improved the gas quality indicates a very important effect of pellet contact heat transfer that is facilitated by a gasification airflow rate in the same direction as gravity.

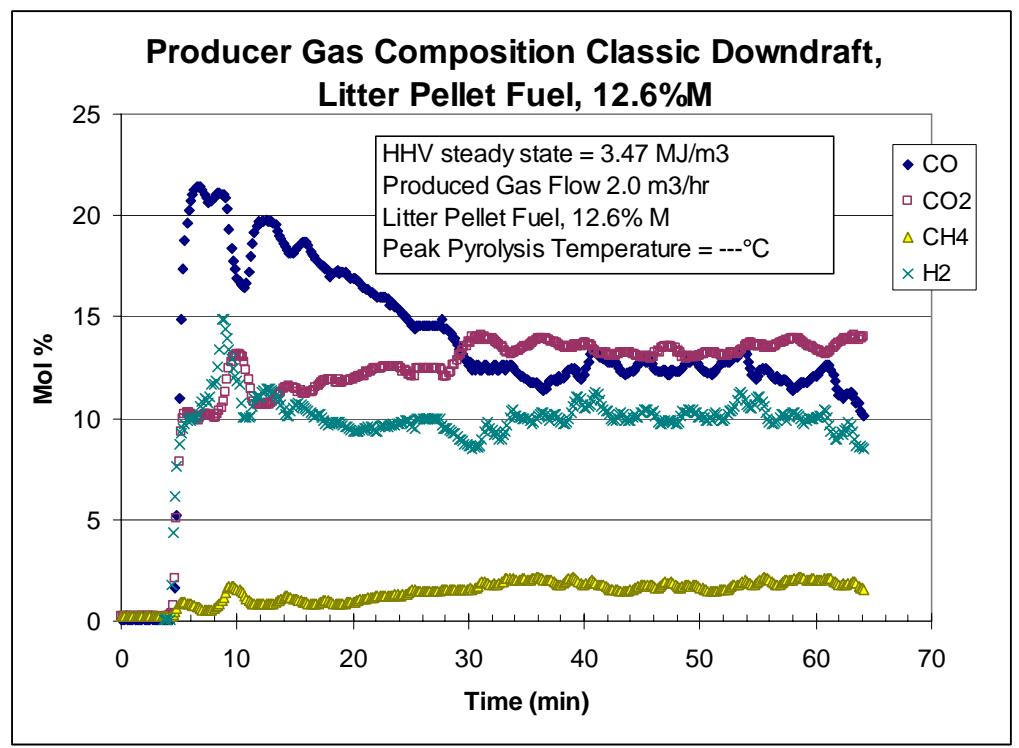

In the batch form of a classic downdraft reactor the pellet bed decreases volume as it is gasified and the flame front propagates upward against gravity, so sometimes, the flame front never passed through the fixed thermocouple position, as was the case with this test and a flame front temperature was not measured. The observed high $\mathrm{CO}_{2}$ content in both tests with high pyrolysis temperatures implicates the high-density characteristic of the litter pellet as inhibiting good gasification. 
A batch test was performed where the effect of moisture content was investigated in an inverted updraft (updraft configuration of the downdraft gasifier). In an inverted updraft configuration (air flow up that encounters fuel, then pyrolysis zone, then char) with $8.6 \%$ moisture litter pellets, the pyrolysis temperature was reduced, but the flame front propagation did not increase significantly, and steady state gas energy remained poor, $\sim 2 \mathrm{MJ} / \mathrm{m} 3$. A large agglomerate of fused char was formed inside the reactor under these conditions. See picture below.

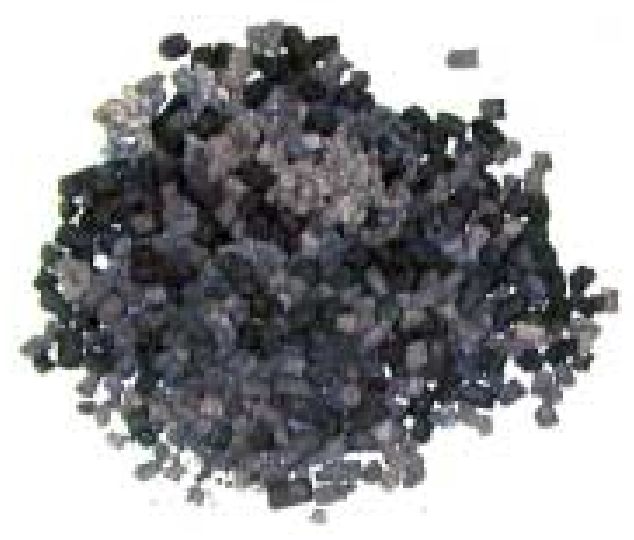

Loose Pellet Char

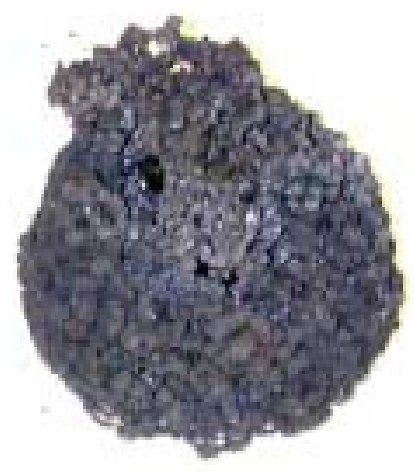

Char Agglomerate

\section{RuN $\$ 3 \quad \mid 2-11-01$}

\section{$8.6 \% M$}


Another test was performed in a classic downdraft configuration with litter fuel dried at $85^{\circ} \mathrm{C}$ to constant weight; the moisture content was $1.8 \%$ prior to gasification. The resulting producer gas energy content was $4.7 \mathrm{MJ} / \mathrm{m}^{3}$ at steady state with a much improved gas quality using dried litter fuel compared to the previous downdraft test with litter pellets at $12.6 \%$ moisture.

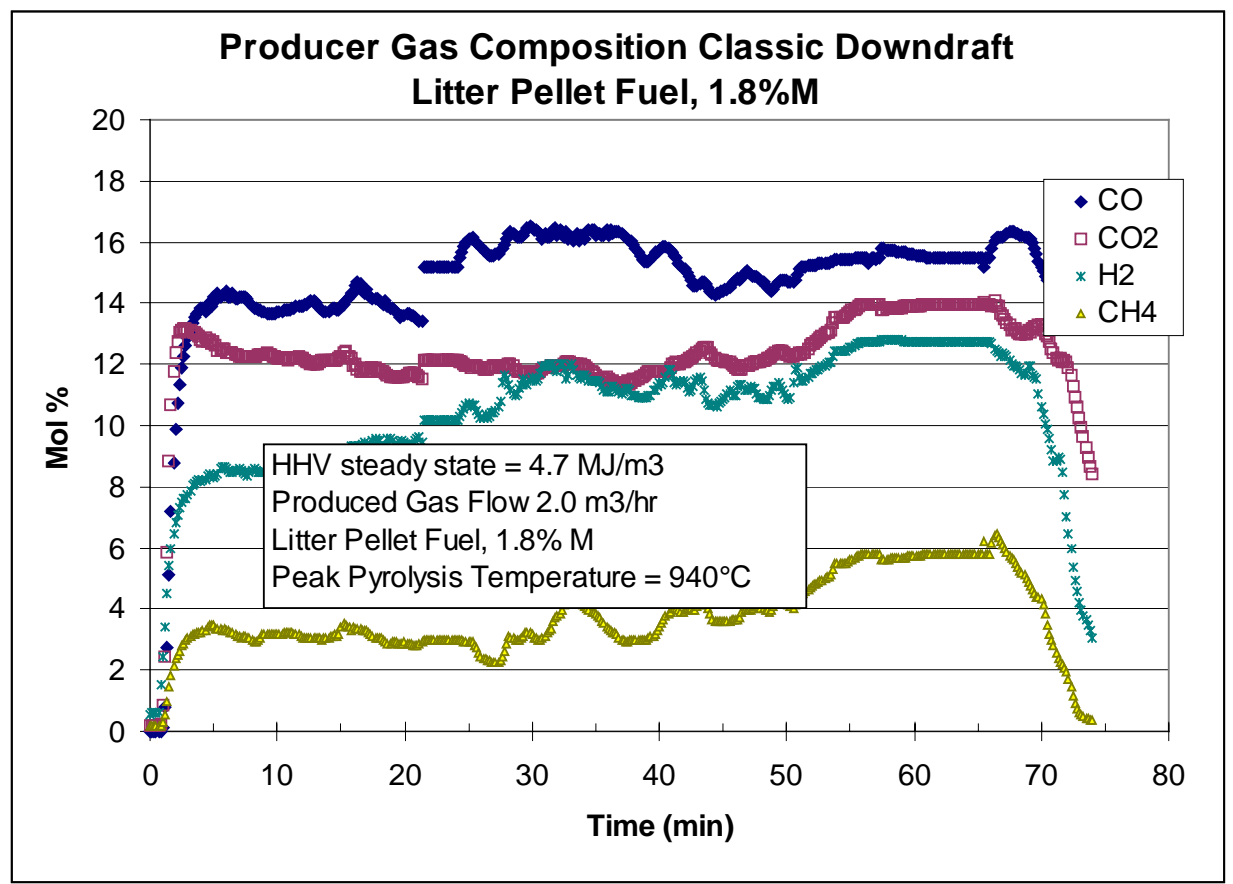

One of the more notable results of the low moisture downdraft gasification test was that the resulting ash product had an excellent quality. Ash fusion was negligible during this test, and the char conversion was $99 \%$. See the picture below of the quality ash product.
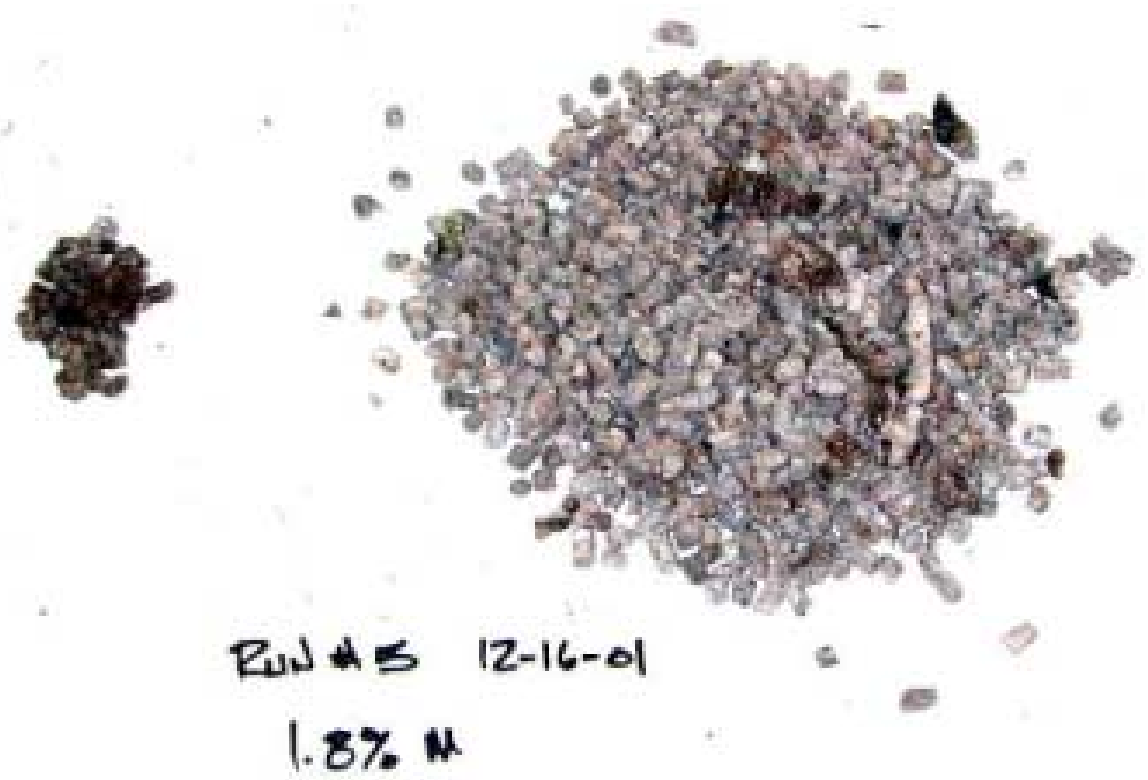
It is suspected that the manure and mineral content of the litter causes a dense pellet to be formed with very low porosity, which inhibits pyrolysis rates. Therefore, we investigated the gasification of low-density rooster manure to understand how it performed in batch gasification tests. An inverted updraft test with Rooster manure IVD that was dried at $85^{\circ} \mathrm{C}$ to constant weight had $1.3 \%$ moisture before gasification and produced fair quality gas with minimal char fusion. However, the hydrogen content was lower than expected.

The rooster manure is a low-density agglomerate so that in the updraft configuration this fuel would have unfavorable conduction heat transfer because of a low bed mass. Nevertheless, tests showed that a higher pyrolysis rate did occur with the lower density rooster manure agglomerate, which minimized combustion and produced improved quality gas.

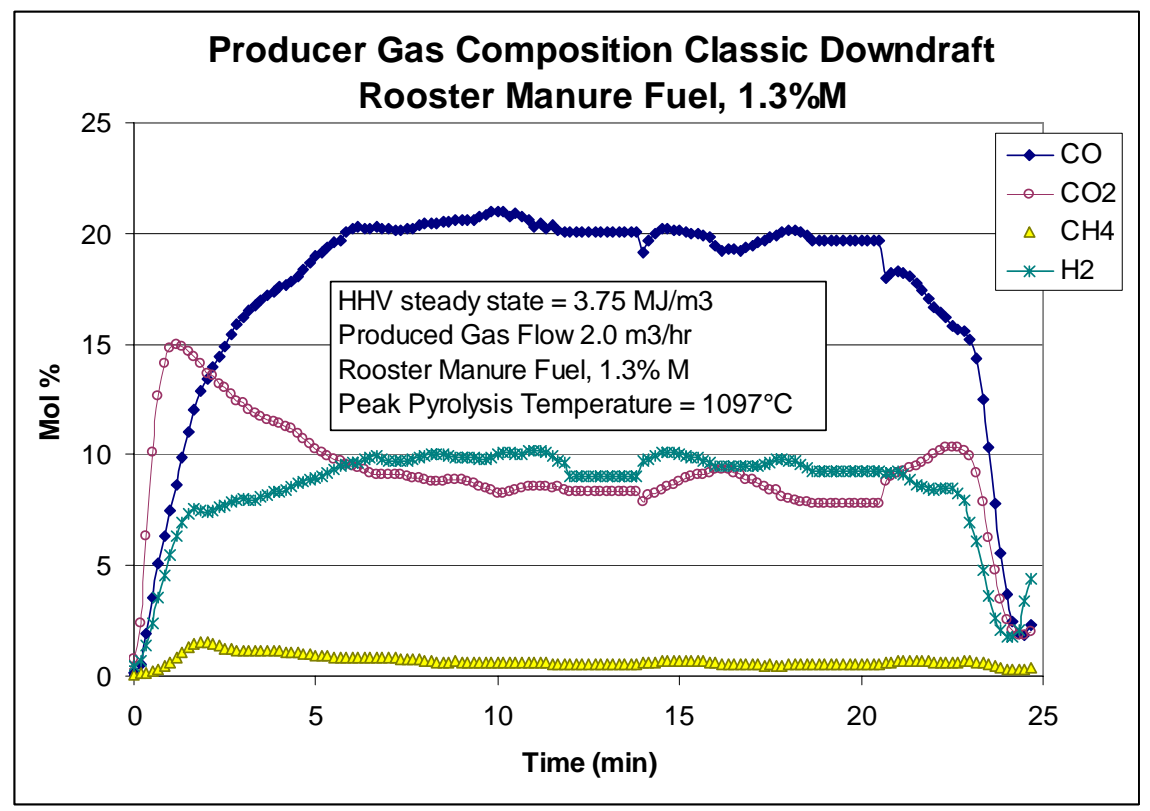

When rooster manure was tested in the down draft configuration with $13.5 \%$ moisture, the gas had a low energy content, $2.4 \mathrm{MJ} / \mathrm{m} 3$. Low moisture was also necessary for quality gasification of the rooster manure agglomerates. Among the fixed bed gasifier tests, the classical downdraft configuration was preferred as it gave the highest potential for conduction heat transfer to assist flame front propagation. Lower density pellets may improve gasification quality by increasing the pyrolysis propagation rate, but sufficient bed mass is also important, so in addition to reducing pellet density it will be important to increase the fresh fuel head above the pyrolysis zone to promote conduction and flame front propagation.

Once approach to increasing the flame front propagation rate was to decrease the moisture content, and results show this to be effective in improving the quality of gasification. Another approach that was not fully explored in Phase I was to increase flame front propagation rates by reducing the fuel pellet density in order to minimize additional fuel drying requirements. Gasification of low-density, low moisture rooster manure was also successful in the downdraft gasifier. 


\section{$\underline{\text { SMB Pilot Scale Test Data (5 hours of Electricity Production) }}$}

Based on the results of bench testing a larger gasifier was constructed to study scaleup of the poultry litter downdraft gasifier. The superficial velocity should be low to help reduce the temperature in the flaming pyrolysis zone to 800 to $900^{\circ} \mathrm{C}$, which helps minimize char fusion as a result of high alkali content in the fuel. The larger gasifier was installed onto the small modular biopower system and a 5-hour test was completed.

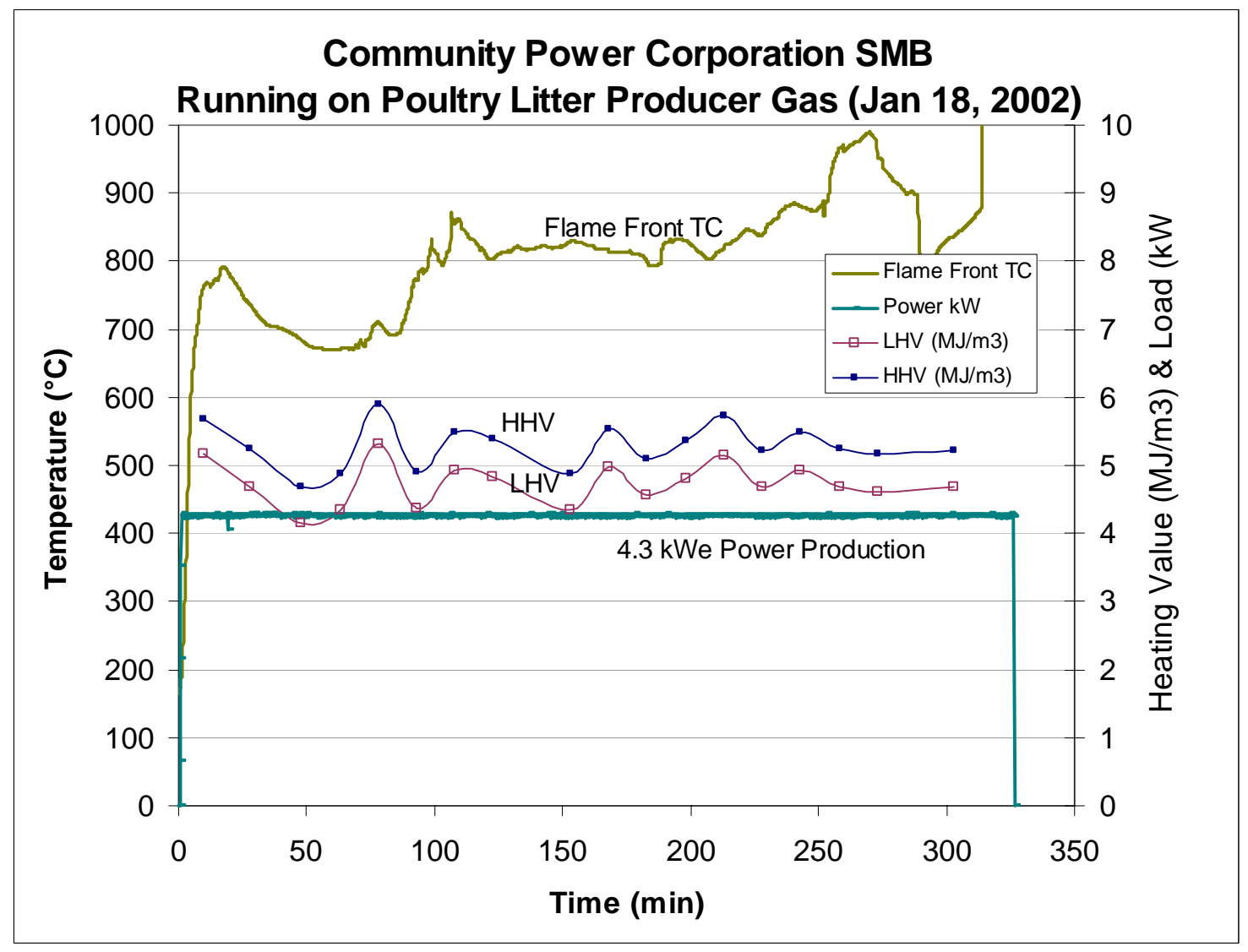

The engine exhaust emissions during this test were and 1.1\% CO, $6 \mathrm{ppm} \mathrm{HC}$, and $5000 \mathrm{ppm}$ NOx, dry basis, which equates to $1.0 \% \mathrm{CO}, 5 \mathrm{ppm} \mathrm{HC}$, and $\sim 4383 \mathrm{ppm}$ NOx on a wet basis. The $\mathrm{CO}$ and NOx emissions are unacceptable for stationary power generation by one to two orders of magnitude, equating to about $0.797 \mathrm{lb} / \mathrm{hr}$ at stoichiometric combustion and $4.3 \mathrm{~kW}$, equates to $186 \mathrm{lb} / \mathrm{MWh} .55$ The engine-generator system was not optimized for air pollution during this test and was operating below its optimum power point. Adjustments to the engine timing, lower engine rpm and downstream catalytic conversion will mitigate CO. However, the chemical NOx contribution (intrinsic fuel constituent precursors to NOx including ammonia) to air pollution is the most important aspect to consider when designing an air pollution control strategy for poultry litter. A new gas production module designed for poultry litter must have ammonia and

\footnotetext{
${ }^{45}$ New England \& Mid Atlantic NOx emissions standards are $2.9 \mathrm{lb}$ NOx/MWh until 2006 when this standard is reduced to $2.25 \mathrm{lb} / \mathrm{MWh}$. California stationary source standards, per Rule 502 are $10 \mathrm{lb}$ NOx/day.
} 
chemical NOx reduction prior to engine or furnace combustion. Catalytic conversion strategies based on upstream catalytic ammonia conversion are proposed. NOx emissions attainment is possible with $98 \%$ reduction in fuel gas ammonia and $25 \%$ improved engine efficiency.

It is very important to reduce chemical NOx precursors in the fuel gas, which are significant in poultry litter producer gas, before delivery to a brooder array inside a poultry house, or before delivery to an engine for power production. If the NOx is reduced before combustion it is possible to achieve very low NOx emissions from a typical engine system with a standard 3-way catalytic converter. Staged combustion burners would also have some success in reducing chemical NOx production from nitrogen rich fuel gas, however, reduction of the NOx within the GPM gas cleanup system is important for the broadest application of the producer gas in a generalized combustor or engine application.

\section{Material Energy Balance}

The mass-energy balance table for the 5-hour pilot test run is produced below:

Table 122. Pilot Test Mass Energy Balance

\begin{tabular}{|c|c|c|c|c|}
\hline Component & $\begin{array}{c}\text { Mass Flow } \\
\text { Volume Flow } \\
\end{array}$ & LHV & $\begin{array}{c}\text { Energy Flow } \\
(\mathrm{kW})\end{array}$ & $\begin{array}{c}\text { Energy Flow } \\
(\mathrm{MJ} / \mathrm{hr})\end{array}$ \\
\hline Litter Feedstock & $\begin{array}{c}22.5 \mathrm{~kg} / \mathrm{hr} \text { at } \\
12.5 \% \mathrm{M}\end{array}$ & $13.62 \mathrm{MJ} / \mathrm{kg}$ & 85.12 & 306.4 \\
\hline Char Out & $\begin{array}{r}1.74 \mathrm{~kg} / \mathrm{hr} \text { at } \\
1.9 \% \mathrm{M}\end{array}$ & $6.79 \mathrm{MJ} / \mathrm{kg}$ & 5.47 & 19.7 \\
\hline $\begin{array}{l}\text { Produced Gas } \\
\text { At } 80^{\circ} \mathrm{C}\end{array}$ & $\begin{array}{c}45 \mathrm{Nm}^{3} / \mathrm{hr} \text { at } \\
12 \% \mathrm{M}\end{array}$ & $4.79 \mathrm{MJ} / \mathrm{Nm}^{3}$ & 59.88 & 215.6 \\
\hline $\begin{array}{l}\text { Gasifier Heat Loss } \\
\text { +Gas Cooling }\end{array}$ & $\begin{array}{l}\text { Cooled gas to } \\
\qquad 80^{\circ} \mathrm{C}\end{array}$ & $\begin{array}{c}(\text { By } \\
\text { Difference })\end{array}$ & 19.75 & 71.1 \\
\hline $\begin{array}{l}\text { Electricity Product } \\
(4.25 \mathrm{kWe})\end{array}$ & & & 4.25 & 15.3 \\
\hline $\begin{array}{l}\text { Engine Water } \\
\text { Cooling }\end{array}$ & & $\left(95-80^{\circ} \mathrm{C}\right)$ & 19.5 & 70.2 \\
\hline $\begin{array}{l}\text { Exhaust Heat } \\
\text { Recovery }\end{array}$ & $\begin{array}{l}\sim 58 \mathrm{Nm} 3 / \mathrm{hr} \\
\mathrm{MW}=28.5\end{array}$ & $\begin{array}{c}\text { Potential } \\
\left(600 \text { to } 80^{\circ} \mathrm{C}\right)\end{array}$ & 13 & 46.8 \\
\hline $\begin{array}{l}\text { Unrecoverable } \\
\text { Engine-Generator } \\
\text { Heat Losses }\end{array}$ & & $\begin{array}{c}\text { (By } \\
\text { difference) }\end{array}$ & 23.1 & 83.2 \\
\hline
\end{tabular}

Gasifier Efficiency (char inclusive): $\eta_{g a s}=\frac{215.6}{306.4-19.7}=75 \%$

Gasifier Efficiency (char exclusive): $\eta_{g a s}=\frac{215.6}{306.4}=70 \%$

Engine-Generator Efficiency: $\eta_{g a s}=\frac{4.25}{59.88}=7 \%$ 
Note the phase I feasibility testing was performed at low engine power relative to the size of the engine used for testing, therefore a much lower engine-generator efficiency was acquired than is possible at higher power levels. Ideally adapted gasifier size and engine generator capacity can give engine generator efficiencies that would be $\sim 20 \%$.

\section{Phase-II System Designs}

Several issues are apparent at the conclusion of this Phase-I poultry litter gasification project and these include chemical NOx reduction in fuel gas, accommodation of litter feedstock fines, ash product recovery, and integrated litter management of the excess litter accumulated on the farm beyond the energy needs of the poultry house, and addressing the poultry farmers fertilizer needs. In summary, a phase II system:

1. Must reduce Chemical NOx and any amine precursors in producer gas prior to delivery to combustion application, which is vital to the broadest success of Phase II demonstration system;

a. Ensures broadest application of the farm-scale technology: "brooders", farm furnaces, and back-up and base-load engine generator systems.

2. Must accommodate fines in litter feedstock;

a. Downdraft gasifier option

i. Suggest consideration of low-cost $(<\$ 20 /$ ton $)$ piston type pelletizer or cuber using pressures in the range 16,000 to 50,000 psi. (150,000 psi extruder type pellets present some pyrolysis rate limitations)

ii. Low density agglomerated litter (using power agglomeration technology) is a potential low-cost fuel processing option for the downdraft gasifier, and may be a viable and economic fuel processing technique.

iii. Lower tar production from an optimized downdraft gasifier, 25 to $50 \mathrm{ppm}$, is possible.

iv. Limited scale-up to single farm system.

b. Fluidized bed gasifier option

i. Minimal fuel processing required other than some fuel drying.

ii. Higher tar production, but integrated tar reforming may have the added benefit of chemical NOx mitigation.

iii. Good potential for scale-up to multiple farm system

3. Must have product ash recovery for wholesale value or integration in a multiple farm LIMCO process.

a. A small modular LIMCO may have the capacity for integrated fertilizer production with litter gasification for ammonia production and added value for mineral ash management (Tailored N-P-K ratios for local farm co-op, and export)

4. Must consider excess litter management above the poultry house energy needs; 
a. A litter integrated management company (LIMCO) is a farm community management concept that would give the highest return for excess litter.

b. The gasification technology basis for a LIMCO can be a Small Modular Biopower System scaled up for a small farm community, 20-50 poultry houses.

CPC is developing integrated modular architectures for small modular biopower systems. This concept separates the product development and manufacturing of the a "gas production module (GPM)", which includes gas cleanup and heat recovery systems for fuel drying, from the development of "power conversion module (PCM)" assemblies, which are available elsewhere. Therefore, with a modular architecture, CPC may focus its experience and knowledge to the GPM product. The GPM would have integral gas cleanup, heat recovery for fuel drying and gas pumping for a generic gas application including poultry farm furnaces, a range of enginegenerator systems, and poultry farm "brooder" arrays.

CPC is developing two dry gas clean-up approaches for phase II, one involves tar reforming, and secnd involves tar condensation in a heat exchanger with a tar-trap media. CPC seeks to demonstrate two systems in phase II: one that is based on a downdraft gasifier has secondary air injection to reduce tar content in the gas and uses a low density pellet litter or agglomerated litter as a fuel; a second system considered for phase II demonstration is a fluidized bed gasifier with a tar reformer that can manage as received litter fines.

Concept Gas Production Module

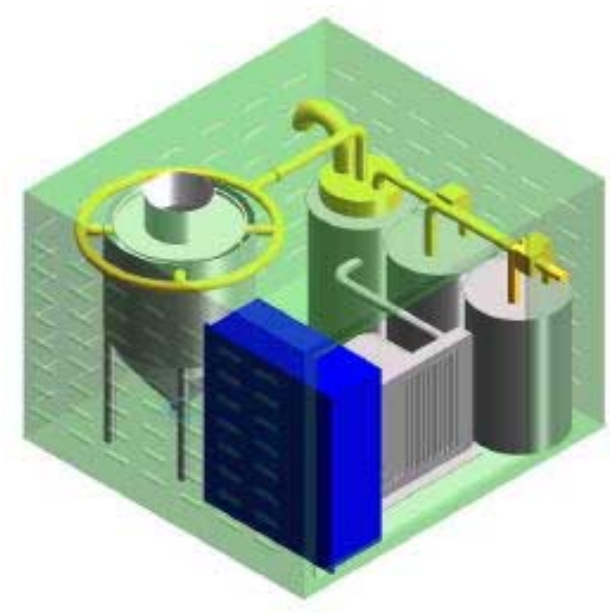

Concept Power Production Module

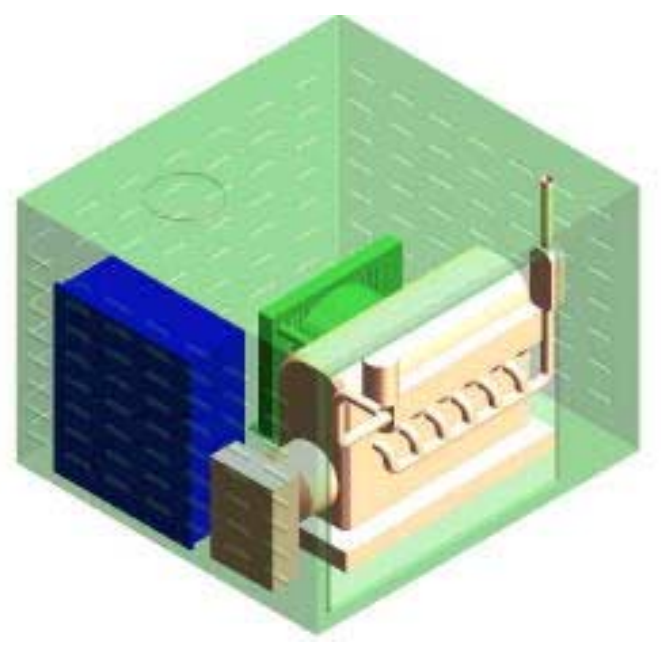




\section{Downdraft Gasifier System}

Tests with a downdraft gasifier in phase I shows the feasibility of using this type of gasifier with poultry litter; in this case litter particle size make-up, pellet density, fuel moisture and gasifier superficial velocity are design items important to reliable operation with poultry litter fuel. Fuel pelletization at the farm scale is feasible with die-piston type pelletizers, and economic analysis of existing systems suggests a granularization costs on the order of $\$ 20 /$ ton. The gas production module would have a motive air blower integrated after tar trap and sensible gas cooling in the system diagram below which would give enough fuel pressure for distribution to farm furnaces and brooder arrays as required by a fuel distribution control system. Integration with existing fossil fuel backup is also vital to overcoming resistances to innovation including compatibility with existing approach to poultry house heating, reversibility of the installation, and insuring against failure consequences. The proposed system also has sulfur adsorption and catalytic NOx and ammonia reduction. Catalytic ammonia reduction ${ }^{16}$ using a blend of copper oxide and platinum catalyst at $200^{\circ} \mathrm{C}$ will be applied to CPC's gas production module design for phase II demonstration. The figure below shows a phase II litter gasification module integrated with an existing gas furnace and a brooder array. $\mathrm{NH}_{3}$ reduction prior to combustion is vital to the integration with the brooder array.

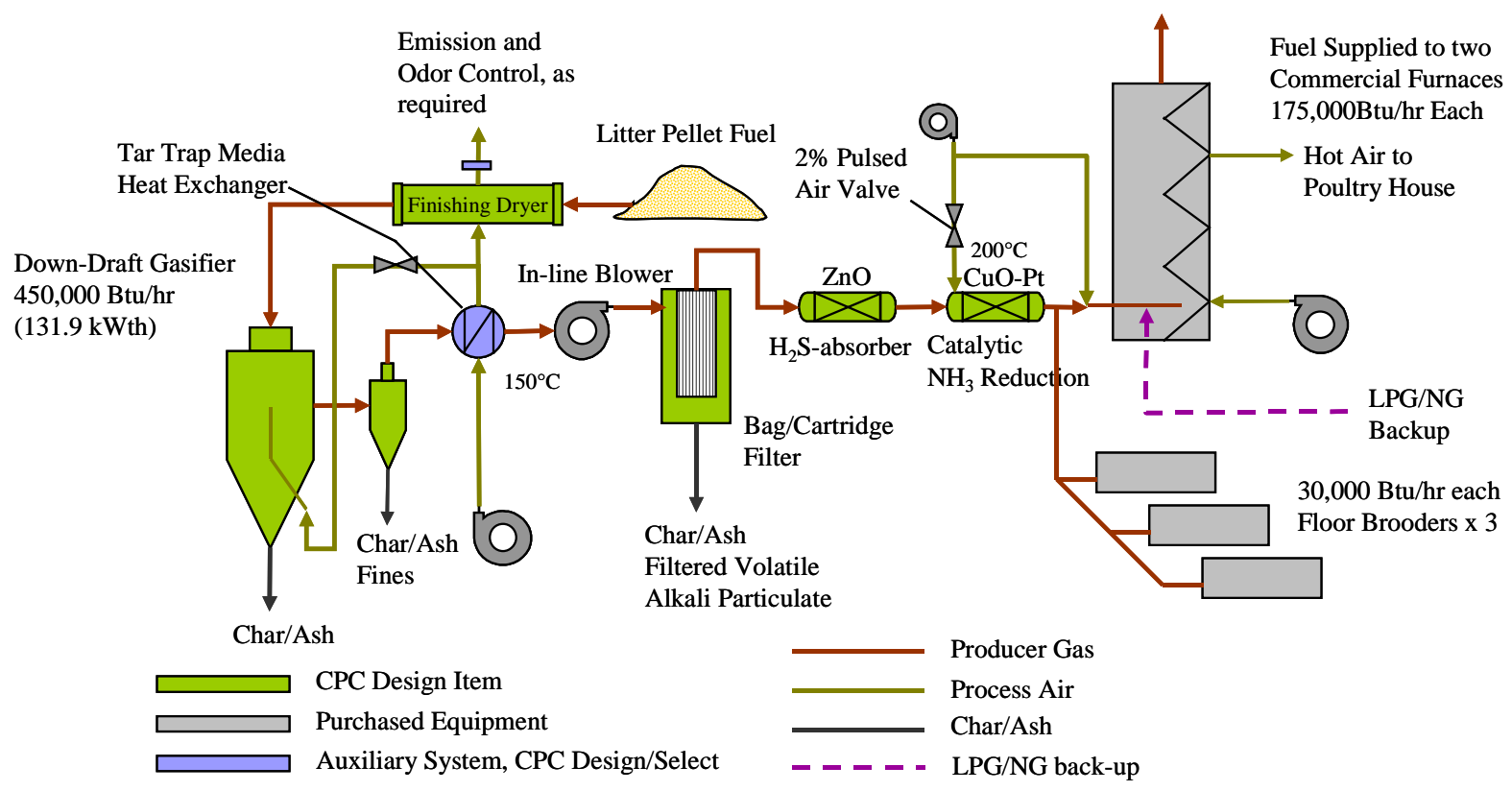

\footnotetext{
${ }^{46}$ Burch, R.and Southward, B.W., "Low-Temperature, clean catalytic combustion of N-bearing gasified biomass using a novel $\mathrm{NH}_{3}$ trapping catalyst. Chemical Communications. Vol 13, 1115-1116 (2000).
} 
The second down draft configuration shows how a back-up generator could be integrated so that combined electrical energy production and furnace gas delivery could be achieved with the same GPM.

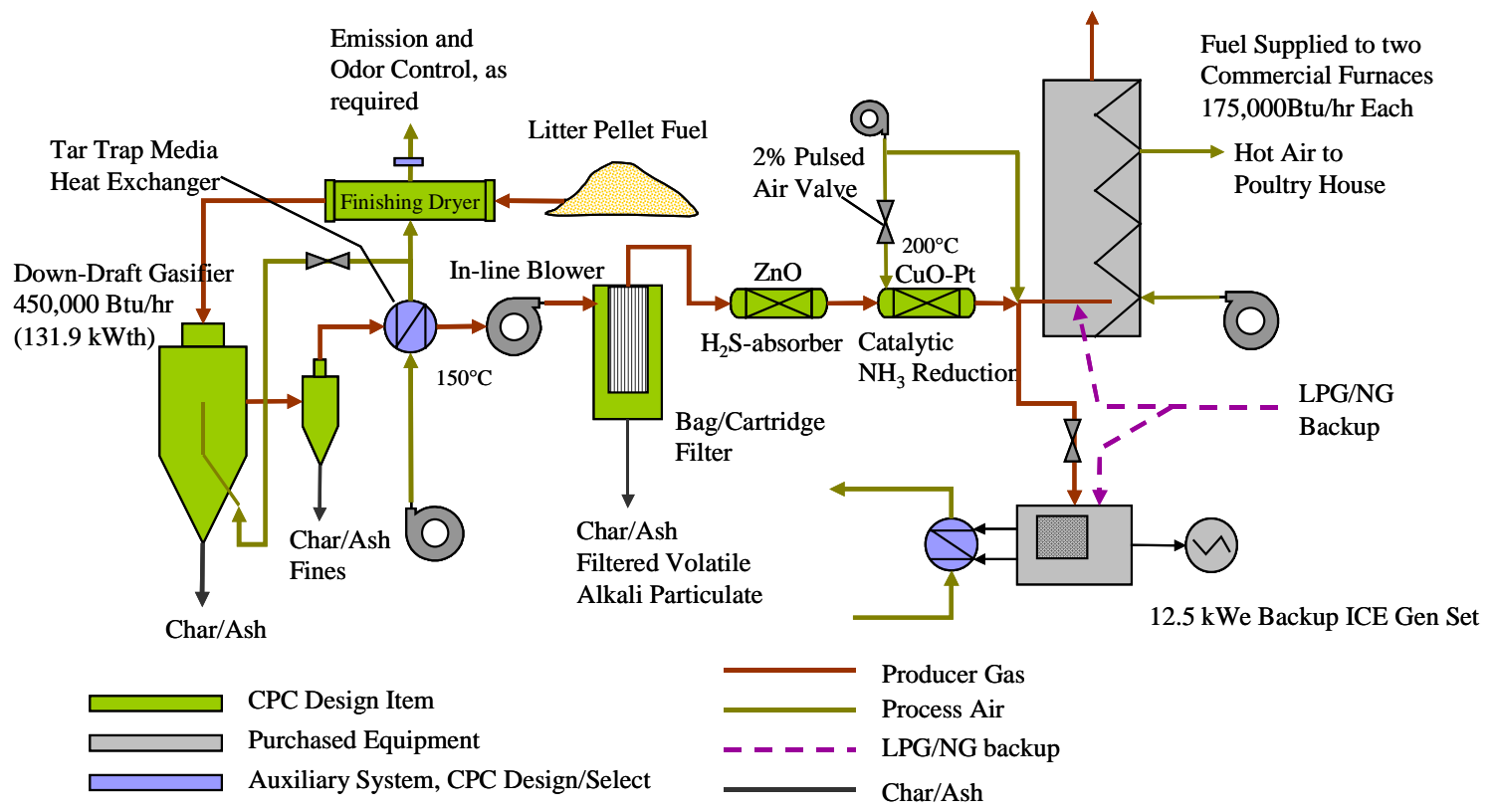

\section{Fluidized Bed Gasifier System}

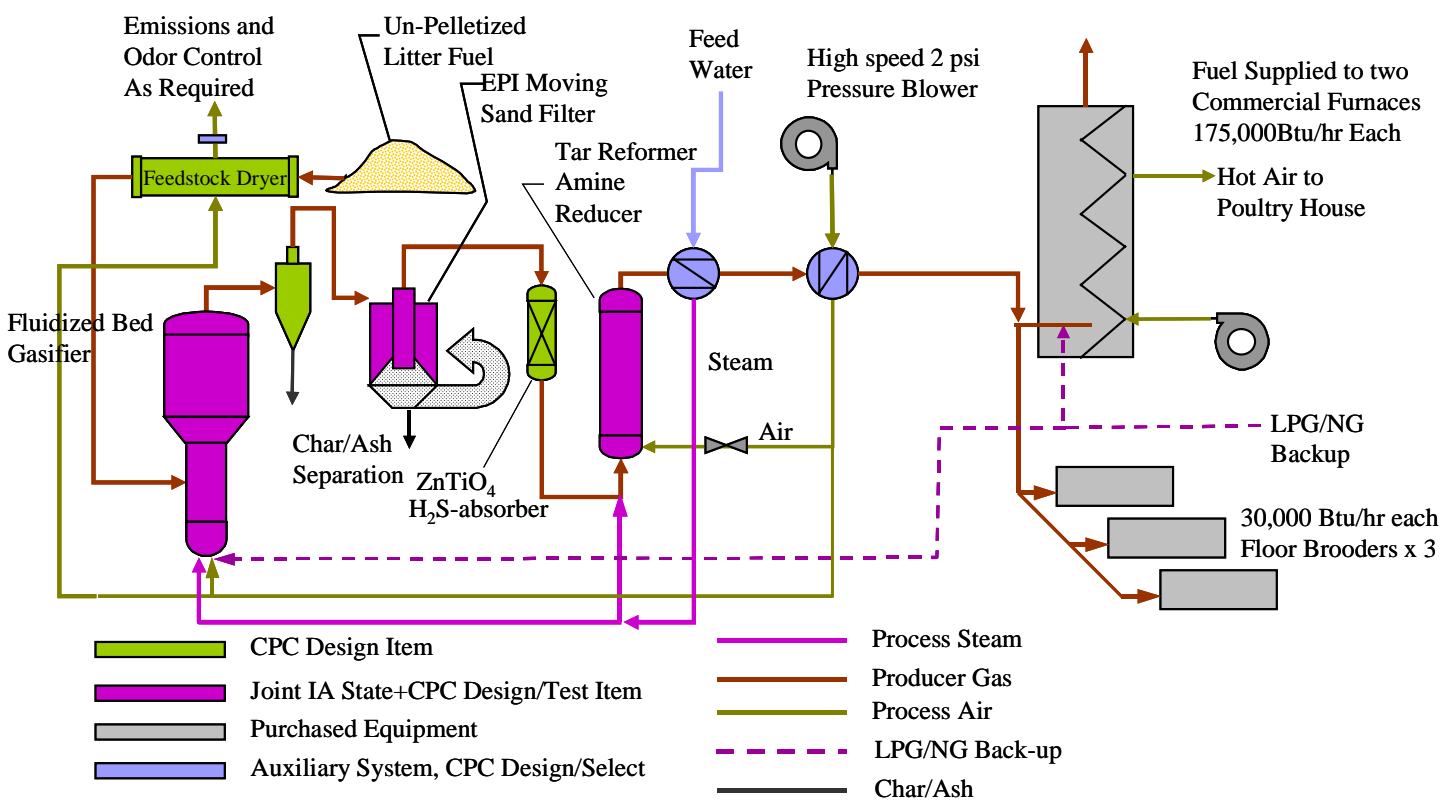

A small modular fluidized bed gasifier system is also proposed for evaluation for a phase II demonstration system because features of this type of reactor will enable uniform temperature control inside the gasifier, excellent heat transfer with in the reactor bed, and an inherent ability to manage a finer particle size in the litter fuel stream. A secondary benefit of the fluid bed 
gasifier is that it has been demonstrated in the Netherlands on poultry litter with stable operation when co-feeding litter fuel with a small percentage of dolomite or limestone. This approach to avoid bed freezing is common in the biomass industry. Other non-silica based bed media may have some advantage for poultry litter gasification for the prevention of bed agglomeration, since a fusion of potassium and silica forms a low melting point eutectic and contributes to bed agglomeration. Finally, CPC is teaming with Iowa State University for this secondary Phase II system because of their experience with air-blown fluid bed biomass gasifiers. In addition, CPC would evaluate the Iowa State developed moving sand-bed, hot gas filter for use in small modular systems (SMS), although an intellectual property licensing option has already been sold as it pertains to larger system applications.

The fluid bed gasifier produces higher tars $(10,000 \mathrm{ppm})$ compared to the downdraft gasifier, so additional tar destruction is recommended for this approach. Iowa state university has already tested nickel catalysts reforming tars and report success with an observed benefit of simultaneous ammonia reduction. This synergistic effect is interesting to the farm-scale application. The production of steam in the integrated system is not of primary importance and may not be required in large concentrations, but steam addition to the tar reformer may help prevent catalyst deactivation by Boudart carbon (coke) deposition.

\section{$\underline{\text { LIMCO Concept: Community-scale Hydrogen Enrichment and Ammonia Production }}$}

An advantage of demonstrating two approaches for farm-scale litter gasification is that the fluid bed gasification system may have some advantages for a scale-up to the multi-farm LIMCO scale. The litter integrated management company (LIMCO) is a farm community-scale litter management concept proposed by CPC that, like a farm-scale system, would also minimize litter transportation but also give the highest return for recovered product ash and also excess accumulated litter (above meeting the energy needs of a poultry house). The LIMCO would take advantage of synergistic co-location with small industrial CHP demands or it may stand alone as for independent integrated fertilizer production. A small modular LIMCO may have the capacity for integrated fertilizer production with litter gasification toward ammonia production yielding added value for mineral ash management though the manufacture of fertilizer with tailored N-P$\mathrm{K}$ ratios toward the needs of a local farm co-op or high value export application. A concept system, whose demonstration is not proposed in phase II, could be assembled with a scaled-up Phase II GPM adding staged water gas shift and subsequent catalytic ammonia production.

A quick estimate of anhydrous ammonia production from gasified poultry litter assuming $78 \%$ gasification efficiency, $40 \%$ hydrogen content after water gas shift reaction, $10 \%$ energy loss on reheat for ammonia production, and $2 \mathrm{NH}_{3} / 3 \mathrm{H}_{2}$ gives $0.45 \mathrm{Nm}^{3} \mathrm{NH}_{3} / \mathrm{kg}$ litter gasified, or 0.314 $\mathrm{kg}$ ammonia produced/kg litter processed. Anhydrous ammonia is valued at $\$ 205 /$ ton ammonia, which equates to $\$ 96 /$ ton litter; or if converted to Urea it would be valued $40 \%$ more per $\mathrm{kg}$ nitrogen, or $\$ 134 /$ ton litter. Process efficiencies are very important to the economics, and there may be a minimum scale that would be practical for ammonia production, but evaluation of a proposed processes and economics for various manifestations of the of-farm LIMCO concepts will be studied in proposed future work. 


\section{Cost Estimate}

A capital cost estimate was generated based on historical bill of materials and experience developing prototype small modular biopower systems. It should be well noted by the reader that these capital cost estimates are based on very early system concepts and require further development to fully prove the production system capital costs. Nevertheless, the prototype estimates were created assuming all non-recurring engineering and development costs are complete before the first production prototype is assembled.

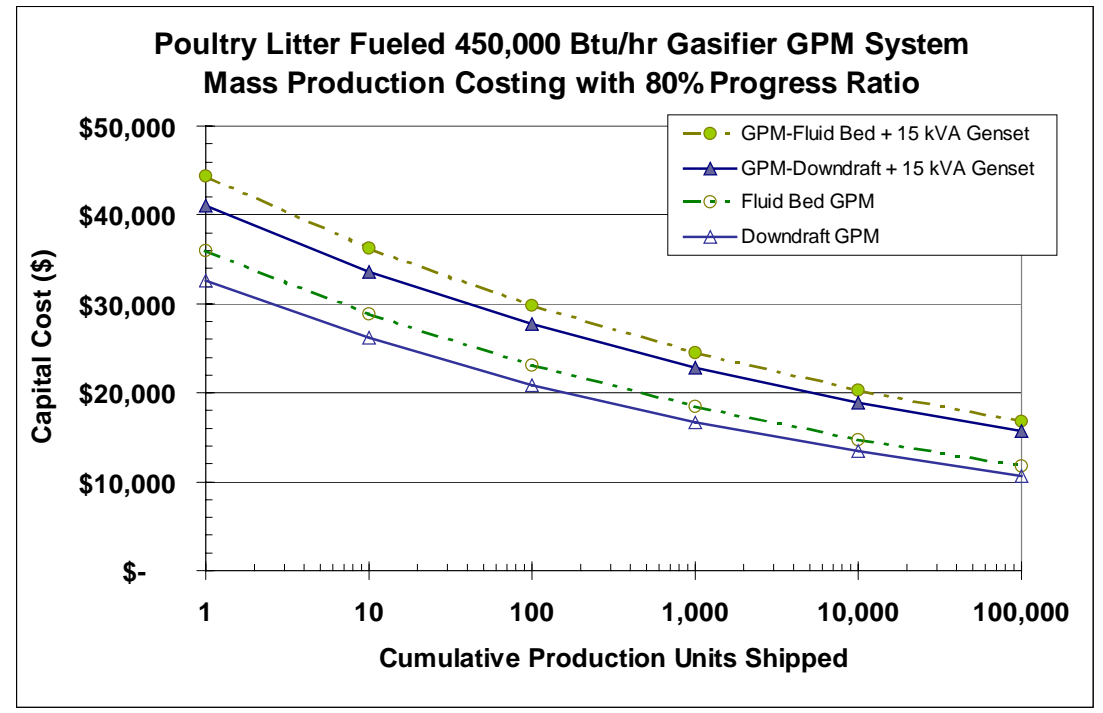

Fabrication and technician labor is assumed to be $\$ 20 /$ hour with a $50 \%$ production overhead and margin. Labor and Materials are weighted with an 18.6\% G\&A charge. Manufacturing technology, fabricator learning, technology development and materials costs reductions for both the design implementation and for quantity purchasing contribute to lowering the costs in mass production. Cost projections in mass production are based on learning curve theory with a progress ratiofof 0.8 , which is consistent with other manufacturing based technology development. ${ }^{7748}$ The engine-genset addition to the GPM would cost $\$ 8,380$ for the first production unit, but this is fully developed technology so its progress ratio is assumed to be 0.9 with costs reductions occurring mainly because of volume purchasing; at the $10,000^{\text {th }}$ unit PCM costs are $\$ 5,500 /$ unit.

\footnotetext{
47 Christopher Flavin and Nicholas Lenssen, "Power Surge: Guide to the Coming Revolution," The Worldwatch Institute, Washington, D. C. 1994, pg. 305

${ }^{48}$ Historic progress ratios in the renewable energy sector are 0.81 for PV and 0.84 for Wind. IPCC Special Report on Emissions Scenarios Section 3.4.4.3 Renewable Energy Technologies; http://www.grida.no/climate/ipcc/emissions/074.htm. Small Modular Biopower is a manufacturing technology system, with many opportunities for cost reduction, but no data on PR has been compiled for SMBs.
} 
Table 13. Capital Costs with \% Market Share; 86,000 Poultry Houses in the United States

\begin{tabular}{|l|c|c|c|}
\hline System Description & $\begin{array}{c}10 \% \text { Market Share } \\
\left(8600^{\text {th }} \text { Unit }\right)\end{array}$ & $\begin{array}{c}20 \% \text { Market Share } \\
\left(17,200^{\text {th }} \text { Unit }\right)\end{array}$ & $\begin{array}{c}\text { Long term Target } \\
\left(100,000^{\text {th }} \text { Unit }\right)\end{array}$ \\
\hline \hline Downdraft GPM $(450,000 \mathrm{Btu} / \mathrm{hr})$ & $\$ 13,577.91$ & $\$ 12,695.80$ & $\$ 10,704.72$ \\
\hline Downdraft GPM + 15 kVA Engine/Genset PCM & $\$ 19,113.44$ & $\$ 18,058.52$ & $\$ 15,652.43$ \\
\hline Fluidized Bed GPM $(450,000 \mathrm{Btu} / \mathrm{hr})$ & $\$ 14,962.71$ & $\$ 13,990.63$ & $\$ 11,796.48$ \\
\hline Fluidized Bed GPM + 15 kVA Engine/Genset PCM & $\$ 20,498.24$ & $\$ 19,353.35$ & $\$ 16,744.20$ \\
\hline
\end{tabular}

\section{Cost Comparison}

\section{Material and Energy Flows}

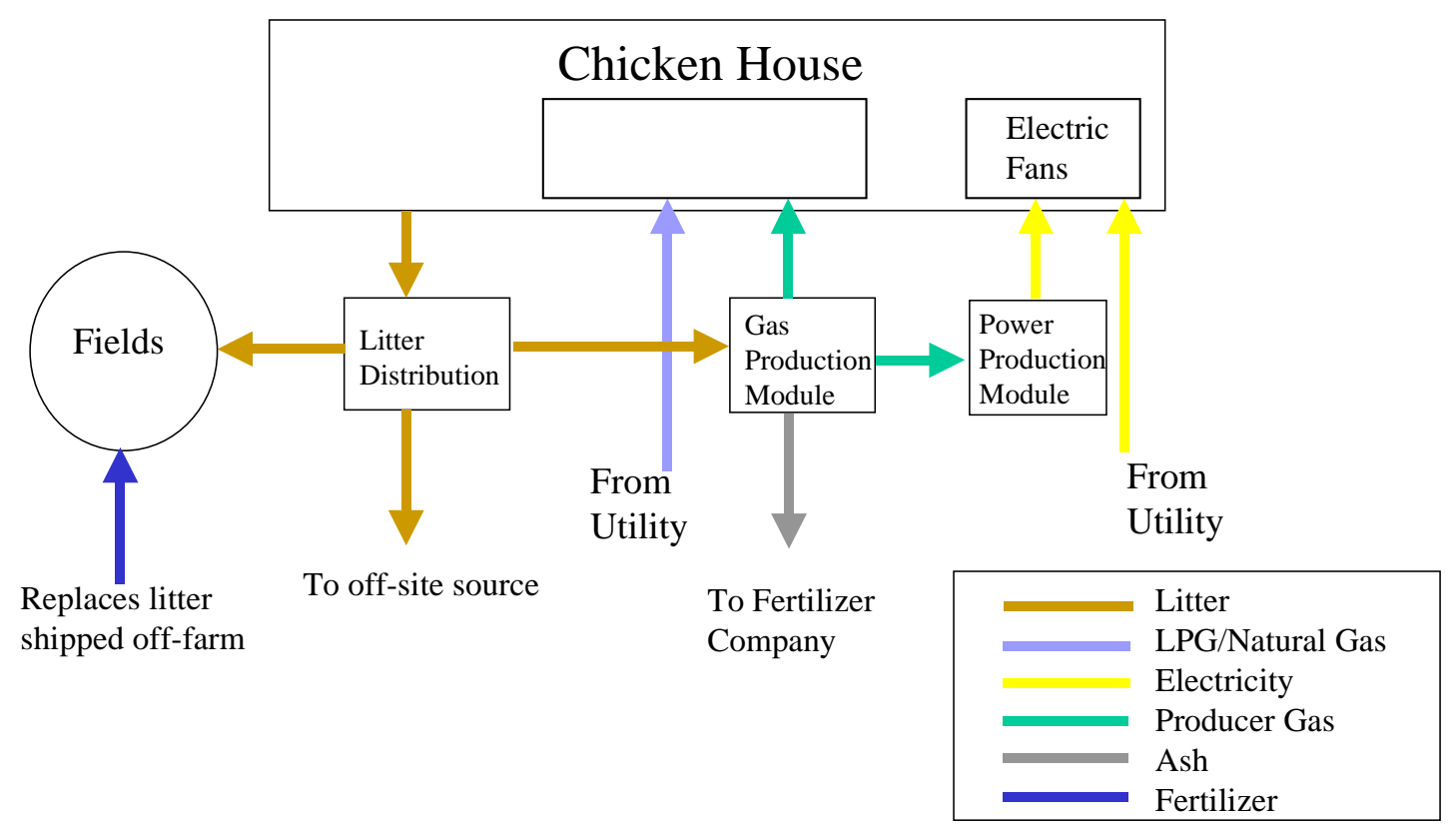

The purpose of this preliminary analysis is to compare the costs of utility-supplied electrical and thermal energy with that of converting chicken litter to heat and power. Sensitivity analyses are performed to determine the impact of key variables on costs of energy. Least cost options, and insights derived from sensitivity analysis, will provide direction to the research and development to be performed in the Phase II SBIR. The only case that is presented in this report is the Farmer Owned SMB system. However, another interesting concept which has economic viability is a LIMCO Owned SMB system. There are significant opportunities for a LIMCO, especially where the LIMCO assumes ownership of all the litter for a contracted poultry house; but detailed study of the near-farm LIMCO concept are beyond the scope of this SBIR phase I project. 
The figure above illustrates the litter management options available to the Farmer. Litter may be removed from the house and applied as a soil amendment, valued at $\$ 15 /$ ton in fertilizer displacement. Or, the farmer may sell the litter to an offsite source-for example his fields are saturated with phosphorus, or the farmer has limited land available for land application according to his nutrient management budget. If the litter is transported to an end user it may receive payment of $\$ 10$ to $\$ 12 /$ ton, but the farmer may incur significant transportation costs to deliver the litter, and the net value is essentially equal to the value of litter on the poultry house floor: $\$ 2$ to $\$ 5$. An alternative that is studied here is a litter management solution where the farmer would utilize a portion of the accumulated litter in a farmer owned poultry house litter-to-energy scheme.

This first chart compares the life cycle costs of a various litter-to-energy options with a baseline case where a farmer sells his litter at the farm gate $\$ 5 /$ ton or is shipped elsewhere for a net return of $\$ 5 /$ ton. Energy cost savings are based on at $\$ 0.65 /$ gal for LPG and $\$ 0.068 / \mathrm{kWh}$ for electricity. Any excess litter not consumed in the litter-to-energy process is sold at $\$ 5 /$ ton.

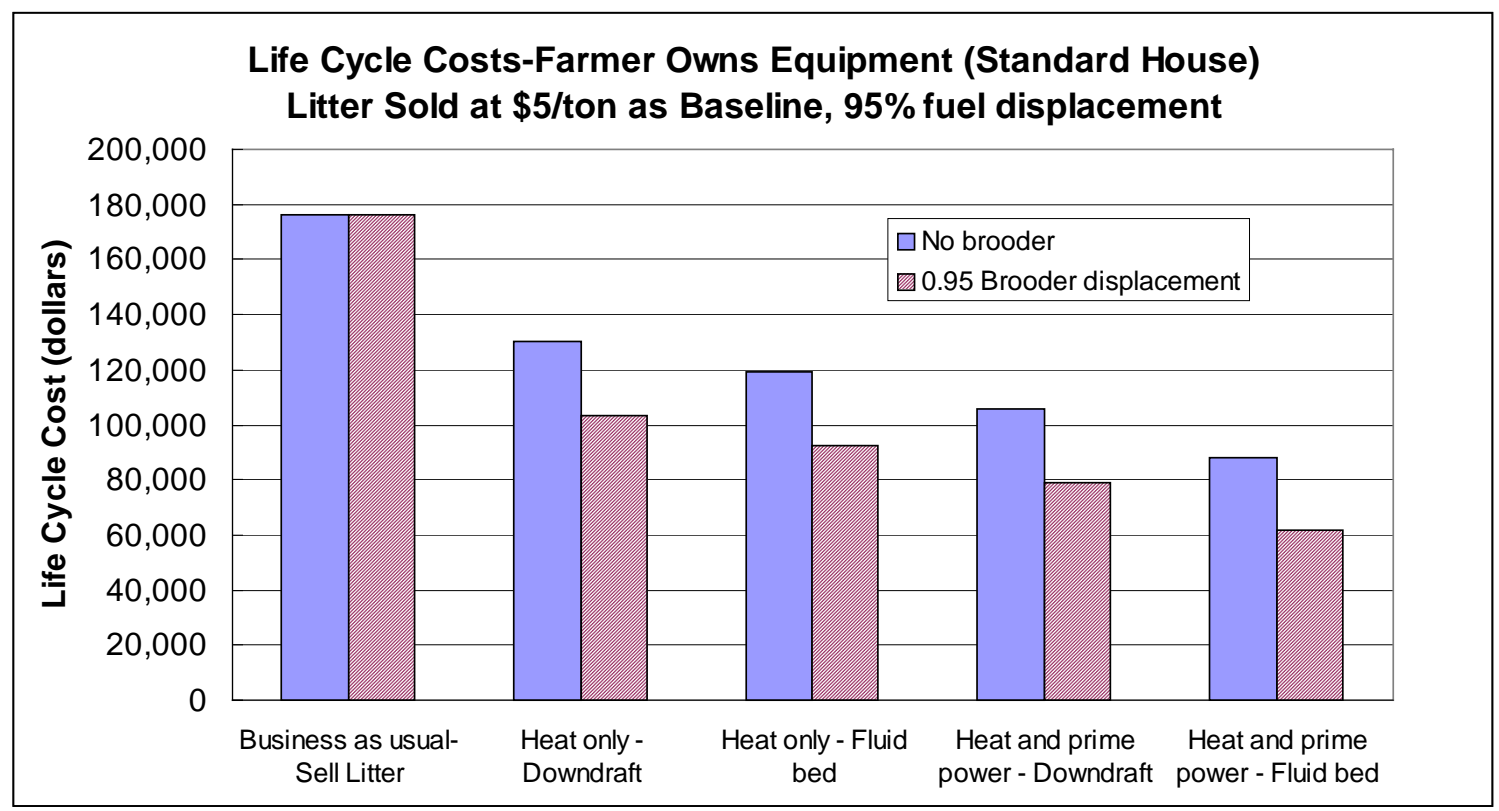

\section{Assumptions-Farmer Owned Equipment, Sell Litter as Baseline:}

- Life Cycle Cost Analysis discount rate: 3.3\% (NIST Recommended)

- Energy Cost Inflation: 3\%

- Other Inflation: $2.7 \%$

- Standard Poultry House: 24,000 kWh/yr; 5,500 gal LPG/yr

- Energy Costs: $\$ 0.068 \mathrm{c} / \mathrm{kWh} ; \$ 0.65 / \mathrm{gal}$ LPG.

- 100 tons dry litter/house

- Pelletization costs for Downdraft gasifier only: $\$ 20 /$ ton

- Litter Consumption: 21.5 lb/gal LPG direct heat; 32.9 lb/gal LPG CHP+H.

- Gasifier Efficiency: $75 \%$

- Excess Litter Sold: $\$ 5 /$ ton at the farm gate or net value after transportation costs

- Recovered Ash sold: \$50/ton; Litter is $24 \%$ ash.

- Propane usage during engine/gasifier start cycle: $1.125 \mathrm{gal} / \mathrm{cycle}$; 1 cycle per day. 
- $0 \%$ or $95 \%$ heat displaced in Brooders; $40 \%$ of total propane for Brooder consumption

- $95 \%$ of furnace fuel displaced

- $95 \%$ of electricity displaced

- Engine minor overhaul: $\$ 1000,4000$ hours operation

- Engine major overhaul: $\$ 3000,12,000$ hours operation

- Labor cost: $\$ 780 / \mathrm{yr}$, heat only; $\$ 3,120 / \mathrm{yr}$ CHP

- Additional O\&M Labor: \$250, heat only; \$1000/yr, CHP

- O\&M parts replacement: $25 \%$ of capital costs

- Capital costs consistant with 10\% market share (see Table 13)

If the farmer is able to land apply excess litter at a net value of $\$ 15 /$ ton then the life cycle cost for business as usual would be $\$ 100,500$, but this baseline should be compared to litter-to-energy options where the farmer consumes litter for energy and land applies excess litter for the same baseline value, $\$ 15 /$ ton.

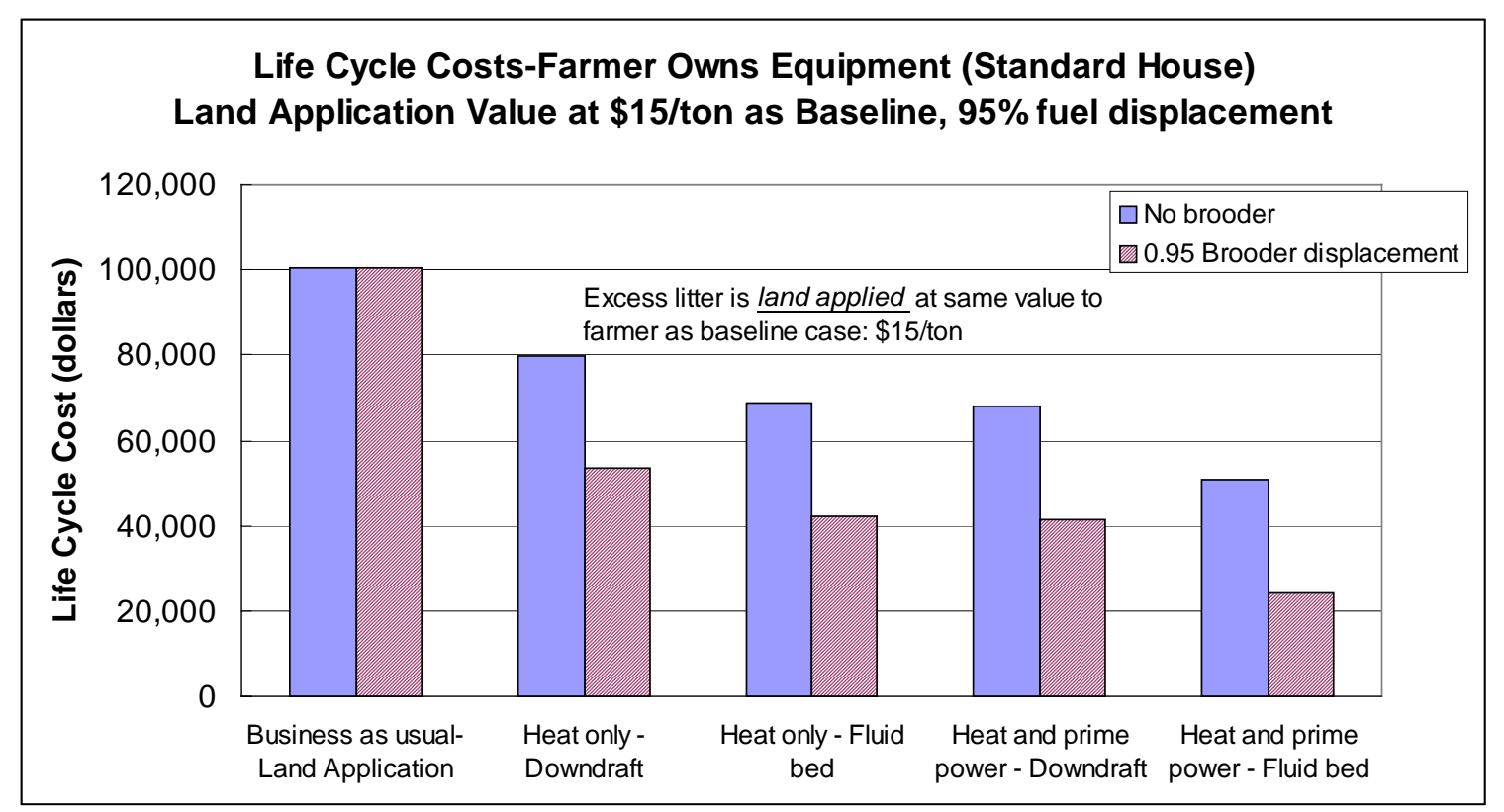

\section{Assumptions-Farmer Owned Equipment, Land Apply Excess Litter:}

- All assumptions are the same as previous analysis except where noted:

- Excess Litter Sold: $\$ 15 /$ ton at the farm gate or net value after transportation costs

The preliminary economic analysis for farmer owned systems shows economic viability for the small modular biopower concept. $\mathrm{CHP}+\mathrm{H}$ applications had the lowest life cycle costs since these applications convert a larger amount of litter to value added products- heat, electricity and salable ash.

The internal rates of return for alternative litter management with a LIMCO owned farm-scale system also has favorable internal rates of return depending on the end-use application (heat only or combined heat and power, CHP). The LIMCO concept could expand the opportunity for litter 
management and complete processing of all accumulated litter for a given poultry house using a near-farm litter processing station. The near farm station would utilize scaled-up versions of small modular biopower (SMB) technology demonstrated at a pilot scale in Phase II of this effort. When multiple farms participate in the LIMCO co-op, incremental specific capital costs advantages are realized by increased processing capacity, and transportation costs are kept to a minimum. There are several configurations, which are not evaluated in detail for this Phase I SBIR, but options could include third party ownership of the LIMCO and farmer co-op shared ownership, or even a non-profit structure. LIMCO owned heat only or CHP systems could be installed on the farm with maintenance responsibility assumed by the third party LIMCO, and displaced energy costs paid to the LIMCO by the farmer. Excess litter could be acquired under contract to the farmer for negotiated energy cost fees. The acquired litter would be transported to a multiple-farm scale SMB for processing litter into a range of value added products including industrial process heat, $\mathrm{CHP}$, and integrated ammonia and chemical fertilizer manufacture from recovered mineral ash. Highest rates of return would be realized with heat only applications or chemical fertilizer manufacture since these applications gives the highest return for recovered ash. Heat only applications may realize high IRRs approaching $40 \%$, if excess litter is acquired for free. Heat only near-farm applications are also less sensitive to the price paid for litter than CHP applications. The present economic analysis will be expanded in Phase II with detailed capital cost and operating cost estimates for the LIMCO near-farm systems in various configurations.

\section{Value of Ash Product}

The value of recovered litter ash has been calculated elsewhere, but similar analysis is provided here to support our ash value estimation based on ash macronutrient analysis for various litter samples collected by CPC. The value of phosphorous and potassium will vary depending on their form; super-phosphate (0-46-0) has a market price of $\$ 195 /$ ton, or $\$ 0.212 / 1 b \mathrm{P}_{2} \mathrm{O}_{5}$; and muriate of potash (0-0-60) has a market value of $\$ 128 /$ ton, or $\$ 0.107 / 1 b \mathrm{~K}_{2} \mathrm{O}$. A report by Wimberly and Goodwin use the values $\$ 0.18 / \mathrm{lb}$ for $\mathrm{P}_{2} \mathrm{O}_{5}$ and $\$ 0.11 / \mathrm{lb}$ for $\mathrm{K}_{2} \mathrm{O}$, and these are the values used in Table 14. Sample of broiler litter, turkey litter and Colorado rooster and brooder litter were analyzed for ash composition. The value of the macronutrients is calculated for each ash analysis and then reported in the table below. 
Table 14. Mineral Composition of Litter Ash and its Estimate Mineral Market Value

\begin{tabular}{|c|c|c|c|c|c|c|c|c|c|c|}
\hline \multicolumn{3}{|l|}{ Sample ID } & $1-\mathrm{A}$ & $1-\mathrm{D}$ & $2-\mathrm{A}$ & $3-\mathrm{A}$ & 4-A & 4-D & $5-\mathrm{A}$ & \\
\hline \multicolumn{2}{|c|}{ Weight \% Ash Basis } & $\begin{array}{c}\text { Value of } \\
\text { Minerals } \\
(\$ / \mathrm{lb})\end{array}$ & \begin{tabular}{|c} 
CO \\
Turkey \\
Litter- \\
Core \\
\end{tabular} & $\begin{array}{c}\text { CO } \\
\text { Turkey } \\
\text { Litter- } \\
\text { Crust } \\
\end{array}$ & $\begin{array}{c}\text { Arkansas } \\
\text { Broiler } \\
\text { (Pine) }\end{array}$ & $\begin{array}{c}\text { Arkansas } \\
\text { Broiler } \\
\text { (Pine + } \\
\text { Rice) } \\
\end{array}$ & $\begin{array}{c}\text { Colorado } \\
\text { Brooder } \\
\text { (Wood- } \\
\text { chips) }\end{array}$ & \begin{tabular}{|c} 
Colorado \\
Rooster \\
Manure \\
\end{tabular} & $\begin{array}{c}\text { Arkansas } \\
\text { Pelletized } \\
\text { Litter } \\
\end{array}$ & $\begin{array}{c}\text { Average } \\
\text { for All } \\
\text { Samples } \\
\end{array}$ \\
\hline Aluminum as & $\mathrm{Al}_{2} \mathrm{O}_{3 \%}$ & & 4.24 & 2.24 & 0.92 & 4.65 & 6.89 & 0.66 & 1.03 & 2.9 \\
\hline Calcium as & $\mathrm{CaO} \%$ & & 18.16 & 21.91 & 21.25 & 14.22 & 17.42 & 27.92 & 28 & 21.3 \\
\hline Iron as & $\mathrm{Fe} 2 \mathrm{O} 3 \%$ & & 1.68 & 1.2 & 1.02 & 2.84 & 2.96 & 0.83 & 1.05 & 1.7 \\
\hline Magnesium as & $\mathrm{MgO} \%$ & & 5.27 & 5.54 & 5.77 & 3.72 & 3.79 & 5.95 & 4.8 & 5.0 \\
\hline Mangan & $\mathrm{MnO} \%$ & & 0.28 & 0.32 & 0.4 & 0.28 & 0. & 0.38 & 0.5 & 0.3 \\
\hline Phosphorous as & $\mathrm{P}_{2} \mathrm{O}_{5} \%$ & $\$ 0.18$ & 18.48 & 22.8 & 20.98 & 12.94 & 9.79 & 29.35 & 27.2 & 20.2 \\
\hline Potasium as & $\mathrm{K}_{2} \mathrm{O} \%$ & $\$ 0.11$ & 11.82 & 13.43 & 15.13 & 9.12 & 10.15 & 16.41 & 14.15 & 12.9 \\
\hline Silicon as & $\mathrm{SiO}_{2} \%$ & & 25.2 & 12.42 & 17.11 & 44.82 & 38.86 & 7.38 & 9.32 & 22.2 \\
\hline Sodium as & $\mathrm{Na}_{2} \mathrm{O} \%$ & & 3.29 & 3.71 & 5.52 & 3.22 & 3.08 & 4.15 & 4.36 & 3.9 \\
\hline \begin{tabular}{|l|} 
Sulfur as \\
\end{tabular} & $\mathrm{SO}_{3} \%$ & & 7.66 & 9.3 & 7.16 & 4.12 & 4.14 & 9.7 & 6.93 & 7.0 \\
\hline Titanium as & $\mathrm{TiO}_{2} \%$ & & 0.18 & 0.1 & 0.1 & 0.38 & 0.46 & 0.15 & 0.23 & 0.2 \\
\hline Value of Miner & n Ash & & $\$ 92.53$ & $\$ 111.63$ & $\$ 108.81$ & $\$ 66.65$ & $\$ 57.57$ & $\$ 141.76$ & $\$ 129.05$ & $\$ 101.14$ \\
\hline Wholesale Value & & & $\$ 46.27$ & $\$ 55.81$ & $\$ 54.41$ & $\$ 33.32$ & $\$ 28.79$ & $\$ 70.88$ & $\$ 64.53$ & $\$ 50.57$ \\
\hline
\end{tabular}

The average retail market value of the macro-nutrient components of the broiler and turkey litter is $\$ 101 /$ ton, and an estimated wholesale value is $50 \%$ of this number, or $\$ 50.5 /$ ton. Market prices paid for litter ash by a fertilizer integrator is unknown, but the best return on the litter ash is to acquire with in an integrated litter-to-energy network and convert it to a high value chemical fertilizer for sale at retail prices. With added nitrogen and controlled potassium content a tailored N-P-K fertilizer could yield more than $\$ 200 /$ ton; for example DAP (18-46-0) is \$210/ton, and MAP (11-52-0) is \$215/ton.

As a point of interest the average ash content for all raw litter samples was $22 \%$, and the average moisture was $24.1 \%$. Therefore, an estimated wholesale value of poultry litter based on the mineral content is $\$ 2.6 /$ ton for Colorado brooder litter and $\$ 15.0 /$ ton (as received) for Arkansas broiler litter pellets. The average value for raw litter is $\$ 8.50 /$ ton based on mineral content, although the market value for litter as a soil amendment is usually $\$ 10$ to $\$ 12 /$ ton, or $\$ 2$ to $\$ 5 /$ ton net after transportation costs. 


\section{Market Estimate}

CPC's approach is to provide a total systems solution, addressing this as a litter management problem, not as an energy or environmental problem. Therefore, we propose to evaluate the economics of a Litter Management Company (LIMCO) that will provide a range of value-added products and services. Chicken litter will be converted to heat, power, and ash using a variety of small modular biopower system designs. In all cases, we will use a distributed generation approach, both on-farm and near-farm.

LIMCO will own and operate all of the on-farm power generation equipment in return for the farmer's litter and payment for any heat or power displaced. On-farm systems will be relatively small, sized to meet site loads. LIMCO will make a margin on the manufacture of power systems, and the sale of electricity, heat and ash. In addition, LIMCO could also generate other revenues from the sale of fertilizer and biomass litter to farmers, however, these opportunities are not included herein.

The primary market is for broilers and turkeys due to their large volumes and the nature of the litter. Egg layers are not considered to be a significant opportunity. There are about 60,000 broiler production houses in the United States, and about 26,000 production houses for market turkeys. It is assumed that $10 \%$ to $20 \%$ of all these poultry houses could be served in a reasonable technology implementation and marketing plan. It is assumed that the same size modular biopower system could serve each of the houses in the achievable market share.

For the subsequent presentation it is assumed that all systems are fluidized bed heat only systems that have a capital cost equal to the costs presented in Table 13. These systems are about 30\% lower in price than an option providing both heat and power.

- $\quad 10 \%$ market share, Poultry House GPM: $\quad \$ 15,000$

- 20\% market share, Poultry House GPM: $\quad \$ 14,000$

Given the reduced number of near-farm systems, their capital cost would not change significantly with market share.

- $\quad 0.5 \mathrm{MW}_{\mathrm{e}}$, near farm system $\$ 760,000 \quad(\$ 1520 / \mathrm{kW})$

- $\quad 1.0 \mathrm{MW}_{\mathrm{e}}$, near farm systsem $\$ 1,121,000 \quad(\$ 1121 / \mathrm{kW})$

Table 15. LIMCO (A) Gross Capital Equipment Sales. 40 houses/cluster

\begin{tabular}{|c|c|c|c|c|}
\hline \multirow{2}{*}{$\begin{array}{l}\text { Case } \mathbf{A} . \\
10 \text { Farms/cluster } \\
40 \text { houses/cluster }\end{array}$} & \multicolumn{2}{|c|}{$10 \%$ market share } & \multicolumn{2}{|c|}{$20 \%$ market share } \\
\hline & $\begin{array}{l}\text { Systems } \\
\text { Sold }\end{array}$ & $\begin{array}{c}\text { Capital Sales }(\$ \\
\text { Million })\end{array}$ & $\begin{array}{l}\text { Systems } \\
\text { Sold }\end{array}$ & $\begin{array}{c}\text { Capital Sales (\$ } \\
\text { Million) }\end{array}$ \\
\hline On-farm equipment (450 Mbtu/hr) & 8,600 & $\$ \$ 129.0$ & 17,200 & $\$ \$ 240.8$ \\
\hline Near-farm equipment (0.5 MW) & 215 & $\$ 163.4$ & 430 & $\$ 326.8$ \\
\hline
\end{tabular}


Table 16. LIMCO (B) Gross Capital Equipment Sales. 80 houses/Cluster

\begin{tabular}{|l|r|r|r|r|}
\hline Case B. & \multicolumn{2}{|c|}{$10 \%$ market share } & \multicolumn{2}{|c|}{$20 \%$ market share } \\
\cline { 2 - 5 } $\begin{array}{l}\text { 20 Farms/cluster } \\
80 \text { houses/cluster }\end{array}$ & $\begin{array}{c}\text { Systems } \\
\text { Sold }\end{array}$ & $\begin{array}{c}\text { Capital Sales (\$ } \\
\text { Million) }\end{array}$ & $\begin{array}{c}\text { Systems } \\
\text { Sold }\end{array}$ & $\begin{array}{c}\text { Capital Sales (\$ } \\
\text { Million) }\end{array}$ \\
\hline \hline On-farm equipment & 8,600 & $\$ 129.0$ & 17,200 & $\$ 240.8$ \\
\hline Near-farm equipment (1 MW) & 107.5 & $\$ 120.5$ & 215 & $\$ 241.0$ \\
\hline \multicolumn{2}{|r|}{ Total Gross Equipment Sales } & $\$ 250$ & $\$ 482$ \\
\hline
\end{tabular}

Ash is valued at $\$ 50$ per ton. All propane displaced is valued at $\$ 0.65$ per gallon. Electricity displaced is valued at $\$ 0.068$ per $\mathrm{kWh}$. In case A, electricity production is achieved with $25 \%$ efficient engine and generator, $500 \mathrm{~kW}$ systems, or $3.0 \mathrm{lb}$ litter $/ \mathrm{kWh}$. Heat is displaced at a rate of $21.5 \mathrm{dry} \mathrm{lb} / \mathrm{gal}$ LPG on the farm, consuming 50.4 dry tons ( 68 tons at $20 \% \mathrm{M}$ ); with the remainder of litter utilized in the near farm system proportional to the waste heat of the generator, 32.9 dry lbs litter/gal LPG in CHP mode.

Table 17. LIMCO (A) Annual Revenues for Energy and Ash Products

\begin{tabular}{|c|c|c|}
\hline Case A. $\quad 10$ Farms and 40 houses/Cluster & $10 \%$ market & $20 \%$ market \\
\hline Tons Litter Processed $(20 \% \mathrm{M})$ & $1,075,000$ & $2,150,000$ \\
\hline \hline Value Added Products & \multicolumn{2}{|c|}{ Annual Revenues (\$ million) } \\
\hline \hline Displaced Electricity Sales $(\$ 0.068 / \mathrm{kWh})$ & 17.8 & 35.6 \\
\hline Thermal Sales $(\$ /$ gal LPG equivalent) & 15.5 & 31.0 \\
\hline Ash Sales (\$50/ton) & 10.32 & 20.64 \\
\hline
\end{tabular}

In case $\mathrm{B}$, electricity production is achieved with $30 \%$ efficient engine and generator, $1000 \mathrm{~kW}$ systems, or $3.0 \mathrm{lb}$ litter $/ \mathrm{kWh}$. Heat is displaced at a rate of $21.5 \mathrm{dry} \mathrm{lb} / \mathrm{gal} \mathrm{LPG}$ on the farm, consuming 50.4 dry tons $(68$ tons at $20 \% \mathrm{M}$ ); with the remainder of litter utilized in the near farm system proportional to the waste heat of the generator, $32.9 \mathrm{dry}$ lbs litter/gal LPG in CHP mode.

Table 18. LIMCO (B) Annual Revenues for Energy and Ash Products

\begin{tabular}{|c|c|c|}
\hline Case B. $\quad 20$ Farms and 80 houses/Cluster & $10 \%$ market & $20 \%$ market \\
\hline Tons Litter Processed $(20 \% \mathrm{M})$ & $1,075,000$ & $2,150,000$ \\
\hline \hline Value Added Products & \multicolumn{2}{|c|}{ Annual Revenues (\$ million) } \\
\hline \hline Displaced Electricity Sales (\$0.068/kWh) & 21.3 & 42.7 \\
\hline Thermal Sales (\$/gal LPG equivalent) & 15.5 & 31.0 \\
\hline Ash Sales (\$50/ton) & 10.32 & 20.64 \\
\hline \multicolumn{3}{|c|}{47.2} \\
\hline
\end{tabular}


Based on a $20 \%$ IRR, the net present value for Case A including all capital sales and value added product revenues for the $10 \%$ market share is $\$ 505$ million. Similarly, the net present value of Case B at $10 \%$ market share is $\$ 479$ million; which would seem to favor the smaller cluster if the smaller scale LIMCO cluster can achieve the same IRR as the larger cluster. The feasibility of creating 100 or 200 clusters of 80 poultry houses (20 farms), and the transportation costs may be higher with the larger cluster.

\section{Summary}

In summary, the poultry market is significantly large with more than 86,000 poultry houses in the United States involved in broiler chicken and market turkey production, that manufacturing technology could be applied to develop small modular biopower systems to meet an alternative litter management strategy. Approximately 125 dry tons litter is produced per broiler production house when the production capacity is $100-110 \mathrm{k}$ head per year (20,000 bird/flock). The poultry farmer who has mineral saturated land may not be able to dispose of his litter in the traditional way as a local soil amendment, or the implementation of a nutrient management program may limit land application so that excess litter would be accumulated requiring alternative litter management approaches. Land application is valued at $\$ 15 /$ ton litter when used on the farm, but if the farmer must sell the accumulated litter then the net return to the farmer is limited by transportation and handling costs. It has been estimated the break-even transportation distance is 30 miles from the source, if litter is purchased for $\$ 15 /$ ton. Often the net value of sold litter is on the order of $\$ 2$ to $\$ 5 /$ ton. In some regions of concentrated poultry production, the transportation distance may be so great that the excess litter actually has a negative value. When litter is used as a fuel it has the potential to substantially reduce life cycle costs for the farmer compared to the baseline business as usual cases: either selling litter at \$5/ton or land applying litter at \$15/ton.

CPC was successful in gasifying poultry litter in downdraft gasification experiments when dense litter pellets were substantially dried and a low superficial velocity was used. Flame front propagation was slow, but a quality ash product was produced in bench-scale testing. Reactor design optimization and demonstration would be continued in a phase II follow on project.

Substantial organic nitrogen content in poultry litter produces high ammonia content in the produced gas, and this ammonia causes significant emissions problems in downstream power conversion modules and combustors without additional gas cleanup equipment. The economics of a litter-to-energy system are substantially benefited by its ability to displace the maximum amount of propane in a poultry house, which requires the modular biopower system to deliver clean gas with low ammonia content in order to prevent significant chemical NOx delivery into the poultry house during combustion in a radiant brooder. The ability to fuel a brooder requires upstream ammonia reduction technology as well as a consistently low tar gas. CPC has identified two technologies that can catalytically reduce ammonia in a poultry litter producer gas stream prior to delivery to various combustion applications by as a secondary process that occurs in a tar reformer or with dedicated upstream catalytic reduction technology using lower temperature catalytic $\mathrm{NO}_{\mathrm{x}}$ reduction.

CPC's approach is to provide a total systems solution, addressing this challenge as a litter management problem, not specifically as an energy or environmental problem. In this manner, $\mathrm{CPC}$ has identified several potentially viable litter-to-energy solutions that give as much as a 
$50 \%$ reduction in life cycle costs for combined heat and power applications. Heat only systems have a 30\% lower capital cost and are simpler to install and operate. The equivalent fuel value of litter in a 75\% efficiency gasifier is 93 gallons LPG/dry ton poultry litter. A single poultry house can generate 100 dry tons litter $(125$ tons at $20 \% \mathrm{M})$ each year; this equivalent fuel value using a 75\% efficient gasifier is 9300 gallons of LPG, or $\$ 6000$ in equivalent value.

Approximately 25 tons of gasification product ash could be recovered from the litter of a single house, and its value is $\$ 50 /$ ton wholesale; the total value of recovered ash from a given broiler house would be $\$ 1250$. In contrast, when a farmer sells his litter at $\$ 5 /$ ton, the total value is $\$ 625 /$ house. If the farmer applies the litter to his land as a soil amendment the value of displaced fertilizer is $\$ 15 /$ ton, and the total value of the litter is $\$ 1875 /$ ton for land application.

Life cycle cost comparisons show that a farmer could reduce his life cycle costs by as much as $50 \%$ with small modular systems that cost between $\$ 13,000$ and $\$ 20,000$ if automatic operation were included to minimize operator costs. The reduction in LCC is equal to an annual savings for the farmer of between $\$ 3,000$ and $\$ 6,000 /$ year.

The farmer only uses approximately 6000 gallons LPG in a given year, and only 24,000 $\mathrm{kWh} / \mathrm{year}$. And meeting all the farmers' energy demands will only consume just 82 dry tons, even with lower efficiency small generator systems. Meeting only the heating demands will consume just 54 dry tons litter. Therefore there may be an opportunity for a Litter Integrated Management Company (LIMCO) to service farmers with small modular biopower equipment and in turn acquire excess litter as a low cost feedstock for larger systems, $500 \mathrm{~kW}$ to $1000 \mathrm{~kW}$. The LIMCO has an opportunity to get a high value for ash when added with appropriate amounts of nitrogen compounds like urea; the value of the recovered gasification ash could be in excess of $\$ 100 /$ ton ash if a commercial NPK product was created. 